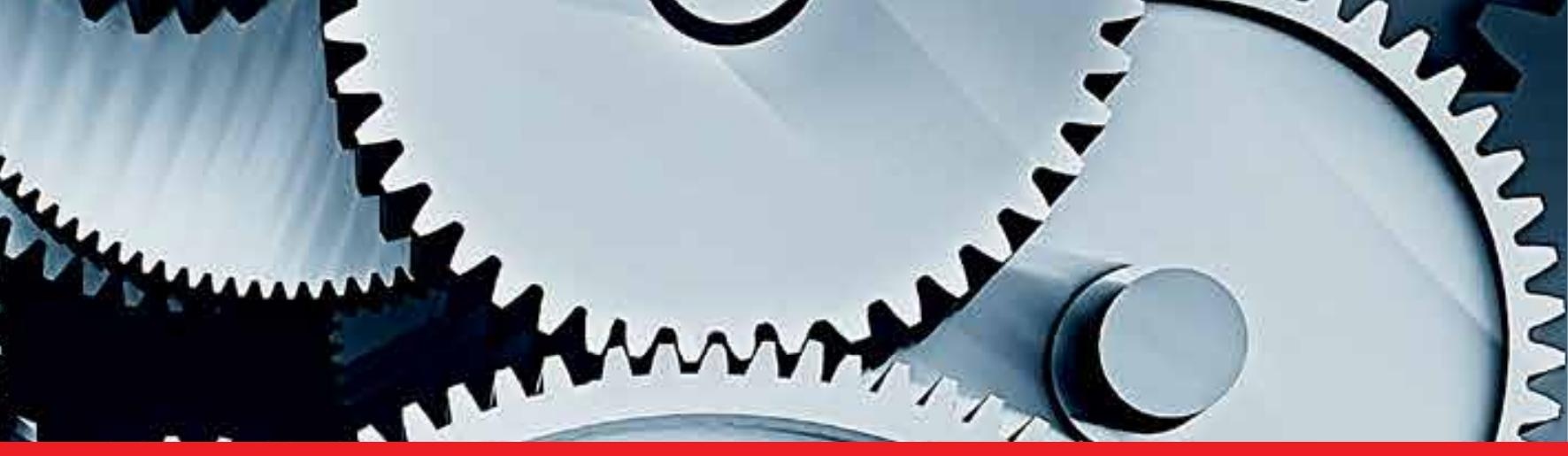

\author{
IntechOpen
}

\title{
Perspectives on Business and Management
}

Edited by Vito Bobek

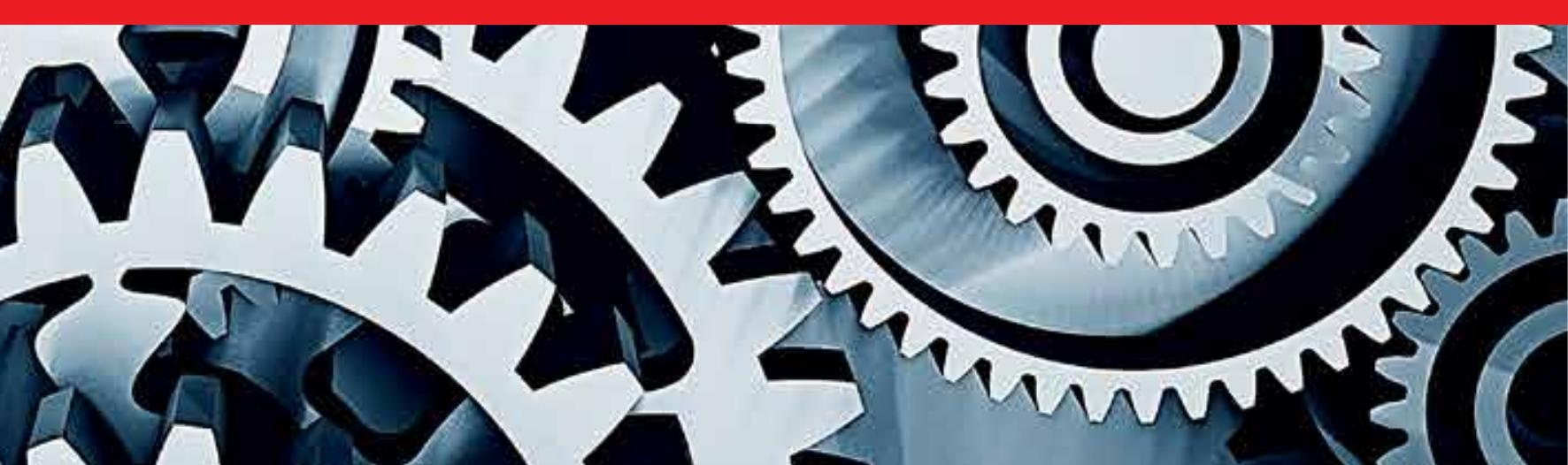





\section{PERSPECTIVES ON BUSINESS AND MANAGEMENT}

Edited by Vito Bobek 


\section{Perspectives on Business and Management}

http://dx.doi.org/10.5772/59635

Edited by Vito Bobek

\section{Contributors}

Kee-Luen Wong, Min-Hooi Chuah, Vito Bobek, Jasmina Mavrič, Schapour Zafarpour, Štefka Gorenak, Anita Maček, Rasto Ovin, Jelena Zvezdanović Lobanova

\section{(c) The Editor(s) and the Author(s) 2015}

The moral rights of the and the author(s) have been asserted.

All rights to the book as a whole are reserved by INTECH. The book as a whole (compilation) cannot be reproduced, distributed or used for commercial or non-commercial purposes without INTECH's written permission.

Enquiries concerning the use of the book should be directed to INTECH rights and permissions department (permissions@intechopen.com).

Violations are liable to prosecution under the governing Copyright Law.

\section{(cc) BY}

Individual chapters of this publication are distributed under the terms of the Creative Commons Attribution 3.0 Unported License which permits commercial use, distribution and reproduction of the individual chapters, provided the original author(s) and source publication are appropriately acknowledged. If so indicated, certain images may not be included under the Creative Commons license. In such cases users will need to obtain permission from the license holder to reproduce the material. More details and guidelines concerning content reuse and adaptation can be foundat http://www.intechopen.com/copyright-policy.html.

\section{Notice}

Statements and opinions expressed in the chapters are these of the individual contributors and not necessarily those of the editors or publisher. No responsibility is accepted for the accuracy of information contained in the published chapters. The publisher assumes no responsibility for any damage or injury to persons or property arising out of the use of any materials, instructions, methods or ideas contained in the book.

First published in Croatia, 2015 by INTECH d.o.o.

eBook (PDF) Published by IN TECH d.o.o.

Place and year of publication of eBook (PDF): Rijeka, 2019.

IntechOpen is the global imprint of IN TECH d.o.o.

Printed in Croatia

Legal deposit, Croatia: National and University Library in Zagreb

Additional hard and PDF copies can be obtained from orders@intechopen.com

Perspectives on Business and Management

Edited by Vito Bobek

p. $\mathrm{cm}$.

ISBN 978-953-51-2183-1

eBook (PDF) ISBN 978-953-51-5146-3 


\section{We are IntechOpen, \\ the world's leading publisher of Open Access books}

Built by scientists, for scientists

\section{$3,800+$}

Open access books available

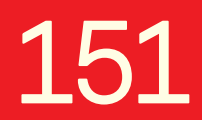

Countries delivered to

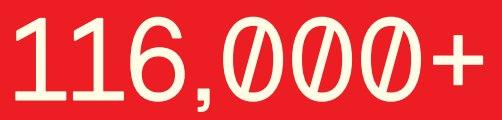

International authors and editors
$120 \mathrm{M}+$

Downloads

Our authors are among the

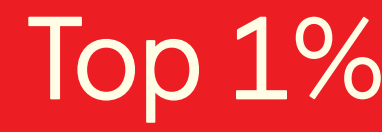

most cited scientists

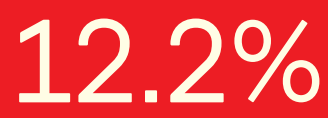

Contributors from top 500 universities

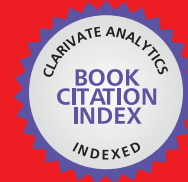

WEB OF SCIENCE ${ }^{\mathrm{TM}}$

Selection of our books indexed in the Book Citation Index in Web of Science ${ }^{\mathrm{TM}}$ Core Collection (BKCI)

Interested in publishing with us?

Contact book.department@intechopen.com

Numbers displayed above are based on latest data collected.

For more information visit www.intechopen.com

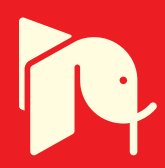





\section{Meet the editor}

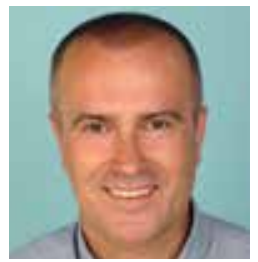

Professor Vito Bobek currently works as a Professor of International Management at the University of Applied Sciences FH Joanneum (Graz, Austria) and at the University of Maribor (Slovenia). He is also a Manager and owner of Palemid - Consulting, Research, Education LLC. His other positions are: Member of Supervisory Board at KBM Infond (Investment company, Maribor, Slovenia), Regional Editor for Central and Eastern Europe for the European Journal of International Management, Member of Editorial Board for the International Journal of Trade and Global Markets, Member of Editorial Board for Imago Europae (Florence, Italy) and Member of Editorial Board for the International Journal of Diplomacy and Economy. His research interests are related to International Business, Strategic Management, Regional Economic Integration, Cross-Cultural Management and Management of Cities and Regions. 



\section{Contents}

Preface XI

Section 1 Theoretical Framework 1

Chapter 1 A Theoretical Framework (Modelling) for International Business Management 3

Schapour Zafarpour

Section 2 Management of Companies 21

Chapter 2 European Foundation for Quality Management Excellence Model Can Encourage ISO 26000 Implementation 23 Štefka Gorenak

Chapter 3 Does the Demographic Factor Impact Enterprise Business Intelligence Maturity Initiaves in Companies in Malaysia? 45 Min-Hooi Chuah and Kee-Luen Wong

Section 3 Management of Cities 55

Chapter 4 A Development Vision and Strategy Model as a Response of Cities to the Challenges of Globalization 57

Anita Maček and Vito Bobek

Chapter 5 Measuring Urban Development and City Performance 71 Jasmina Mavrič and Vito Bobek

Chapter 6 FDI Blessing - How Is It Recognized by Local Communities? A Comparative Study of Slovenia and Serbia 101

Anita Maček, Rasto Ovin and Jelena Zvezdanović Lobanova 



\section{Preface}

Looking at business through an economic perspective can provide a more complete picture of the relationship between society and the markets. In microeconomics, one learns about how the decisions of individuals can affect trends in business. The emphasis is on the system as a whole and is used as a tool to examine business at a national or global level. Being able to see the "forest through the trees" without losing sight of individual parts of the business landscape is an important leadership skill to have. Economics helps leaders create more effective business strategies.

With a more holistic view of the interrelationships between individuals, markets and the larger economy, leaders can make more informed decisions and guide their organizations to higher profits. Understanding past trends in light of today's particular challenges can mean making more powerful contributions to company goal-setting. In addition, a wider knowledge of economics also allows business leaders to create more persuasive arguments when attempting to affect positive change within an organization.

Therefore, this book is organized into three sections.

The section on Theoretical Framework at the very beginning deals with multiple theoretical analyses of international business management and represents a contribution to the understanding of the complexities and independency of different protagonists and players to bring the economy of a country to higher levels of equilibrium. It means reduction in unemployment and increased per capita incomes of people, especially of the low and middle class, who will consume, save and invest more that would lead to higher employment levels. This would ultimately lead to the maximization of total economic welfare, in other words, meet Maslow's conditions of needs.

The section on Management of Companies begins with the chapter that highlights the fact that interest and initiatives related to Social Responsibility-ISO 26000 and the EFQM Excellence Model have increased over the last decade. Strategic management models are the frameworks for achieving sustainable growth and sustainable competitive advantages. The purpose of this chapter is to trace and define the relations between several EFQM (European Foundation for Quality Management) criteria and the components of ISO 26000 as well as total responsibility management and interrelationships between organizations and their stakeholders. In the light of the analysis, the systemic and holistic EFQM model may be considered as a tool for governance and implementation in the corporate strategy according to ISO 26000 recommendations. The chapter also considers that the social responsibility perspective is a key element of the EFQM Excellence Model, which includes stakeholders and potential contributors to sustainable development. Organizations are paying more attention to continual quality improvement and the implementation of the EFQM Excellence Model 
including social responsibility models, and their interrelationships will reflect the real and potential synergies like sustainable competitive advantages, sustainable cooperative advantages and sustainable cooperative excellence in the future.

The second chapter in this section proposes an Enterprise Business Intelligence (BI) Maturity Model that involves thirteen key process areas (Strategic Management, Performance Measurement, Balanced Scorecard, Information Quality, Data Warehousing, Master Data Management, Metadata Management, Analytical, Infrastructure, Knowledge Management, People, Organization Culture and Change Management). The key objective of this chapter was to investigate the impact of the Enterprise Business Intelligence Initiative on demographic factors such as the age of BI initiatives, organizational size, number of IT/BI employees, type of industry and revenue of the company. Results show that the age of BI initiatives, organizational size and number of IT/BI employees are related to the BI maturity level, while the BI maturity level has a significant impact on the revenue of the company. Results also show that the type of industry has no significant impacts on the BI maturity level.

The section on Management of Cities consists of three chapters. The first chapter in this section highlights the fact that exposure to new sources of competition across the world encourages cities to become more competitive and to allocate their resources more effectively and efficiently. Responding to the demands of many different groups and managing the allocation of resources between different claims have become nowadays among the most challenging tasks for city governments. In order to reach their development goals, cities must be aware of where they are starting out. First, they should identify their strengths and weaknesses and after that define the position they want to strive for in the future. Once this position is defined, they need to become aware of the significant trends and other factors that will influence the direction in which the future unfolds. To overcome the challenges mentioned, many successful European cities designed a model which simplifies the monitoring of long-term goals. It is very important that these goals are consistent with the city's development vision and strategy, and both must be based on values, wishes and priorities of local residents.

The second chapter in this section introduces the fact that cities represent the driving force of development in economic, social and cultural life, reflecting also the spatial organization of human society. Taking into account the fact that cities are becoming generators of economic development and a source of growth for the national economy, there is an increasing urge to identify the stages of development and to establish a system for the ranking and positioning of cities and regions in this process (the level of categorization). This will allow for the preparation of appropriate strategic and development guidelines for cities and urban regions. In order to be able to compare the level of their efficiency in fostering development, there is an intensifying need to develop indicators, which can measure the performance of cities, are representative and comparable between countries, and allow verification to others. At present, there are many different urban indicators and institutions that compile and analyze them. Performance measurement systems, developed for internal use in some cities, already show a degree of measurement feasibility. The fundamental problem is that this variety of indicators lacks consistency and comparability (over time and between compared cities). Therefore, their use cannot be approved in a wider context (benchmark) of comparative situations. In the case of medium-sized cities, one needs to question the applicability of the methodology and indicators, used mostly for large, global cities by internationally recognized institutions. With the established set of indicators and assistance of computer pro- 
grams for multi-parameter decision-making processes (AHP), this chapter also seeks to investigate comparisons between performances of selected European cities (on a qualitative basis).

In the third chapter of this section, authors discuss the development and effects of foreign direct investments on local communities of Slovenia and Serbia. Based on data gathered through a questionnaire, a comparative statistical analysis was used to find stylized facts, which could be a sign of a different stage of transition in both countries. The study was conducted at the end of 2014, and the sample consisted of 66 communities from Slovenia and 61 communities from Serbia. The study proves that the more progressive path of transition in Slovenia was not offset by a significantly higher level of foreign direct investment activities. In both countries, however, foreign direct investments proved to have mostly positive effects on the economic development of the local communities concerned.

Finally, I would like to thank InTech publishing company for giving me the opportunity to become the editor of this book. I appreciate that they believed I could provide the necessary knowledge and technical assistance. We together managed to find the other great colleagues that contributed to this book. I thank each of them for their valuable contributions that resulted in this book; I think that it will be an asset to the professional community. I also wish to thank our technical reviewers and colleagues at InTech. We could not have done it without you.

Vito Bobek

University of Applied Sciences FH Joanneum, Graz, Austria

University of Maribor, Slovenia 

Section 1

Theoretical Framework 

Chapter 1

\title{
A Theoretical Framework (Modelling) for International Business Management
}

\author{
Schapour Zafarpour \\ Additional information is available at the end of the chapter \\ http://dx.doi.org/10.5772/60903
}

\begin{abstract}
The international business management is one of the most relevant parts for the development of the countries and at the same time the most complicated matter in this complex. There are many economic players on different levels with different tasks to achieve the final goal of the economy in a country, depending on the level of development [1]. The need for managing international business arises in the flowing areas or levels: 1 . The international framework with all the institutions and organisations that determine country's economic and support policy in emergent situations. 2. Impact of globalisation on international and national policy and activities. 3. The national framework, which fairly complicated because there are many active players: a) National economic policy: understanding it and the environment for trade activities. b) National economic structure and competiveness of the domestic companies. c) International management capacities. d) Local or regional environment and conditions for the companies. e) Focus on the world market conditions and their development

1. Real trade activities in general and special types of countries. 2. Financing possibilities of trade activities according to the financing infrastructure (financial market) in countries. 3. Benefit of trade balance to national development and economic welfare of the people in countries concerned particularly: a) Increasing of the purchasing power of the people, i.e., per capita income, b) Creating more employment opportunities
\end{abstract}

Keywords: International institutions, international organisations, globalisation process, national support for international trade, international management, trade activities, benefit of international trade activities on national development 


\section{Introduction}

The aim of this paper is to show and to interpret the real motivation of international trade business with all the benefits, barriers, and problems. The model we propose illustrates our approach to International Business Management. Our proposed theoretical framework could be easily applied and would probably hold good in practically $80 \%-90 \%$ of countries.

The international trade management is the backbone of every economy. This implies that the trade balance of a country heavily influences the economic development of the country.

The process of managing international business is not an easy one because there are many problems and barriers that need to be overcome to reach the ultimate goals of national economic policy, i.e., the economic welfare of the people, which implies a low unemployment level and a higher purchasing power of the income earners to meet their basic needs (for greater details, see discussion by $[2,3]$.

Our model demonstrates the complexity and independency of different levels in international business management. Each level has different goals and directions.

Level 1: International framework

$\rightarrow$ Financial institutions

$\rightarrow$ Organisational institutions

Level 2: Globalisation

Level 3: National objectives

$\rightarrow$ Political stability

$\rightarrow$ Infrastructure

$\rightarrow$ Trade policy

Level 4: Location

Level 5: Company

$\rightarrow$ Company structure

$\rightarrow$ Decision-making process (management)

$\rightarrow$ World market conditions

Level 6: Foreign trade activities

$\rightarrow$ Basic

$\rightarrow$ Special

Level 7: Foreign trade financing

$\rightarrow$ Short term

$\rightarrow$ Medium term 
$\rightarrow$ Long term

Level 8: International business

$\rightarrow$ Reduction of unemployment rate

$\rightarrow$ Increasing purchasing power

$\rightarrow$ Welfare in the countries

\section{Level 1: International framework}

At this level, we have two kinds of organisations with the objective to develop the world trade activities and to improve the world market sales.

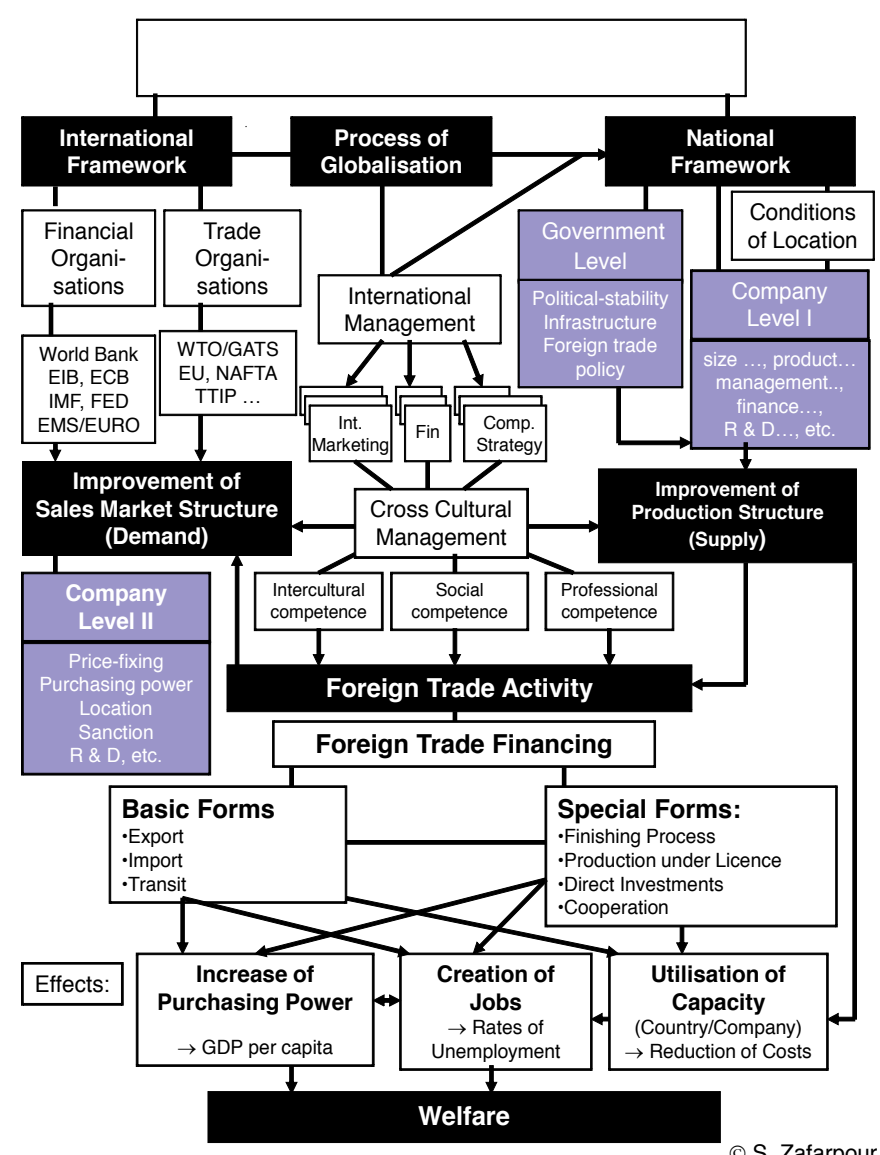

Figure 1. International business management 


\subsection{International financial institutions}

The World Bank, International Monetary Fund, National Reserve Banks, European Central Bank, and other National Financial Institutions

These organisations can and do support only the countries (infrastructure, etc.) and not the individual companies. The country has to apply for their financial support. The support always depends on accepting the laid down conditions (e.g., restructuring the country) of these organisations. The importance of there is now visible in the current economic and financial crisis. We must note that these financial institutions work on the benefit for the financial market.

\subsection{Organisational institutions}

\subsubsection{WTO, EU, NAFTA, MERCOSUR, ASEAN, etc. (TTIP)}

The task of these mentioned trade organisations is to create standards and free competition on the world market. However, countries with more political or economic power do and can influence the rules and get more favourable treatment.

\section{Level 2: Globalisation}

The phenomenon of globalisation has practically started some thirty years ago, coming down from international institutions. It was a copy of the U.S. success model of neo-liberalisation policies. Many EU countries did follow the model. The globalisation is a process and has following preconditions:

\subsection{Change of economic policy}

- Deregulation of employment markets

- Privatisation of nationalised companies

- Reduction of taxes for earnings and property incomes

- Low inflation to avoid the inflation of monetary capital

- Simplification of the international capital flows

- Improvement of the chance to success for companies to create an attractive climate for investments

\subsection{Liberalisation of international trade and capital}

- Simplification of trade in goods and services as well as the transfer of capital

- General Agreement on Trade and Tariffs (GATT) of 1948 was basis for the worldwide free movement of goods 
- WTO (reform of GATT agreement): from 1993 to 1999.

- Facilitation of to the movements of good and regional free trade zones (e.g., EWR, NAFTA, MERCOSUR, and ASEAN)

- Further liberalisation of the capital flow

\subsection{International standards and norms}

- Efforts in harmonising the technical production standards to be able to push the transnational processing trade (car industry, amperage of white goods, configuration of copy machines, and printers)

Following these conditions, we do have some advantages and some disadvantages:

Liberalisation of domestic markets: The national property does not belong to any current government but to the people of a country. The governments are elected to follow the needs of the people and not to follow personal whims and interests of the people or the interests of financial markets. Privatisation could support corruption and nepotism.

The globalisation has altogether different impact on politics, people and national economies.

\subsection{Process of globalisation on companies}

The process means liberalisation of four markets

- Capital market

- Labour market

- Information market

- Technology market

\begin{tabular}{cccc}
\hline Size of company & Strategy & Problems & Task of government \\
\hline Multinational companies & Internationalisation & $\begin{array}{c}\text { Shifting the jobs to abroad } \\
\text { (low-cost countries })\end{array}$ & $\begin{array}{c}\text { Support of passive foreign } \\
\text { direct investment }\end{array}$ \\
\hline Middle-sized companies & Regionalisation & $\begin{array}{c}\text { Lack of competitiveness to } \\
\text { compared with multinationals }\end{array}$ & $\begin{array}{c}\text { Tax relief and support of } \\
\text { active foreign direct } \\
\text { investment }\end{array}$ \\
\hline Small-sized companies & Specialisation & Lack of cheap capital & $\begin{array}{c}\text { Improvement of domestic } \\
\text { capital market and cheap loan }\end{array}$ \\
\hline
\end{tabular}

Table 1. Globalisation process has different impacts depending on the size and strategy of a company 


\section{Level 3: National objectives}

This level is perhaps the most complex level because of complications that result due to the multiplicity of factors, players, goals, and strategies. It is expected that all of them that they create the best congenial conditions for international trade and business.

\subsection{Political stability}

Political stability is absolutely necessary for foreign trade activities of a country. It depends on and must thus be is based on ownership laws

- that must be written down in the constitutional laws

- that are totally independent of the three national institutions
- Justice
- Executive
- Legislative

The following picture shows us how important political stability is.

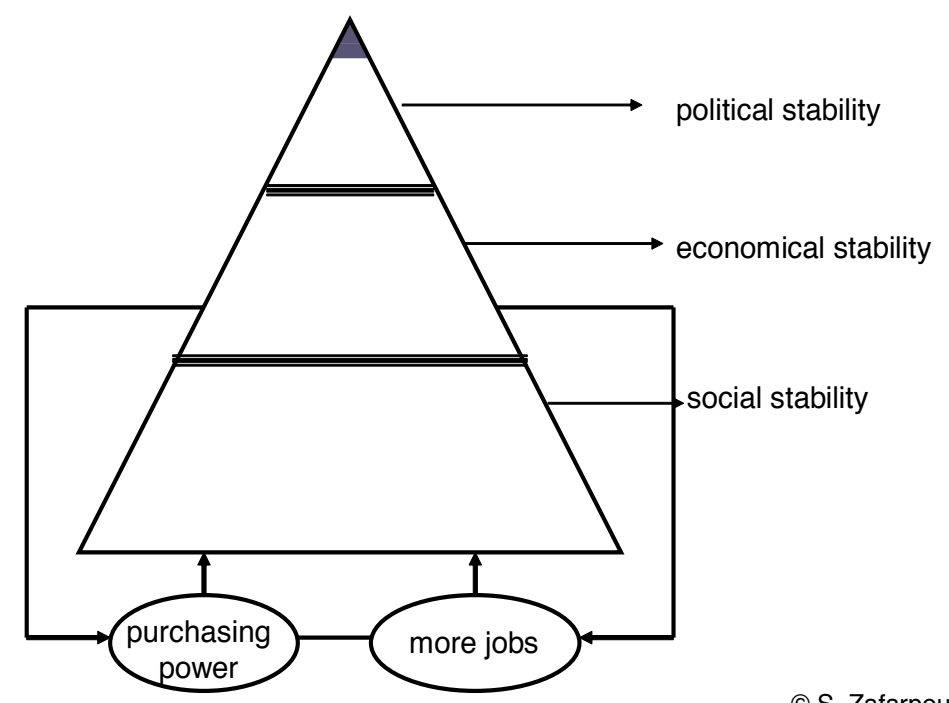

Figure 2. Importance of political stability for the countries

Political stability is necessarily based on economic stability. Economic stability is based on social stability. Social stability in turn depends on low unemployment rate and purchasing power of the per capita income of the people (currently many countries in crisis days are faced with frequent strikes and labour unrest due to the lack of two). 


\subsection{Infrastructure}

\subsubsection{Material infrastructure}

This must essentially need to be improved, built, and maintained in the country (e.g., roads, harbours, railways, airports, bridges, etc.). It covers the needs of the people and the companies (reducing the transport costs to become more competitive).

\subsubsection{Institutional infrastructure}

These are financial institutions on microlevel within countries (banks, insurance companies, and financial markets) that respond to the domestic market needs (of the people and companies). On the other hand, they pay taxes to the government. With these taxes, the government can cover the needs of the macroeconomy.

The building of a capital market in a country depends on the policy decisions (centripetal or centrifugal) of the government.

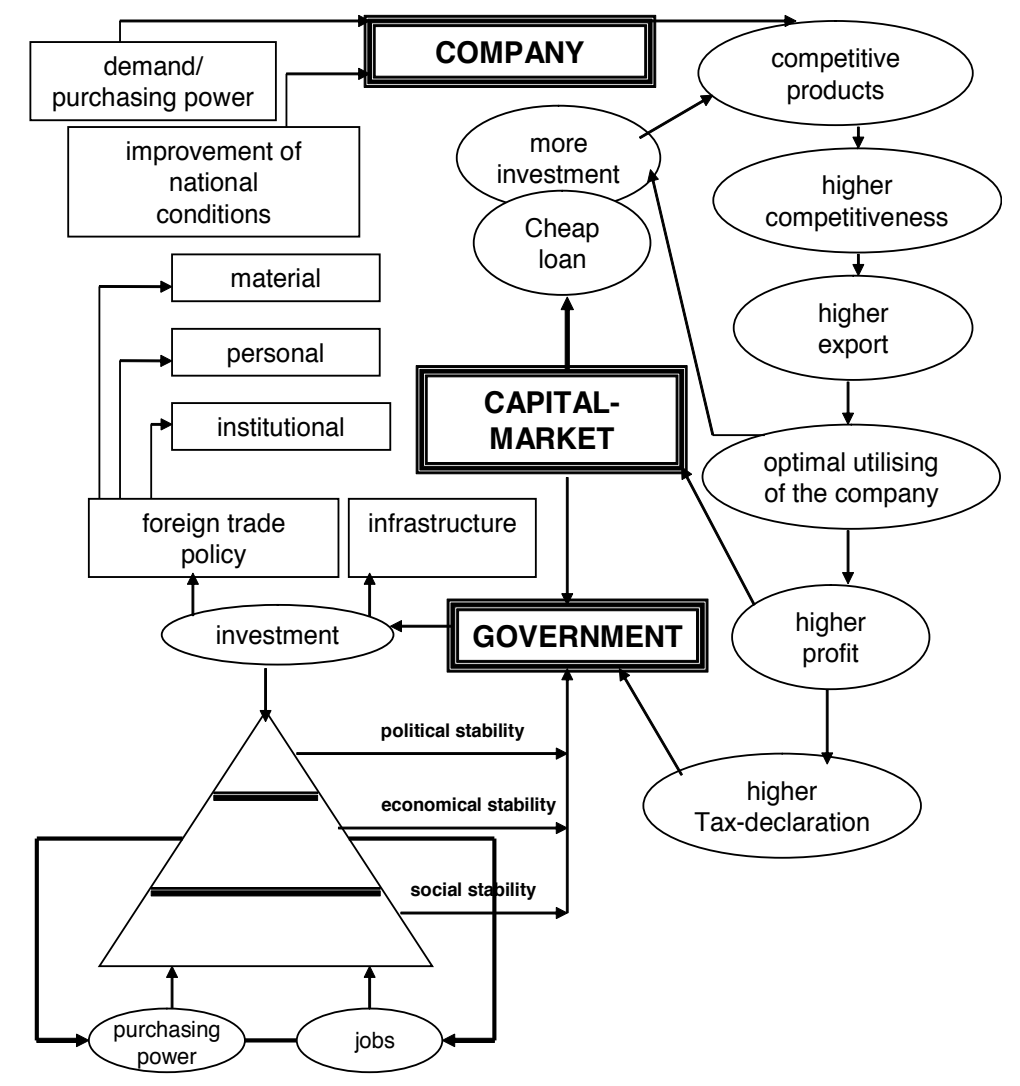

\section{(C) S. Zafarpour}

Figure 3. Significance of the domestic capital market for the development of a country 
- Companies need demand and purchasing power as well as improvement of national conditions to get competitive products, higher competiveness against other companies (economy of scales), higher export, optimal use of the companies' capacities, and higher profit.

- Higher profit could be invested in capital market, which means cheap loan and more investment for the companies.

- Companies with higher profit pay more taxes to the government.

- The government can get higher taxes for investment in political stability, economic stability, and social stability.

- On the other hand, the government can invest in institutional, material, and personnel infrastructure.

\subsubsection{Personnel infrastructure}

Personnel infrastructure is the quality and quantity of professional educated people-in private and government sector-in a country. The government has a relevant role in allocating the resources and to support the sectors in quality and quantity term.

The best hardware does not work without software and the best software does not work without hardware. The country should thus educate the future decision makers in professional, social, and international competences. This is the key of success in international business management.

\subsection{Trade policy}

Trade policy depends only on elected government. It could be progressive or digressive. The government may (or may not) support the companies (financially) in active and passive trade activities. The national frameworks for companies in international business may differ from country to country (e.g., state guarantee for international trade of the companies).

\section{Level 4: Location}

The location is essential for the success of a company. Companies are located in different areas with different conditions for different products. The selection of the right location has a direct impact on the transportation costs, which means being more or less competitive to other companies.

Conditions and factors of location are different on the mezzo level between macro and micro. That is a tandem between government tasks (responsible for infrastructure) and company needs. Many companies of any size get problems because they are not at the best matching location. The following picture demonstrates the importance of the location in general and regional determinants. 


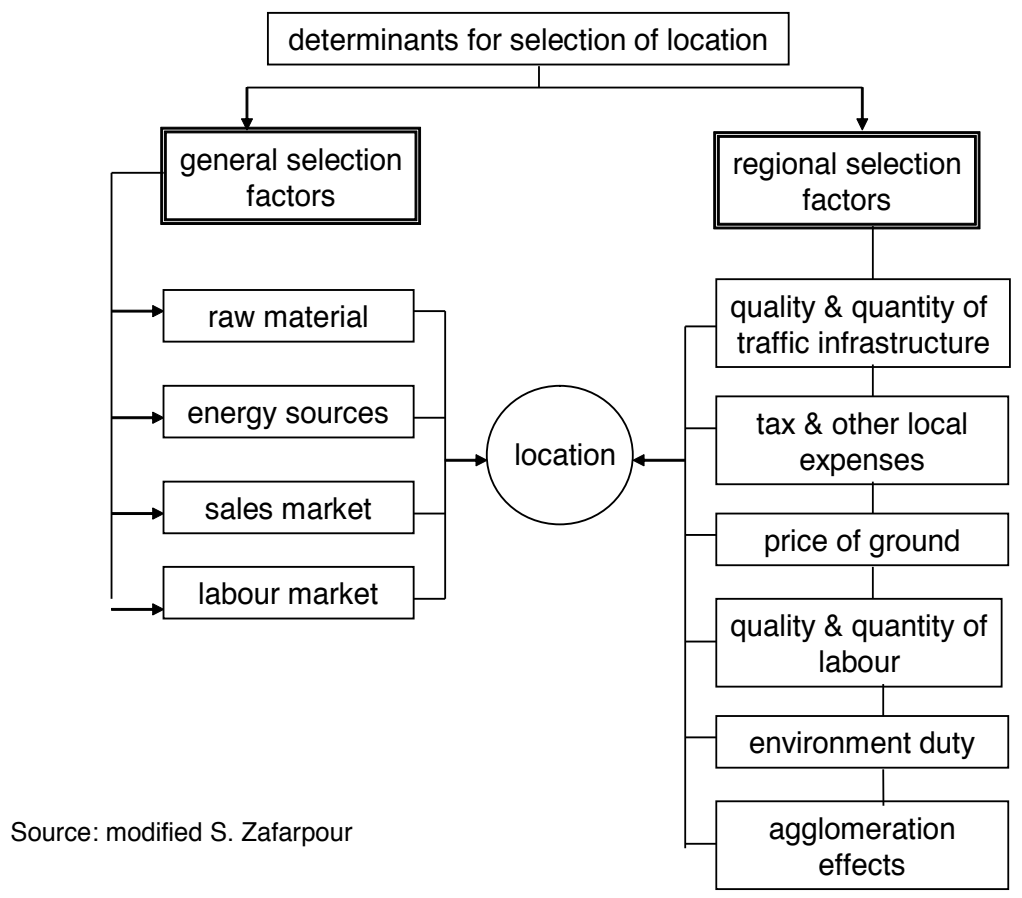

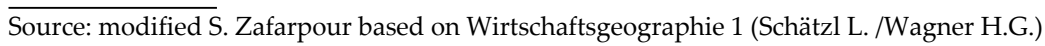

Figure 4. General selection factors for location of businesses

\section{Level 5: Company}

The company is the fundamental and essential unit in international business and trade management. There are too many intricacies at company level too. No companies, no business - no trade at all. Success of the companies depends on the competitiveness on the market (domestic or world market):

- Qualification of the staff (quality and quantity)

- Creation of company potential

- Innovation (products, services)

On this level, there are three different factors that act on its success in the world market.

\subsection{Company organisation and its production structure}

Size, product, management, finance, research and development 


\subsection{Decision-making process (international management)}

It is much easier to act in the domestic market, whereas it is important to have more international competences in the world market because each business aspect becomes "international" (financing, organisation, marketing and advertising are all measured by international parameters).

This would mean that we have more competences as well as more costs, which are to be covered through the international trade. The most important person in a company is the decision maker. He or she should have special skills:

- Professional competence (technical education and experience) - it is more or less the same in Europe and probably everywhere

- Social competence is to receive and understand the social signals and to react adequately (which could be a problem in globalised activities)

- Cross-cultural competence is to understand and evaluate your own cultural values to receive other cultural signals, to understand, and to react in the right way according to the following picture

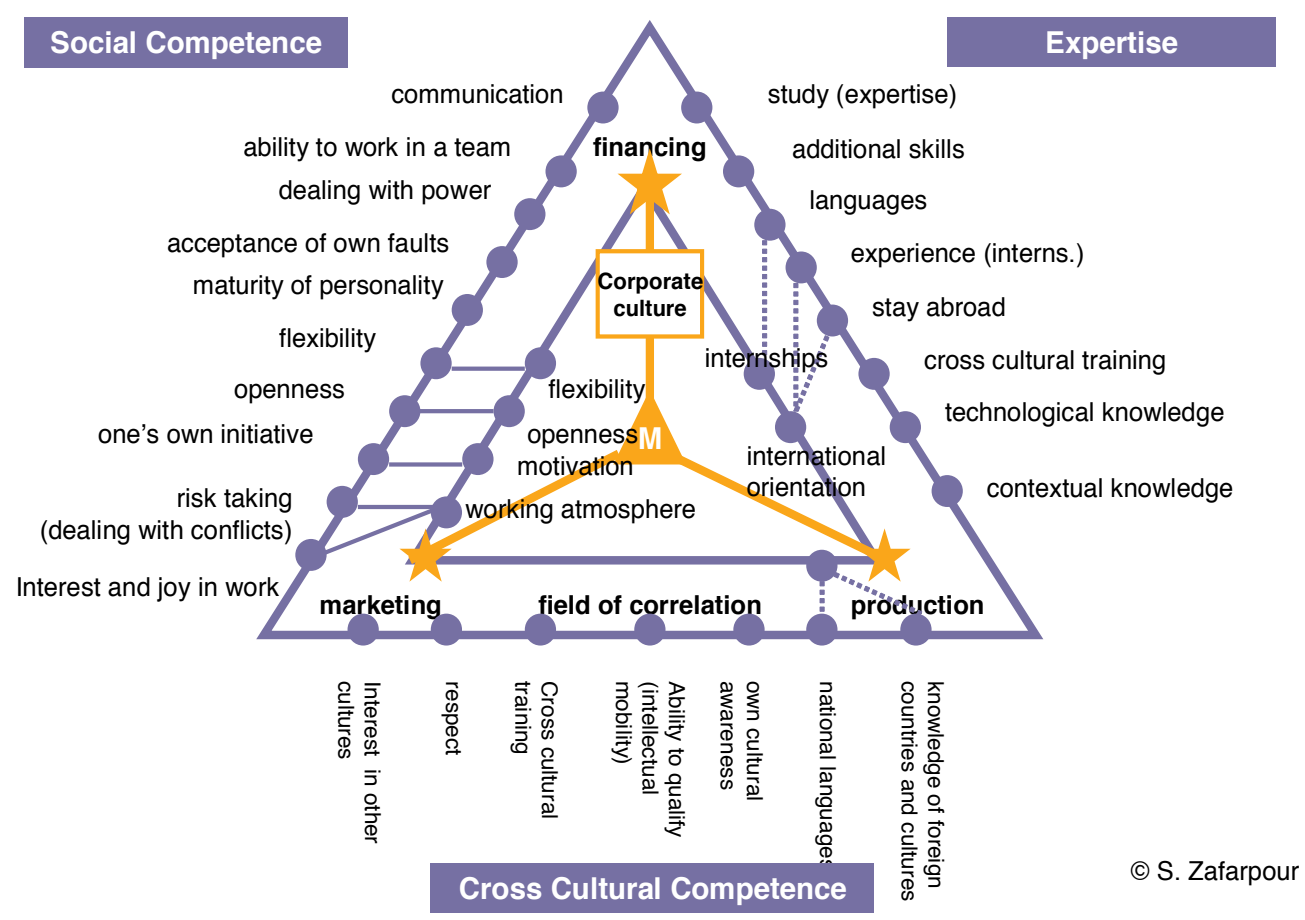

Figure 5. Cross cultural management factors 
The picture explains the different views of companies with expectations inside the companies and external expectations on employees/labour markets.

The inside triangle shows all the tasks, capacities, and responsibilities of the company:

- Corporate culture and the atmosphere

- Different departments with fixed goals

- Financing capacities

- Production structure and capacities

- Marketing strategy and capacities

The outside triangle shows the labour market with different skills and expectations.

The problems come from the different sides of views. There are some correlations between the expectations, but not always. For example, on social competence, flexibility, openness, and so on depend on both sides understanding. The companies will profit more and the employees will have more income to cover their own needs in general.

\subsection{World market}

International trade management is the link between total demand on the world market and the available supply in countries. The decision maker is the key person in this process. He or she can make-with or without support-the final decision. The key person can keep direct influence on all the factors inside the company. He or she has an indirect influence on regional factors but not any significant influence on factors on the world economy. Only rare multinational companies could have some influence.

Once we have demand on the world market through international framework for all the countries and companies, we require adequate national framework at all levels to create favourable conditions for the companies to create the required level of supply. However, the task of international management or decision makers (with all their competence and skills) is to bring supply and demand together cross border.

The world market demand for the products is basically:

- Demand for labour-intensive products (under 29\%)

- Demand for capital-intensive products (about 44\%)

- Demand for know-how intensive products (over 50\%)

\section{Level 6: Foreign trade activities}

The measurement of success of all steps we have mentioned before are the following trade activities. 


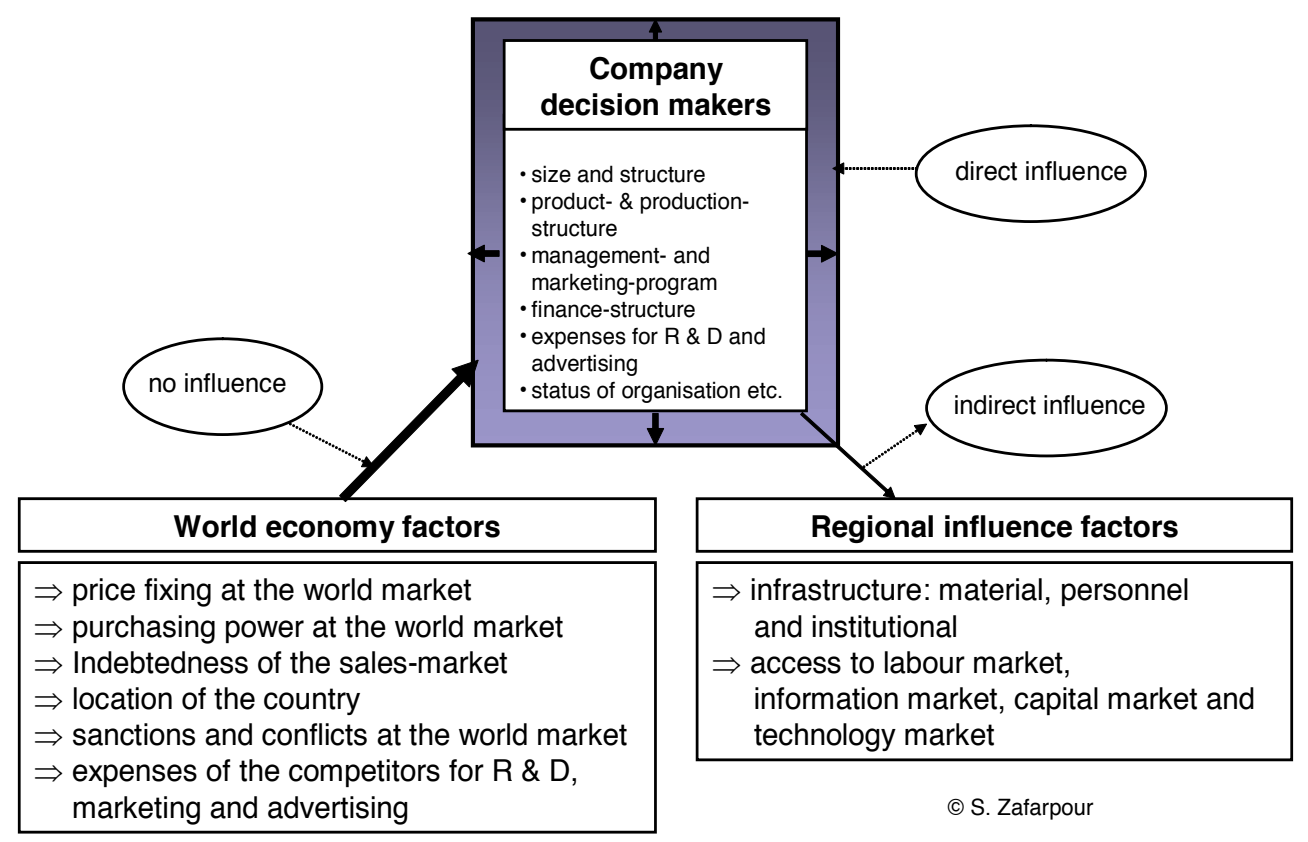

Figure 6. Influence of decision-makers on three different business level

\subsection{Basic types of international trade}

7.1.1. Exports (direct/indirect)

7.1.2. Imports (direct/indirect)

7.1.3. Transit trade (through third country)

\subsection{Special types of international trade}

7.2.1. Across the border processing

\subsubsection{Licensing, franchising}

7.2.3. Foreign direct investment (FDI) and joint ventures

\subsubsection{Cooperation}

Reason: creation of better framework conditions and reduction of production costs.

$\rightarrow$ Increase in competitiveness by

- reducing production costs abroad (cost and location advantage),

- accessing core resources (safeguard supplies of raw materials),

- making easier market entry in case of trade barriers, 
- lowering taxation on earnings in the host country,

- reducing exchange risk (risk avoidance).

7.2.1. Across the border processing

\section{active processing}

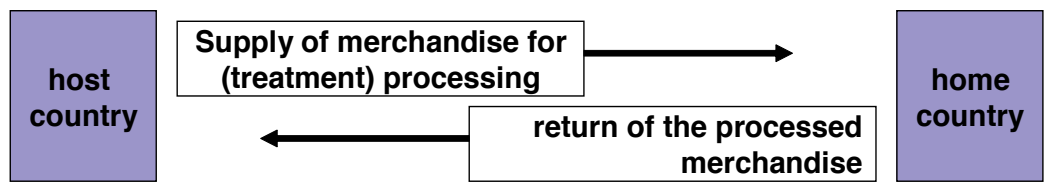

\section{passive processing}

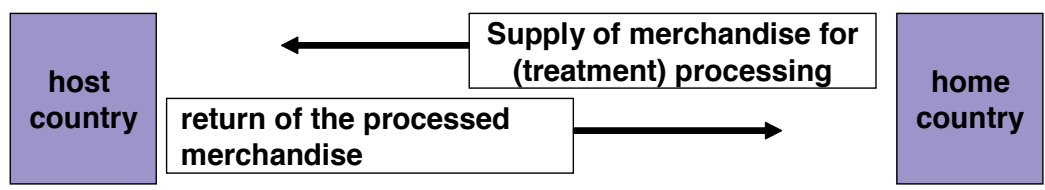

Reasons: Utilisation of wage differences

Division of labour between partner companies

Outsourcing of production due to capacity reasons

Export promotion

Figure 7. Across the border processing

\subsubsection{Licensing, franchising}

Export of know-how and patents

- Unwanted direct investment

- Low investment for licensors

\subsubsection{Direct Investment (DI)}

Advantages:

- Utilisation of low labour costs/wages

- Presence on the sales market

- Desired from the viewpoint of development policy

Disadvantages

- Fewer jobs in the home country

- Transfer of profits might be regulated or limited 
- Political risks

\section{Active direct investment}
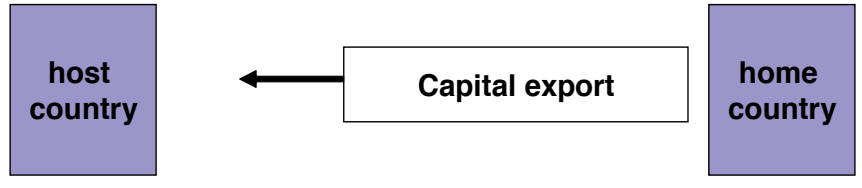

Passive direct investment

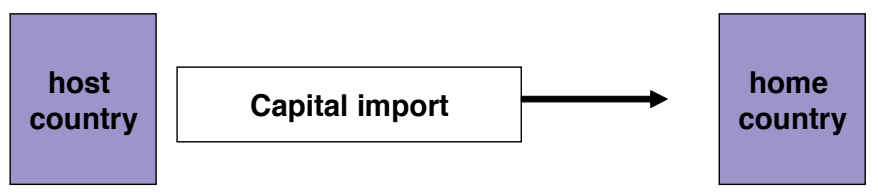

Figure 8. Direct Investment (DI)

\subsection{Cooperation}

Joining of economically and legally independent companies in order to execute offers together

Economic boom

Cheap capital (low interest rate) $\rightarrow$ self-automation tendencies

Result: Establishment of many small enterprises

Recession

Expensive capital (high interest rate) $\rightarrow$ saving tendencies

Result: Bad orders position (cutback in employment)

Enforcement for cooperation

Advantages:

- Economies of scope (joint marketing, acquisition, R\&D, etc.)

- Abolishment of intercompany competition (price war)

- Reduction of foreign trade risks

- Opportunity to create direct contacts with foreign partners

Disadvantages:

- In case of flat hierarchy (on leadership level)

Types: vertical horizontal, complementary 


\section{Level 7: Foreign trade financing}

The financing of trade and any other businesses are of the most challenging barriers.

- The multinational companies have no big problems with it because of their own reserve capital from one hand, and they are successful enough to get money from the banks.

- The middle-sized companies do not have problems until the balance is positive over many years.

- The small-sized companies have more problems in this field if the percentage of own capital is less than $30 \%$ of the investment volume and if the company cannot offer any guarantees or property.

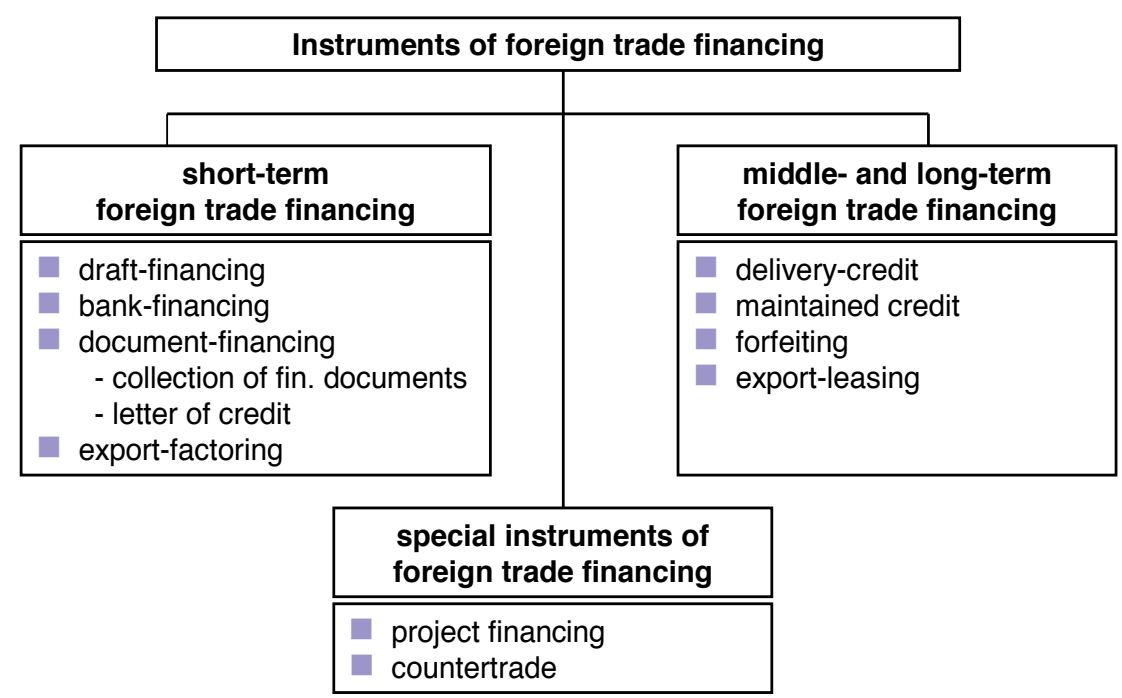

$\overline{\text { Source: modified S }}$. Zafarpour based on Das Exportgeschäft (Moser R., Topritzhofer E.)

Figure 9. Financing on different levels

\section{Level 8: International business}

Every society basically aspires to have low unemployment, to have high rates of increase in per capita national income, and to maximise economic and social welfare. This fundamental idea has been imbibed in conventional Keynesian economics [4] and well implemented in the New Deal policies of the United States in the 1930s. Keynesian policies have been largely responsible for achieving the said goals at national and international level during the 1950s and 1960s. The spell was broken in 1973 with stagflation and recession in the United States and Europe. However, with the process of globalisation that started in the 1990s, the liberali- 
sation policies of WTO have once again focused on the mentioned goals. This has made the role of international business management more or less indispensible.

\section{Summary}

This multiple theoretical analysis of international business management is a modest contribution to the understanding of the complexities and independency of different protagonists and players to bring the economy of a country to higher levels of equilibrium. It means the reduction in unemployment and increased per capita incomes of the people, especially of the low and middle class, who will consume, save, and invest more that would lead to higher employment levels. This would ultimately lead to the maximisation of total economic welfare; in other words, it would meet Maslow's conditions of needs.

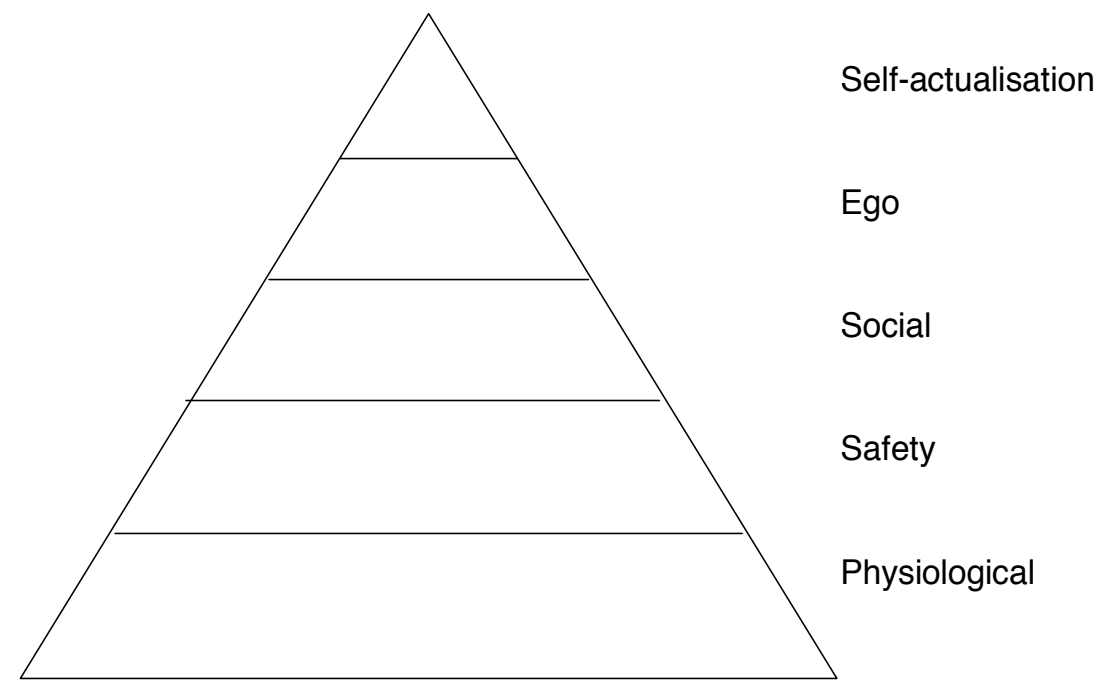

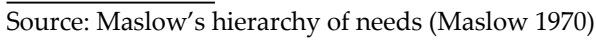

Figure 10. Basic needs of the people everywhere

\section{Author details}

Schapour Zafarpour

Address all correspondence to: schari.zafarpour@chello.at

Vienna University for Economic and Business, Austria 


\section{References}

[1] Rostow, W. W. (1962). The stages of economic growth. London: Cambridge University Press.

[2] Maslow, A. (1943). A theory of human motivation. Psychological Review, Vol. 50, No. 4, pp. 370-396.

[3] Maslow, A. (1954). Motivation and personality, 1st ed. New York: Harper.

[4] Keynes, J. M. (1936). A general theory of employment, interest and money. London: Macmillan. Michael E. Porter: Wettbewerbsstrategie, Campus Verlag, Frankfurt, 5 Auflage 1988

[5] Buns, P., and Dewhurst, S. (1991). Small business and entrepreneurship. Macmillan.

[6] Popa, I., and Filip, R. (1999). Management international. Editura Economica.

[7] Piper, J. (1999). The way to trade. Pitmanpublishing.

[8] Dülfer, E., and Jöstingmeier B. (2008). Internationales management. Oldenbourg.

[9] Daniels, Radebough, and Sullivan. (2009). International business environment and operations. Pearson.

[10] Magla, S. (2005). Cross cultural competence. Routledge.

[11] Livermore, D. (2010). Leading with cultural intelligence. Amazon.

[12] Moser, R., and Toprizhofer, E. (1986). Das Exportgeschäft. Service Verlag.

[13] Export/import in der praxis by Austrian Chamber of Commerce. (1992). Wirtschaftsverlag.

[14] Zafarpour, S. (1988). Grundlagen des internationalen Handels, Unterrichtsbehelf für den Außenhandelskurs, BFI Wien.

[15] Zafarpour, S. (1993). Let's go international. Einleitung und Problemstellung, Schriftenreihe des Zentrums für Auslandsstudien.

[16] Zafarpour, S. Internationalisierung und die dreidimensionale Managerausbildung, in "der markt," Zeitschrift für Absatzwirtschaft und Marketing, 32. Jahrgang, 1993/1994, Nr. 127 Vienna

[17] Zafarpour, S., and Fink G. (1995). Kultur \& management, in Arbeitspapier Nr. 1, Gesellschaft für Ostkooperation, pp. 1-16, Vienna.

[18] Zafarpour, S. Manager im 21. Jahrhundert, in Festschrift Heinrich Stremitzer, Versicherung, Risiko und Internationalisierung, Hrsg: Josef Mugler, Linde Verlag Vienna, pp. 485-496.

[19] Zafarpour, S. (1997). Außenhandelsstruktur der Alpen-Adria-Länder, in Tourism and Hospitality Management, Vol. 3, No. 1, Vienna-Opatija, pp. 101-157. 
[20] Zafarpour, S. Journal of the International Association of Cross Cultural Management and Competence, IKO Verlag, Frankfurt, co-editor.

[21] Zafarpour, S., and Bobek, V. (2000). Vergleich der Förderungssyteme für internationale Direktinvestitionen in Österreich, Italien, Slowenien und Kroatien, in Ekonomska Misao i Praska (Economic Thougt and Practise) X, Dubrovnik.

[22] Zafarpour, S. (2001). Interkulturelle Kompetenz und Management in der globalen Wirtschat, in Interkulturelles Management, Österreichische Perspektiven (Hrsg. G. Fink/S. Meierwert). Wien: Springer Verlag, pp. 315-337.

[23] Moser, R./ Topritzhofer (1986), Das Exportgeschäft, Fachverlag an der Wirtschaftsuniversität Wien.

[24] Schätzl, L (1981), Wirtschaftsgeographie I, UTB Schöningh Verlag, Paderborn/ München/Wien.

[25] Wagner, H.G. (1981), Wirtschaftsgeographie, Westermann, Braunschweig. 
Section 2

Management of Companies 

Chapter 2

\title{
European Foundation for Quality Management Excellence Model Can Encourage ISO 26000 Implementation
}

\author{
Štefka Gorenak
}

Additional information is available at the end of the chapter

http://dx.doi.org/10.5772/60959

\begin{abstract}
Interest and initiatives related to Social Responsibility, ISO 26000 and EFQM Excellence Model, have increased over last decade. Strategic management models are framework for achieving sustainable growth and sustainable competitive advantages. The purpose of this paper is to trace and define the relations between several European Foundation for Quality Management (EFQM) criteria and the components of ISO 26000 as well as total responsibility management and interrelations between organizations and their stakeholders. In the light of the analysis, the systemic and holistic EFQM model may be considered as a tool for the governance and implementation in the corporate strategy according to ISO 26000 recommendations. The ISO 26000 standard tries to link with the EFQM Excellence Model. This paper considers that the social responsibility perspective is a key element of the EFQM Excellence Model, which includes stakeholders and potential contribution to the sustainable development. Organizations pay from year to year more attention to continual quality improvement and implementation of EFQM Excellence Model, including social responsibility models, and their interrelations reflect the real and potential synergies like sustainable competitive advantages, sustainable cooperative advantages, and sustainable cooperative excellence in the future.
\end{abstract}

Keywords: EFQM Excellence Model, ISO 26000, social responsibility, stakeholders, sustainable development 


\section{Introduction}

Interest in social responsibility (SR), corporate social responsibility (CSR), total quality management (TQM), European Foundation for Quality Management (EFQM), and especially in ISO 26000 as well as their interdependence is increasing. Social responsibility is one of the most important management topics in companies as well as in other organizations in the last decade. There is a clear recognition that strategic management models are the framework for achieving sustainable growth and sustainable competitive advantages.

"The practical application of SR can be well supported by guidelines of business excellence as defined by the EFQM and includes five input and four result criteria" [1]. This changing model follows the present organizations environment, and it is reviewed every 3 years (the last version EFQM 2013). Flexibility is one of the most important factors that influence the success within global and local organizations.

The EFQM Excellence Model 2013 incorporates current key business challenges: “(1) build agility into the business; (2) greater emphasis on developing approaches; (3) more important are the accountability of leadership, governance and risk management; (4) doing the right thing is important; (5) measurement indicators; (6) criteria are now more explicit and prescriptive; (7) futuristic focus; (8) wider focus covering entire value chain; (9) greater emphasis on corporate social responsibility; (10) sustainability; (11) innovation; (12) other subtle and notable changes made are changes made in fundamental principles of excellence, changes in excellence model, changes in RADAR logic" [2]. EFQM 2013 helps organizations to manage quality successfully and operate according to sustainable determination.

"The principles and guidelines of social responsibility are outlined in the most recent release of the ISO 26000 standard, which links the principles of management with the business excellence model EFQM" [3]. The new SR definition has been implemented by International Organization for Standardization (ISO). "Social responsibility is the responsibility of an organization for the impacts of its decisions and activities on society and the environment through transparent and ethical behavior" [4].

The practice by implementation of ISO 9000 and EFQM is different; some organizations tend to implement ISO 9000 procedures first and the EFQM Excellence Model is included later. The EFQM specialists as well as the practice confirm that the most appropriate is to apply ISO 9000 and EFQM together, but it is a never-ending process. The resources limitation is sometimes the reason why organizations are not able to implement both at the same time. Moreover, we have to now that ISO 9000 (day-to-day quality standard) has limitations; on the other hand, the EFQM Excellence Model is long-term oriented (prepares organization for long-term sustainable excellence).

Social responsibility guideline-ISO 26000-was issued by a well-known authority - ISO. ISO 26000 is a CSR guideline that enables all organizations to define and implement CSR in their corporate strategy. "ISO 26000 exposes seven core subjects-human rights, labour practices, the environment, fair operating practices, consumer issues, community involvement and development [4]" in which an honest behaviour supports success; all of them are linked by 
two crucial concepts: (1) interdependence and (2) holistic approach. ISO 26000 is reference standard for all (C)SR topics-EFQM, SA 8000, AA 1000, ILO, ISO 14001, GRI, ISO 9001, ISO 31000, OHSAS, and EMAS.

"Business can be understood as a set of relationships among groups which have a stake in the activities that make up the business. A stakeholder approach to business is about creating as much value as possible for stakeholders, without resorting to trade-offs" [5]. Relationships with stakeholders are also very important in the educational institutions (all levels), health system, government and public sector, local communities, nongovernmental institutions, and public-private partnerships. At the same time, we can discuss about relationships with primary and secondary stakeholders. Organizations are trying to meet their own requirements as well as the requirements and expectations of their stakeholders.

Responsible competitiveness - "Businesses can compete effectively across the responsibility spectrum" [6]. The importance of corporate responsibility increases. It requires that it be integral to and supportive of broader sustainable development strategies and policies (at organizational level and governmental levels). The relationship between competitiveness and $\mathrm{SR}$ is not a simple one. CR can also encourage innovation, investment, cooperation, and competition. It means that organizations pay attention to ecological, social, and financial aspects of their responsibility in interaction with all stakeholders (for example, they care about their sustainable production, emissions and waste, employee safety and satisfaction, and stakeholder involvement). It is clear that responsible shareholders are important stakeholders who must support sustainable leadership orientation.

"Public policies to amplify SR practices need to be, and indeed are being, formulated in the context of this complexity at an international level, and also at regional, national, and even community levels" [7].

The purpose of this paper is to trace and define the relations between several EFQM criteria and the components of ISO 26000, total quality management (TQM), and total responsibility management (TRM) as well as interrelations between organization and its stakeholders. In the light of the analysis, the systemic and holistic approach EFQM model may be considered as a tool for the governance and implementation in the organization strategy according ISO 26000 recommendations. Socially responsible organizations focus on economic growth, stakeholder strategic management, long-term sustainable development, sustainable indicators, sustainable competitiveness, and cooperative advantages.

\section{European Foundation for Quality Management (EFQM)}

EFQM was established in 1988; its members are companies and other institutions (research, education, and national organizations). "The EFQM Excellence Model is a practical tool that indicates the position of business and other organizations on excellence path and helps them to determine their shortcomings and encourages appropriate solutions" [8]. The first EFQM Excellence Model was published in 1992; it is flexible and can be implemented in large 
companies, SMEs, and other organizations (private and public, government, local communities, and other organizations).

"Business excellence models, particularly the EFQM Excellence Model, are being used by organisations all over the world for self-assessment, benchmarking, sharing of best practices and assessing organisations for national quality business excellence awards" [9].

From a theoretical and practical point of view, the business excellence models (particularly EFQM) have to be applicable and implementable in different types of organizations. Many countries try to encourage implementation of the organizational excellence models, like Deming (Japan), Malcolm Baldrige (USA), and EFQM (Europe).

At the same time, we would like to present the difference between ISO 9000 and EFQM Excellence Model. ISO standards have a long tradition; one of the most important standards is ISO 9000 (requires certification), which is comprehensive and exactly describes quality requirements, protocol, and how to meet all these requirements. On the other hand, EFQM Excellence Model is opened, its implementation needs creativity, but it is possible just in freedom. Furthermore, in such holistic approach, creativity and complexity go together in the EFQM Excellence Model.

“The EFQM Excellence Model is business management framework aimed at sustained wealth generation” [10]. "The EFQM Excellence Model, a non-prescriptive framework, is based on nine criteria. Enabler criteria are concerned with how the organisation undertakes key activities and results criteria are concerned with what results are being achieved" [1, 11].

The basic concepts of this model are extensive and involve results orientation. Customers are one of the main stakeholders; their satisfaction and loyalty are important for each organization. Leadership plays the crucial role; it must be the model as well as the motivator and strategic processes, which are focused on quality, stakeholder partnerships, and sustainability. Employees are one of the main stakeholders, and their involvement reflects as their contribution to innovativeness, improvement, and competitiveness. Stakeholder partnership is a long-term process and is part of the holistic and systemic social responsibility in organizations.

Furthermore, the EFQM Levels of Excellence Scheme was created to provide systemic and holistic recognition to organizations at all levels of their excellence promotion and improvement. "The main objective of the scheme are to: (1) extend recognition to organisations at every level of achievement; (2) maximize the number or organisations who are able to apply the principles of the EFQM Excellence Model for organisational improvement; (3) provide independent feedback from practicing managers to support organisations in their quest to improve and (4) provide practical products and services that help organisations achieve improved levels of excellence" [11].

Organizations practicing excellence scheme may use the EFQM Excellence Model percentages, but on the other hand, they may use percentages more suitable to their own type of organization. Additionally, we present the recommended percentage of "the EFQM Excellence Model criteria: (1) Leadership (10\%); (2) Policy and Strategy (10\%); (3) People (10\%); (4) Partnerships and resources (10\%); (5) Processes (10\%); (6) Customer results (15\%); (7) People results (10\%); (8) Society results (10\%) and (9) Key performance results (15\%)" [11]. 


\subsection{Importance of good leadership and management}

Leadership is similar to as well as different from management. They both involve influencing people, require working with people, and are concerned with the achievement of common goals. Organizations need people who do the right thing and who do the right things right.

Nowadays, managers must also deal with a growing international competition. "Managers, wherever they are in the organization, but particularly in the top management, need to take a long-term perspective" [12]. Transformative leaders lead by values; they are the best model for others within the organization, create and integrate vision into strategies and processes, care and make a public commitment, constantly communicate with stakeholders with the aim to avoid potential problems in the future, and encourage competitiveness and good relations with stakeholders.

The business benefits of good leadership reflect as improved business (competences, innovativeness, and proficiency) and employee performance (employee satisfaction and involvement). In addition, we want to highlight "factors identified as particularly importantcommitment to management and leadership development, human resources practices that reinforce management and leadership development" [13].

How can we define good leadership and management? At the first position are core leadership and management skills. We highlight the most important effective leadership skills. "The best leaders face problems head on and have the confidence to propose sometimes innovative or difficult solutions, all managers need to be effective leaders; (1) Strategy and planning; (2) People management; (3) Budgeting \& financial planning; (4) Risk management; (5) Fostering innovation and creativity-continuous innovation strategies are managed by more highly educated and better informed managers; (6) Partnership working" [14, 15].

"Improving leadership and capability management is very important, so we present 10 top tips for employers: (1) recognise that good leadership and management matters; (2) be a role model: good leadership and management starts at the top; (3) implement good working practices as a framework for good management and leadership; (4) effective leadership runs through organisations like writing through a stick of rock; (5) provide training, support and mentoring to new line managers; (6) be clear about what good management skills and behaviours look like; (7) assess your organisations' management capability at individual and organisational level and act upon it; (8) make the most of the practical tools that are available; (9) invest in your workforce routinely and as part of your business strategy and (10) be authentic about good leadership and employee engagement (adopted 30-35)" [14].

“EFQM Excellence Model is based upon 9 main dimensions and these dimensions are called criteria (input criteria-leadership, policy \& strategy, people, partnership \& resources and processes; result criteria-customer results, employee results, society results and key performance results (criteria are supported by sub-criteria)" [16].

The EFQM Framework for CSR is interrelated on the EFQM Excellence Model and also gives guidelines on integration of social, environmental and economic results or influences. 
"The EFQM model can be described as a higher form of quality management in organizations" [17].

EFQM model refers also to CSR and ISO 26000. European Commission presented CSR definition: "companies integrate their social and environmental concerns in their business operations and in their interaction with stakeholders on a voluntary basis" [3]. Responsible organizations pay attention first to economic growth, but simultaneously they care about their environmental and societal impacts. The real sustainability-oriented winners implement higher responsibility and sustainability standards (as it is necessary according the law). Innovative social responsible organizations cooperate with all stakeholders with the aim to achieve the sustainable stakeholder synergies (excellent case are Scandinavian countries, where governments pay one of the crucial roles).

\section{Total quality management and total responsibility management}

In total quality (TQ), the environment in which the organization operates is changing constantly. Management's job, therefore, is to provide the leadership for continual improvement and innovation in processes and systems, products, and services. Continuous improvement is part of the management of all systems and processes. Improvement and learning need to be embedded in the way an organization operates. Improvements are very often concentrated on customer satisfaction, products and services improvement, productivity improvement, operational performance, work processes, errors minimization, waste minimization, flexibility, responsiveness, organizational management process improvement, continuous learning (learning organization at all levels), competitive comparisons, supplier performance, employee performance, and costs and financial performance. The goal of each organization should be long-term survival; the management has very important role, and it has to focus on improvement and must be able to create a system that can produce quality outputs. Employees are one of the key factors, and from this reason, training and education can provide needed skills. On the other hand, organizations have to pay attention also to structural rationality. It includes horizontal processes from suppliers to customers (as final user or buyer of their products or services). Simultaneously, the management needs to pay attention to the so-called philosophy toward change. It means that change, continuous improvement, and learning are encouraged.

Organizations must be able to adapt to changing environment. Competition is very strong, and the winners will be just the organizations that will be able to provide sustaining total quality and total responsibility. From this reason, the critical self-assessment is needed; it should be concentrated on management and leadership involvement (all levels), products and process design (meet customer needs), product and services control (minimize defects), customer and supplier communication (cooperative relationships), quality improvement (results achieved and plan for improvement), employee participation (employee skills and their participation-quality processes), education and training (skills quality improvement techniques), and quality information (complete information about results).

“The TQM practices suggested in the EFQM Excellence Model allows firms to outperform their competitors in the results criteria included in the Model. Therefore the research published in 
2007 provides a valuable benchmarking data for firms in it substantiates the EFQM Enabler's contribution to the attainment of competitive advantage" [18]. The sustainability leaders constantly involve sustainability initiatives into their processes, organizational culture, and permanent cooperate with all stakeholders. In addition, sustainability must be systemic and holistic, and the expected result is long-term sustainable competitiveness.

Responsibility management through a systemic process is called total responsibility management. It is very important to make this process explicit. In this way, managers (decision makers) understand how to manage quality and how to build constructive and responsible stakeholder responsibilities as well as relationships with them.

The linkages between more responsible practices and better financial performance and productivity come from a variety of sources and in many ways can be relate to simple good management. Some unrecognized costs can actually be reduced when responsible practices are implemented. In this way, responsibility management can be cost-effective.

TRM is very similar to TQM, where top management and customers play the crucial role. TRM pays attention to stakeholders' interests (stakeholder partnerships especially with key stakeholders). A proactive and innovative relationship with stakeholders generates improvement and permanent learning system, which contributes to the organization's growth, sustainable development, and competitiveness, as well as regions and states where they operate.

“The TRM core values include: (1) visionary and committed leadership; (2) stakeholder-driven excellence and responsible practices; (3) organisational and personal learning through dialogue and mutual engagement with relevant stakeholders, (4) valuing employees, partners, other stakeholders; (4) agility and responsiveness; (5) focus on the future (short and long term); (6) managing for responsibility and improvement; (7) management by fact, transparency, accountability; (8) public responsibility and citizenship; (9) focus on positive results, impacts and value-added for stakeholders with responsible ecological practices" [12].

Leadership (especially top management) is very important in each organization. It must be innovative and be able to include and create stakeholder partnerships. Furthermore, they have to be exemplary for the organization's values and innovative strategic management, and they should be able to manage long-term responsibility, which results also as sustainable competitiveness and sustainable development.

"The improvement and innovation elements of TRM create a significant demand for companies to broaden how they measure performance (economic, societal, and environment issues - sustainable indicators)" [19].

\section{ISO 26000-guidance standard on social responsibility}

ISO 26000 is a guidance for SR and an instrument that helps organizations by systemic and holistic SR implementation. In ISO 26000, the working group involved experts from 90 
countries, 40 international organizations, and stakeholder experts (customers, government, industry, labor nongovernmental organizations, services, research and academic organizations, and other organizations).

Social responsibility has a long tradition, and all theories and authors pay attention to the common principles (accountability, transparency, ethical activities, and stakeholder responsibility), which have to be respected in each responsible organization include accountability and transparency.

SR core subjects according ISO 26000 are as follows: (1) organizational governance, (2) human rights, (3) labor practices, (4) environment, (5) fair operating practices, (6) consumer issues, and (7) community involvement and development [4].

Additionally, the main purpose in ISO 26000 of the concept of "SR" has been to make it simple for easier implementation in different organizations (not just in corporations). Of course, it has advantages and disadvantages and difficulties, but it is a guideline for holistic and systemic implementation in the organization's strategy. ISO 26000 is extremely important and deserves attention. Furthermore, it needs explanation for potential users, and in the near future, its review will also be needed.

Moreover, permanent monitoring of SR performance as a requirement for permanent improvement regarding SR is needed (SR tools). A disadvantage of such tools is that not all SR impact areas are relevant for all organizations. ISO 26000 again proposes that stakeholders can play and important part in the evaluation of the SR performance of an organization. Benchmarking against the objectives and achievements of other organizations (SR champions in your industry, competitors, and other organizations with which the organization wants to compare itself) can help to anticipate developments in an industry or sector and evaluate what possible changes and consequences of these changes are important for organization.

Many researches on SR have been published already. "Research conducted by Brandsma showed that $54 \%$ Dutch organizations were at the initial stage of implementing policies on SR and $15 \%$ had not taken any steps at all" $[20,34]$.

ISO 26000 has short history, but there are many misunderstandings that refer to potential users about the scope of guidance and its usefulness in different types of organizations. Moreover, the relationship with other standards needs explanation. Other standards like quality, environment, safety, health, and information security are in interrelation and very close to ISO 26000 .

What is social responsibility? It is the variety of definitions and opinions it attracts, a feature that is both a strength and a weakness. More and more topics are being categorized under the banner of SR, which continues to inflate its meaning. Consequently, discussions about SR are confused by different interpretations because of the debate about the importance and meaning of SR - it is a dynamic concept, and its concerns change in conjunction with the development in markets and society.

The triple-bottom-line concept, introduced by Elkington, argues that paying attention to people (social justice), environment (ecological quality), and society (societal well-being or 
prosperity) can create economic value for organizations. Furthermore, "he argued that only those organisations that systematically align their goals with the goals of society and recognise the interdependence of the 3Ps (people, planet, profit) will be successful and survive in the future" [21].

From this reason, many developments have a role in this, such as governments and public sector authorities in many countries, especially in Scandinavian countries, which increasingly procure sustainability. CSR (or SR) has become more visible and important in the past few years for companies, governments, and NGOs alike. Many companies (especially large companies) have developed CSR strategies and report annually on successes (and failures) of these strategies-usually stand-alone sustainability reports. Moreover, citizens and (future) employees increasingly expect companies to act as "corporate citizens." The number of "green" consumers, who are inclined to buy sustainable products and services, are growing, as is the market of fair trade products.

Corporate social responsibility has a long tradition. The reason in the industrial revolution was to improve employees' health and well-being to protect their own interests.

A good illustration of this is from one of the founders of capitalism, Adam Smith (most famously known for the idea of "the invisible hand"). Smith's well-known works are An Inquiry into the Nature and The Causes of the Wealth of Nations, Theory of Moral Sentiments, and The Wealth of Nations [22, 23]. In his works, he emphasizes the importance of ethical forces in the fee-market mechanism and international trade, taking into account restrictions from a viewpoint of natural justice to prevent a dominance of amoral egoism.

In the first half of the 20th century, many authors paid attention to social responsibility of management in companies. The Functions of the Executive by Barnard, Measurement of Social Performance of Business by Kreps, and Social Responsibilities of the Businessman by Bowen were published [24-26].

The book on CSR written by Bowen is the starting point of the modern era regarding CSR thinking. The book discussed the observation that the largest companies are important centers of power and decision making, and that the actions of these companies affect the lives of citizens in several ways. This book notes that change is a dominant feature of life and that this change requires greater recognition and acceptance of social responsibility by business. Around the same time, some other important publications about CSR appeared, such as Management's Responsibility to Society: The Growth of an Idea by Heald and Corporate Giving in a Free Society by Eells [27, 28].

“In 1960 Davis described CSR as businessmen's decisions and actions taken for reasons at least partially beyond the firm's direct economic and technical interest" [29]. "In 1963 Maguire wrote in his book Business and Society. The idea of social responsibilities supposes that the corporation has not only economic and legal obligations but also certain responsibilities to society which extend beyond these obligations" [30]. Walton (1967) stated in his book Corporate Social Responsibilities that companies should voluntarily acknowledge and accept that they have responsibilities beyond the gates of the company [31]. In 1972, the Limits of Growth [32] described the devastating environmental effects of economic growth. The current interest in 
CSR also comes from other areas and disciplines-quality management, values, and ethical behaviour of organizations. McAdam and Leonard pay attention to employees and customers $[33,34]$. Management models such as those of the EFQM framework also give explicit attention to CSR - and this attention is growing. EFQM perceives the social responsibility for organizations as one of the pillars of excellence, and more attention has to be paid to CSR and sustainability. The explanation for the organization area "society" illustrates that every organization does not only supply services to (members of) society but is also part of society (organization becomes aware of its responsibility for its surrounding-environment, society, and development).

There are also other authors who paid attention to CSR. "In 2005, Kotler and Lee issued Corporate Social Responsibility: Doing the Most Good for your Company and Your Cause" [35]. "In 2006, the new well-known article Strategy and Society: The Link between Competitive Advantage and Corporate Social Responsibility was published" [36]. Strategy guru Prahalad has developed the strategy concept "the bottom of the pyramid," aimed at doing business with the poor, and the well-known management guru Peter Drucker discussed CS-related issues during a large part of his career [37, 38]. "According to Friedman view, there is one and only one social responsibility of business - to use its resources and engage in activities designed to increase its profits so long as it stays within the rules of the game, which is to say, engages in open and free competition without deception or fraud - 'the business of business is business'" [39]. According to Carroll, CSR has an economic, legal, ethical, and philanthropic face and points to the more strategic character of CSR-process in enterprises where ecological, economic, and social aspects are integrated in a strategic way [34, 40,41].

The development of ISO 26000 started in 2005. “ISO 26000 has ambition to be a comprehensive SR guideline that will enable all organisations to define their SR" [34]. The aim of ISO 26000 is to offer practical framework (including international conventions which are close to SR) with relevant systems (interaction with SR). The ISO organization offers several important advantages for the development of a global SR guidelines, from the perspective of the organization's objectives. ISO is one of the few organizations that is broadly acknowledger internationally. ISO will receive visibility in many organizations that already work with other ISO management systems but which have not yet engaged meaningfully with SR. "Research conducted by Brandsma in 2009 confirms this" [20]. Between 55\% and $60 \%$ of the respondents that work with an ISO-certified or related management system standards are considering applying ISO 26000 in their organizations. The development of ISO 26000 has been on the largest multistakeholder process that has ever been organized. Hundreds of experts from numerous countries have cooperated in the process. The aim has been to strive for a mutual and universal basic definition, principles, working methods, and guidelines - an international standard, written in (relatively) straightforward language. In addition, the guideline is applicable to all organizations, in all countries, in all stages of development, in all sectors and does not conflict with other SR standards or demands - it has no intention of replacing these. "The ambition of ISO 26000 , as a generic, overarching SR guideline, is to enable its integration with any existing SR or CSR standards" [34]. 
The results of the before mentioned research showed that most organizations that indicated an interest in ISO 26000 are still at an early stage in terms of SR implementation. For all these organizations, ISO 26000 is an applicable source of guidance as an introduction into SR and SR subject areas and as a guideline to structure their SR activities. Organizations that have already developed SR strategies and initiatives are more likely to apply ISO 26000 to increase the credibility of the own SR claims, e.g., by referring to the guideline in their SR communications. Moreover, ISO 26000 contains a process standard, a performance standard, a principle standard, and a basic standard, but it is not certification standard.

"ISO 26000 guideline aim is to help and support organisations, to contribute to sustainable development" [4]. Moreover, the ISO 26000 guideline highlights many aspects, and it contains advices and instructions for easier implementation in different organizations. Guidelines prescribe many requested activities and expectations, which have to be realized. Additionally, activities on SR implementation are structured, and concepts and principles are explained. SR core subjects are explained, harmonized (uniform and universal concept), and integrate ISO 26000 with other standards. It also provides the map of standards, which are in interrelation with SR and offers overview (core subjects and step-by-step implementation. Finally, the guideline reflects many SR subjects and encourages organizations (in their own context) to use them with the aim to encourage their SR activities, which reflect as their contribution to sustainable organization and sustainable society.

"ISO 26000 intends to give organisations the possibility to formulate an organisation-specific interpretation of SR, based on the SR foundation it provides. ISO 26000 crucially enable organisations to develop their own unique SR profile" [34]. This idea of an SR profile plays an important role in ISO 26000 because it characterizes a new generation of SR.

The four most important clauses in ISO 26000 are preceded by a classification of the scope of the guideline. First, ISO 26000 is applicable to all types of organization and the purpose of ISO 26000. Furthermore, it specifically states that ISO 26000 is not meant as a standard for a management system or for certification purposes. Next, the most important terms and definitions that are used in ISO 26000 are described ("terms, definitions, and abbreviated terms"). After the terms and definitions, ISO 26000 directs attention to the background to Clause 3, which includes a description of trends and developments, characteristics of SR, and the relationship between SR and sustainable development. Moreover, this clause pays attention to the relationship between ISO 26000 and the responsibilities of governments in SR. The guideline also points at the role of government in stimulating SR among companies but offers no further specific guidance on this issue.

\section{Stakeholders involvement and corporate responsibility}

Stakeholder theory has much to say about strategic management. The stakeholder perspective offers an alternative that can enhance the economic perspectives of modern strategic management. After more than half a century of research and debate, there is not a single widely accepted definition on CSR. Researchers in the field of CSR have claimed that the phrase 
"corporate social responsibility" has been used in so many different ideas and concepts (social performance, governance, accountability, sustainability triple bottom line, and social entrepreneurship).

Stakeholder identification and engagement-One of the general CSR principles within ISO 26000 concerns respecting stakeholders' interests. Identifying stakeholders, knowing their expectations, and enabling stakeholder engagement therefore play an important role in the guideline as they are a key to understanding, addressing, and implementing social responsibility. "Porter and Kramer add that by engaging in strategic CSR, new product offerings are likely to emerge, which are in turn benefiting both, social and environmental issues in addition to a company's long-term competitiveness" [36, 42]. Organizations engage and interact with many stakeholders (primary and secondary) with the aim to implement strategic SR processes successfully.

"Freeman et al. suggest the new vision of capitalism-stakeholder capitalism (based at six principles: stakeholder cooperation, engagement, responsibility, complexity, continuous creation and emergent competition)-founded on libertarian and pragmatist lines" [5]. Stakeholder capitalism is based on freedom, rights, and the creation by consent of positive obligations. This kind of value creation shows that on this way it is possible to make our capitalism more responsible and resilient (social nature of value creation).

For the successful processes that refer to stakeholder management, we suggest additional advices and argumentation. The organizations need better description how organizations can manage their relationships with stakeholders. The nature of relationships between different organizations and their stakeholders requires a combination of their divergent interests and ambitions. Accountability, one of key elements, includes environmental responsibilitysustainability reporting, societal demands need more attention, and political and legal trends require more regulation. Value creation is also one of the main challenges from theoretical and practical point of view-a richer description of theoretical explanation including types of measurements as well as stakeholder literature is needed. All these issues allow leaders and academics to create improved organizational practices and outcomes.

In the systemic and holistic context of stakeholder theory, there is also the opportunity to redefine the concepts that are closely related to it. These concepts refer in the literature (and researches) on business ethics, economics, public administration, finance, philosophy, management, governance, private and public sector, as well as private-public partnership and finally to local communities, nongovernmental organizations, and others. In this context, the interdisciplinary nature of stakeholder concepts needs more attention-from theoretical and practical view.

One of the general CSR principles within ISO 26000 concerns respecting stakeholder interests [4]. Stakeholders are seen as a starting point for CSR policies and fulfill an essential role in determining an organization's social responsibilities. The guideline is very clear-ISO 26000 stresses the importance of a stakeholder orientation in an organization's approach toward SR. To identify its social responsibility properly, an organization should, according to ISO 26000, understand three specific relationships [4]: (1) relationship between the organization and 
society - the actions and expectations that ISO 26000 specifies for core subjects and issues can assist an organization in this; (2) an organization should understand the relationship it has with its stakeholders-stakeholder's expectations, as emphasized by ISO 26000, are not necessarily the same as expectations of society; (3) needs to be understood - the relationship with society as whole-it is always useful for an organization to consider whose or which interest certain stakeholder represents. ISO 26000 finds it important in stakeholder relationship that an organization uses its influence to encourage stakeholder to address SR.

According to ISO 26000, determining an organization's sustainability impact is the most important way to identify stakeholders (but the relevant stakeholders are not the same for every organization). Organizations should always consider the legitimacy of their stakeholder's interests, demands, expectations, and wishes. The goal of ISO norm would be to offer practical methods and tools for the identification and involvement of stakeholders with the goal of developing a substantiated basis for supported decisions. Norm can be a useful addition to several standards (the ISO proposal refers to ISO 26000, ISO 9001, ISO 14001, and ISO 10001 - customer satisfaction). For any of these standards, a good stakeholder analysis is an important ingredient (complex broad process and projects with multistakeholder focus are needed as well as importance of stakeholder "sphere of influence") [34].

An organization should also be aware of the interests and needs of its stakeholders and facilitate open dialogue. Furthermore, ISO 26000 adds that the active engagement of stakeholders is based on trust and goes beyond public relations (a mutual belief that they are engaging in dialogue for the right reasons). This means that the essence of the dialogue should concern aspects that are strongly related to sustainable development and sufficiently important for the parties involved, and that the interests of all parties are clearly formulated from the start. Interaction is therefore the basis of stakeholder engagement in the view of ISO 26000, which suggests a number of methods and tools (both formal and informal; both for individual stakeholder and collective negotiations, such as stakeholder panels, seminars, conferences and workshops, roundtables, advisory committees, or internal forums). An organization is constantly interacting with its stakeholders, and it should manage these relationships and its social responsibilities well. Moreover, creating stakeholder engagement is important and offers organizations numerous advantages, but it is not one-off event, and a continuous process and periodically review of policies (activities) in the field of stakeholder engagement is needed.

Implementation is a critical area because the successful implementation of SR is clearly a big challenge for many organizations. ISO 26000 stresses that connecting SR to the culture, values and thus the identity of the organization will have a positive effect on understanding and acceptance, which in turn can facilitate and speed up the implementation process. It means that organizational change tends to be a long-term process - taking years to be realized. For each organization, it is important to indicate the most important barriers to SR implementation. The barrier to SR implementation could be, for example, lack of a clear action plan, too little time available, too little knowledge about SR implementation, too little knowledge of SR, obtaining by-in from the board, economic crisis, too little budget available, creating engagement with employees, and creating engagement with middle management, which might be eliminated by ISO 26000. 
A commitment from the top of an organization is an important prerequisite to making any initiative work. According to ISO 26000, an organization should "make SR an integral part of its strategy, policy, organizational culture, structure and operations" [4]. When the board of an organization is aware of the (economic) advantages of SR in the context of sustainable development or in reaching certain ambitions of the organization, the chances for a long-term and enduring commitment increase. ISO 26000 emphasizes that commitment and understanding of SR are necessary at all levels of an organization. Furthermore, stakeholder dialogue is also an instrument to avoid and possibly solve conflicts or differences of opinion with stakeholders. Additionally, ISO 26000 provides several suggestions on how to enhance the credibility of communications and SR claims and SR report, among which are ensuring that the organization's performance as reported in its sustainability report is comparable over time, is comparable with the performance of similar organizations (in the same sector), contains explanation on why an organization does not report on certain seemingly relevant SR topics, uses eco-labels or existing SR assessment criteria, and is verified by an external third party. According to ISO 26000, "an organisation should develop mechanisms to solve conflicts or disputes with stakeholders appropriate for the kind of conflict or dispute as well as for the particular stakeholder involved" [4]. Moreover, an organization is supported to the transparent with respective stakeholders about the procedures it has in place.

Finally, to make SR a living part of an organization, a structural approach is necessary. Internal and external buy-in as well as support from top management is very important for this. SR implementation is given a lot of space in ISO 26000 and includes advice on SR communication, enhancing the credibility of SR claims and integrating SR in existing systems and structures. Implementing SR successfully depends on getting the soft side (culture, values, and engagement) right, as well as dealing with hard issues (structures, measurement, and embedding). Moreover, it should constantly benchmark performance against its stated aims and change these when and if it becomes necessary as developments inside and outside the organization evolve.

\section{Sustainable business excellence and sustainable competitiveness}

The sources of a nation's (nowadays also regional's or local's and organization's) prosperity is competitiveness. In the global world, it is difficult to compete successfully. Innovativeness and especially SR are two of the most important factors for large or small payers at the global or local market.

SR is important to competitiveness, and placing SR within the strategy seems very important. SR should be the core activity, and it means that the stakeholder expectations regarding SR are in focus at the same time. SR strategy (reflects organization's values and mission) includes relations with stakeholders, measurement (indicators-ecological, social, and financial aspects -according Global Reporting Initiative are recommended) as well as SR reporting. Each organization should focus SR efforts on market, regulatory, and operational actions. In last decade, organizations recognize the importance of SR and care about their impacts on their 
ability to compete successfully. Organizations, especially large and medium sized, must be able to create innovative strategies for SR.

Simultaneously, we would like to highlight some barriers to innovative SR and sustainable excellence, and one of them is insufficient organizational capacity to incorporate SR knowhow. Decision makers in organizations do not build the bridges with their stakeholders and are limited in SME's resources for SR. Furthermore, there are also practical and theoretical limits (stakeholder selection and interpretation).

"SR of creative people, their co-workers and stakeholders are one of the most influential groups. Tolerance for diversity brings talents and makes investment in technology worth, while the 3T model (Florida 3T Model-Talent, Technology, Tolerance) makes the difference between the most successful and other regions" [19].

“The concept of business excellence is deeply rooted in TQM (Rehder and Ralstons's in 1984 - Baldrige criteria the first TQM model). In 1991, the EFQM Excellence Model was developed by the European Foundation of Quality Management to promote quality throughout Europe" [43].

Moreover, it significantly contributes to its competitiveness as whole as well as to competitiveness of organizations and regions or local communities where they operate. Competitiveness is a very complex and long-term process. Nowadays, it is better to discuss about sustainable (responsible) competitive advantages.

The EFQM Excellence Model is very complex, and from this reason, it is very important for each organization to recognize the key aspects or findings. First, business excellence influences short-term and long-term sustainable competitive advantages and performance and awards support competitiveness. Strong competition is one of the reasons why organizations try to improve performance and in this way contribute to sustainable development. The excellence model helps organizations to implement the core values and concepts of excellence in organizations at macro- and microlevels. Furthermore, organizations need assistance with benchmarking, and the most important is learning from the best practice (case studies).

Professional approach to benchmarking is needed. "Some projects fail because $25 \%$ had received not training in benchmarking; $30 \%$ do not use a benchmarking methodology; $30 \%$ do not develop a project plan e.g. poorly defined aims, stakeholder not identified etc. and 35\% do not undertake a cost/benefit analysis. The best practice benchmarking is the most powerful type of benchmarking" [43]. Furthermore, business excellence and benchmarking provide the path of success in future.

Long-term oriented and responsible organization pay attention to the development of excellence and SR model because they are working on it in order to improve the competitiveness and sustainable cooperation (its own competitiveness and competitiveness of the local community or region where they operate). "The EFQM business excellence model can serve as an example of integration and as a system of the improvement of an organization's operational success of the basis of the integration of the models and leadership standards" [44]. 
Scandinavian countries are very often mentioned as a world known leaders in CSR or SR and sustainable development. The concept of "creating shared value" has Scandinavian origins, where institutional and cultural factors play important role and particularly these factors promote CSR, SR, and sustainability. "The recent phenomenon of movement from implicit to explicit CSR in a Scandinavian context and what this may entail" [45]. Stakeholder engagement encourages a cooperative approach to business and other operations.

\section{EFQM excellence model and ISO 26000 implementation}

“EFQM Excellence Model is a practical tool providing various advantages from the perspective of empirical research just like other quality awards" [18].

The EFQM Excellence Model is very useful. It has practical value, meaning it is a practicaloriented model, and we can highlight few of the most significant advantages. The model is permanently revised and updated in these activities, and EFQM consultants are involved because their contribution is significant. EFQM Excellence Model is very complex and needs systemic and holistic approach, and from this reason, it provides a large and comprehensive set of subcriteria and sometimes even sub-subcriteria to explain the precise meaning of any criterion.

Comparison with others, especially with the best organizations (leading organizations in their fields-benchmarking), is very important for each organization. Different award models are helpful for comparison between organizations, as well as a good case on how to achieve the responsible competitive advantages and cooperative relationships with all stakeholders.

The crucial role plays leadership that cares about responsibility for developing infrastructures, as to achieve desirable and requested results. For example, in ecological and social influences, one of the main stakeholders is the employees, and their satisfaction is very important and financial results (not just profit for shareholders but also satisfaction and cooperative relationships with all stakeholders).

Using EFQM model, organizations have the support of a performance excellence framework founded on the SR principles to develop sustainable approaches on for business excellence for people, planet, and profit. Each organization has to include SR as part of its strategy, but these approaches have to be measured continuously, and the results have to be reviewed and improved as necessary.

ISO 26000 is contemporarily not certifiable, but the review is necessary. It should be reviewed periodically, perhaps parallel with EFQM Excellence Model. Improvement should be included in the next version (EFQM is good example). In the near future, ISO 26000 should be transformed (step by step) from suggestions and advices to a certifiable management system. We forecast that the market (private and public organizations) will speak on this challenges (the Scandinavian countries are an excellent case; results confirm the right orientation). The initiatives related to ISO 26000 increases, and use of the guideline for contractual purposes 
grows. The need for a certifiable social management system (SMS) will become clear in near future.

The last revision in EFQM Excellence Model has been realized in 2012. Global economic environment and stakeholder requirements are changing constantly and organizations.

In the future trends, the convergence of international SR standards and other standards, including EFQM Excellence Model, the management of costs related to the implementation of SR, and the opportunities for innovation in large organizations, SMEs, and other organizations are expected.

\section{Conclusions and future research}

“The EFQM Excellence Model 2013 real challenge for organizations will be to become agile and flexible so as to act swiftly to attain and retain its leadership in the global and local market place" [11]. We hope that organizations will recognize and understand their key business challenges and value in EFQM 2013 (manage quality and achieve sustainable excellence).

Sustainable excellence is a long-term process. From this reason, the suggestions according ISO 26000 must be more explicit for different types of organizations (companies, local community management, education at all levels, and other organizations), including indicators as well as reporting. All companies (large- and medium-sized companies) and other organizations from developed countries and BRIC countries should report about their sustainable activities each year. It means that they should use the indicators recommended by ISO 26000 and Global Reporting Initiative. Furthermore, ISO 26000 recommendations, later certification (step by step), and legislation are needed. ISO 26000 certification will be a long-term process, and in this way, the implementation process will be encouraged, comparable between different types of organizations and even different industries. We forecast that the market will speak on this issue. As initiatives related to ISO 26000 increase, and the use of guideline for contractual purposes grows, the need for a certifiable social management (CSM) system will become clear.

How and when to implement the EFQM Excellence Model? In organizations that have introduced the Quality Management System (QMS-ISO 9001), it should already be the next step. Contemporarily, quality philosophy, like TQM, TRM, ISO 26000, and EFQM, requests ISO 9001, which is an excellent basis for the implementation of the EFQM Excellence Model (sustainably oriented according ISO 26000, including indicators and reporting).

On this way, the EFMQ implementation period is relatively short. It provides recommendations that help organizations to evaluate organization quality management level (additional subcriteria and sub-subcriteria are recommended). EFQM Excellence Model leads organizations to continual quality improvement, higher quality, sustainable stakeholder management, sustainable cooperative advantages (or competitive advantages) at local, regional, or global market, and increase the sustainable organizational culture.

The outcomes of this overview represent an innovative contribution to the development and potential implementation aspects, discussion, and conformation. Furtherance of theories is 
important in studying SR (or CSR), TQM, TRM, EFQM, ISO quality standards, ISO 26000, sustainable excellence, and indicators. Literature review (theoretical and empirical base) and debate on TQM, SR, EFQM, and ISO 26000 are still included.

The aim of this study is to highlight the characteristic features, systemic, and holistic ISO 26000 implementation according EFQM, to present the available theoretical frameworks for quality and SR-oriented models, and to compare them to published researches, which pay attention to sustainable models is achieved.

"Finally, we want to draw attention to the Scandinavian contest and encourage the field of strategic management to shift its focus from achieving a competitive advantage toward achieving a cooperative advantage" [46]. In the context of SR (or CSR) according EFQM, ISO quality standards, and ISO 26000, we will discuss about sustainable cooperative advantages or sustainable cooperative excellence in the future.

Future research might also analyze the EFQM and ISO 26000 in different organizations, including their specifics as well as barriers by implementation, measurement, and reporting (in large MNCs, medium-sized companies, government, local community management, educational organizations at all levels, health system, and others). Additions and concretization of ISO 26000 and EFQM especially for SMEs and recommendations for other organizations (in public sector) are needed.

\section{Author details}

Štefka Gorenak*

Address all correspondence to: gorenak.stefka@siol.net

Faculty of Commercial and Business Sciences, Celje, Slovenia

\section{References}

[1] EFQM. Assessing for Excellence: A Practical Guide for Self-Assessment. EFQM, Brussels. 2003.

[2] Thaiwanai, S. The EFQM 2013 Model Changes, Implications for Organizations [Internet]. 2013. Available form: http://www.exin-libary.com/Player/3-knowledge/ efqm_2013_model_changes_implications_for_orgzn_1.pdf [Accessed: 2015-03-20]

[3] Commission of the European Communities. Green Paper: Promoting a European Framework for Corporate Social Responsibility. COM 366 final. 2001. Brussels: Commission of the European Communities. 
[4] International Standard Organization. ISO 26000 [Internet]. 2010. www://iso.org./ISO discovering_iso_26000.pdf [Accessed: 2012-01-21]

[5] Freeman RE, Harrison JS, Wicks AC, Parmar BL, DeColle S. Stakeholder Theory. Cambridge: Cambridge University Press; 2010. 434 p.

[6] Cruz, LB, Boehe DM. How do leading retain MNCs leverage CSR globally? Insights from Brazil. Journal of Business Ethics. 2010; 91(2): 243-263.

[7] Aßländer MS. Corporate social responsibility as subsidiary co-responsibility-macroeconomic perspective. Journal of Business Ethics. 2011; 99(1): 115-128.

[8] Nabitz U, Klazinga N, Walburg J. The EFQM Excellence Model: European and Dutch experiences with the EFWM approach in health care. International Journal of Health Care. 2000;12(3): 191-201.

[9] Jayamaha NP, Grigg NP, Mann RS. Empirical analysis of the Baldrige Criteria as both an organisational performance measure and a theoretical model. Measuring Business Excellence. 2011;15(1): 20-33.

[10] DeDommartin A. ISO 9001: 2000 and the EFQM Excellence Model [Internet]. 2003. file://C:/Users/Uporabnik/Downloads/p.18,\%20Viewpoint\%20(2).pdf [Accessed: 2015-03-22]

[11] EFQM [Internet]. 2013. http://www.efqm.org/efqm-model/fundamental-concepts [Accessed: 2015-03-29]

[12] Waddock S, Bodwell C. Total Responsibility Management. Sheffield: Greenleaf Publishing Limited, Sheffield; 2007. 192 p.

[13] McBain R, Ghobadian A, Switzer J, Wilton P, Woodman P, Pearson G. The Business Benefits of Management and Leadership Development. CMI and Penna.

[14] Leadership \& Management in the UK: The Key to Sustainable Growth [Internet]. 2012. Available from https:/www.gov.uk/government/uploads/system/uploads/ attachment_data/file/32327/12-923-leadership-management-key-to-sustainablegrowth-evidence.pdf [Accessed: 2015-03-30]

[15] Lal K, Dunnewijk T. Entrepreneurship and Innovation Strategies in ICT SMEs in Enlarged Europe (EU 25). Working paper. The Netherlands: UNU-MERIT. 2008; No. 016.

[16] Uygur A, Sümerli S. EFQM Excellence Model. International Review of Management and Business Research. 2013; 2(4):980-993.

[17] Gašparik J, Gašparikova V, Ellingerova H. Improvement of Quality Management Level in Construction Company Using EFQM Model. DOI 10.5592/otmcj.2014.1.5. Research paper. 2014:949-957. 
[18] Santos-Vijande ML, Alvarez-Gonzales L.I. International Journal of Business Science and Applied Management. 2007; 2(2):21-41.

[19] Gorenak Š, Bobek V. Total responsibility management indicators and sustainable development. International Journal of Sustainable Society. 2010;2(3):248-264.

[20] Brandsma M, Moratis L, Cochius T. Motivations for and Potential Barriers of ISO 26000 uptake in the Netherlands. Rotherdam: CSR Academy; 2009.

[21] Elkington J. Cannibals with Forks - The Triple Bottom-line of 21st Century Business. Oxford, UK: Capstone Publishing; 1997.

[22] Smith A. An Inquiry into the Nature and Causes of the Wealth of Nation. London: W. Strahan \& T. Cadell; 1776.

[23] Smith A. The Theory of Moral Sentiments. Indianapolis, IN: Liberty Classics; 1759, 1976.

[24] Barnard C. The Functions of the Executive. Cambridge, MA: Harvard University Press; 1938.

[25] Kreps T. Measurement of the Social Performance of Business. Palo Alto, CA: Stanford University Press; 1940.

[26] Browen H. Social Responsibilities of the Businessman. New York: Harper \& Row; 1953.

[27] Herald M. Management's Responsibility to Society-The Growth of an Idea. Business History Review. 1957; 31(4): 375-384.

[28] Eells R. Corporate Giving in a Free Society. New York: Harper; 1956.

[29] Davis K. Can Business Afford to Ignore Social Responsibilities? California Management Review. 1960;2(3): 70-76.

[30] Maguire JW. Business and Society. New York: McGraw-Hill; 1963.

[31] [31]Walton CC. Corporate Social Responsibilities. Belmont, CA: Wadsworth Publishing; 1967.

[32] Meadows DH, Meadows DL, Randers J, Behrens III W.W. The Limits to Growth-A Report for the Club of Rome's Project on the Predicament of Mankind. New York: Universe Books; 1972.

[33] McAdam R, Leonard D. Corporate social responsibility in a total quality management context-opportunities for sustainable growth. Corporate Governance. 2003;3(4):35-45.

[34] Moratis L, Cochius T. ISO 26000: The Business Guide. Sheffield: Greenleaf Publishing Limited; 2011. 206 p. 
[35] Kotler P, Lee N. Corporate Social Responsibility: Doing the Most Good for Your Company and Your Cause. Hoboken, NY: John Wiley; 2005.

[36] [36]Porter M, Kramer M. Strategy and society - the link between competitive advantage and corporate social responsibility. Harvard Business Review. 2006; December: 78-92.

[37] Prahalad CK. The Fortune at the Bottom of the Pyramid: Eradicating Poverty through Profits. Upper Saddle River: Wharton School; 2004.

[38] Drucker PF. Management Challenges for the 21st Century. New York: Harper Business; 1999.

[39] Friedman M. The Social Responsibility of Business Is to Increase Its Profit. New York: Times Magazine. 1970; 13 September.

[40] Carroll AB. A three-dimensional conceptual model of corporate performance. Academy of Management Review. 1979; 4(4):497-505.

[41] Carroll AB. Corporate social responsibility: evolution of a definitional construct. Business \& Society. 1999; 38(3):268-295.

[42] Porter M, Kramer M.R. Creating shared value. How to reinvent capitalism and unleash a wave of innovation and growth. Harvard Business Review. 2011;90 (1/2): 62 67.

[43] Mann R, Adebanjo D, Tickle M. Development of business excellence in Asia-an exploratory study. International Journal of Quality \& Reliability Management. 2011;28(6): 604-627.

[44] Rusijan B, Castka P. Understanding ISO's 9001 benefits and research through an operations strategy framework. Managing Global Transitions. 2010; 8(1): 97-118.

[45] Stand R, Freeman RE. Corporate social responsibility and sustainability in Scandinavia: an overview. Journal of Business Ethics. 2015; 127:1-15.

[46] Strand R, Freeman RE. Scandinavian cooperative advantage: the theory and practice of stakeholder engagement in Scandinavia. Journal of Business Ethics. 2015;127:6585 . 

Chapter 3

\title{
Does the Demographic Factor Impact Enterprise Business Intelligence Maturity Initiaves in Companies in Malaysia?
}

\author{
Min-Hooi Chuah and Kee-Luen Wong \\ Additional information is available at the end of the chapter
}

http://dx.doi.org/10.5772/60930

\begin{abstract}
This chapter proposes an Enterprise Business Intelligence Maturity Model that involves thirteen key process areas (Strategic Management, Performance Measurement, Balanced Scorecard, Information Quality, Data Warehouse, Master Data Management, Metadata Management, Analytical, Infrastructure, Knowledge Management, People, Organization Culture and Change Management). This key objective of this chapter was to investigate impact on demographic factors such as age of BI initiave, organizational size, number of IT/BI employees, type of industry and revenue of the company towards the Enterprise Business Intelligence Initiave. A survey was conducted around 132 companies in this study. Results shows that age of $\mathrm{BI}$ initiatives, organizational size and number of IT/BI employees have relationship on BI maturity level while BI maturity level has strong relationship on the revenue of the company. Results above also show that the type of industry has no relationship on the BI maturity level.
\end{abstract}

Keywords: Business Intelligence, Maturity Model

\section{Introduction}

Business Intelligence (BI) can be defined as any set of methodology or process or tools that transform raw data into useful information and provide decision support for managers [1]. BI 
can be categorized as a black box, where a backup process takes place, such as where data are processed and translated into knowledge that can be used for decision making. BI can be formed from technological perspective, managerial perspective and product perspective. From the managerial perspective, BI can be named as a process, an emphasis on data collection and an analysis from their internal and external sources in order to produce applicable information [2, 3, 4, 5].From a product perspective, Fernandes et.al [6] described BI as a result of a product for decision making and as a performance evaluation of business data and analysis products practice. From the technological perspective, BI can be labeled as BI systems and it can be considered as a tool to allow decision makers to discover information from the data source $[7,8,9,10]$.

BI consists of three core components: data warehouse, business analysis and business performance management. Data warehouse is one of important features of BI where data are extracted from the external sources such as transaction data, data from enterprise resource planning (ERP), and data source from supply chain management (SCM) and it is stored. In the business analysis component, data are taken from data warehouse where a data mining technique is applied to convert into useful knowledge. Lastly, the end user can view the business performance business performance management component.

BI is essential for the organizations in order to win the business's competitors. However, several of the organizations still find it hard to implement BI. Hwang [11] stated that one of the main reasons why BI failed is the lack of technical staff and the lack of budget. In fact, Pauli [12] pointed out that most BI projects failed because of the lack of technology and right tools. Besides that, change management and organization culture also important factors that determine the success of BI implementation [13, 14].

There are many studies $[15,16,19]$ on the impact of demographic factors on business intelligence initiatives but these are only concentrated on three factors, such as types of industry, organizational size and age of BI initiates. For example, Eckerson [15] stated that the more years the company has implement BI, the higher the level of BI maturity. Rabel et.al [16] stated that the larger the organization, the more mature the BI implementation of the company. Williams and William[19] pointed out that BI adoption is beneficial to all type of industry. Studies that review other demographic factors (number of employees and revenue of the organization) that will affect the implementation of BI maturity are scarce. Thus, this chapter outlines the research question as follows:

RQ1: What is the relationship of the organization's demographic on business intelligence maturity in Malaysia?

This research question is composed of the following:

RQ1.1: What is the relationship between the age of BI initiatives and BI maturity?

RQ1.2: What is the relationship between the organizational size and BI maturity?

RQ1.3: What is the relationship between the types of industry and BI maturity?

RQ1.4: What is the relationship between the numbers of IT/BI employees and BI maturity? 
RQ1.5: What is the relationship between the revenue of the organization and BI maturity?

\section{Literature review and proposed framework}

In this section, the authors had reviewed several existing BI maturity models. These models include TDWI maturity model and Gartner's maturity model. The authors found that most BI maturity models do not cover BI as whole aspect. For example, Gartner's (2010) [23] maturity model proposed five maturity levels: unaware, tactical, focused, strategic, and pervasive but the model only concentrates on business standpoint and lack of technical standpoint. Furthermore, the criteria to rate the maturity levels are not well defined [24]. Eckerson [15] only concentrates on the technical point of view but lacks the technical point of view. Rajteric [24] recommended that there is a need to integrate the existing different maturity models with appropriate design questionnaire and evaluative criteria in order to evaluate the maturity level of the business organizations. Thus, an Enterprise Business Intelligence Maturity Model (EBIMM) is proposed and adopted from the theory of CMMI, which is integrated from technical perspectives and business perspectives.

The proposed Enterprise Business Intelligence Maturity Model (EBIMM) consists of five levels; Level 1-Initial level ; Level 2-the Managed level ; Level 3-the Defined level ; Level 4-the Quantitatively managed level and Level 5 - Optimizing level.

\section{Methodology}

The EBI2M assessment questionnaire is distributed to selected Malaysian companies that implement BI. The questionnaires were distributed through various Big Data Conferences, $\mathrm{CIO}$ forums and emails, online or hand delivered to the head of IT or senior manager or BI experts responsible in the selected organizations across a wide range of organization size. A total of 132 companies were participating in the empirical study.

The respondents were instructed to rate organizations' BI implementation based on thirteen factors, namely change management, culture, strategic management, people, performance management, balanced scorecard, information quality, data warehousing, master data management, metadata management, analytical, infrastructure and knowledge management. The rating for each appraisal criterion is based on the CMMI capability rating as 0 (process that is not performed and completely dissatisfied), 1 (process is performed but mostly dissatisfied), 2 (process is performed but slightly dissatisfied), 3 (process is performed and slightly satisfied), 4 (process is performed and mostly satisfied) and 5 (process is performed and completely satisfied).

Level 1 - Initial: 0 items

Level 2 - Managed: 10 items

Level 3 - Defined: 24 items 
Level 4 - Quantitatively managed: 14 items

Level 5 - Optimizing: 6 items

The items at the respective levels were grouped together and the average scores for the levels were calculated based on procedures that proposed by Baskarada [25].The estimated readiness ratings of the organizations were derived by adding the average capability ratings at each level. For instance, if the average score at Level 2 was 3.92, then the rating was 3.92 divided by 5 giving a rating of $78.4 \%$. These ratings for Level 1 to Level 5 were added to give an estimate rating of the level of readiness for capability level. For example, given that Level $1=100 \%$, Level $2=78.4 \%$, Level $3=51 \%$, Level $4=48.2 \%$, and Level $5=66.7 \%$, then:

$$
\begin{aligned}
\text { Level of Readiness } & =1+0.784+0.51+0.482+0.667 \\
& =3.442, \text { which approximate at Level } 3
\end{aligned}
$$

\section{Results and analysis}

This section elaborates on the analysis of an organization's demographic date such as age of BI initiatives, organizational size, types of industry, number of IT/BI employees and the revenue of an organization on EBI maturity.

RQ1.1: What is the relationship between the age of BI initiatives and BI maturity?

\begin{tabular}{llrr}
\hline age & Mean & $\mathbf{N}$ & Std. Deviation \\
\hline 1-2 years & 2.0000 & 12 & 0.00000 \\
10 years above & 4.0000 & 4 & 0.00000 \\
3-4 year & 3.0000 & 32 & 0.00000 \\
5- 6 Years & 3.2500 & 48 & 0.43759 \\
7-8 years & 4.0000 & 12 & 0.00000 \\
9-10 years & 4.0000 & 12 & 0.00000 \\
less than 1 year & 2.0000 & 12 & 0.00000 \\
Total & 3.1212 & 132 & 0.68829 \\
\hline
\end{tabular}

Table 1. Description statistic for age of BI initiatives

From the table 2, it is found that Spearman Correlation, rho $=0.873$, which is larger than 0.7, indicates that there is strong relationship between the age of BI initiatves and the BI maturity.

Conclusion: There is strong relationship between the age of BI initiatives and BI maturity

RQ1.2: What is the relationship between the organizational size and BI maturity? 


\begin{tabular}{|c|c|c|c|c|}
\hline & & & age_no & maturity_level \\
\hline \multirow[t]{6}{*}{ Spearman's rho } & age_no & Correlation Coefficient & 1.000 & $.873^{* *}$ \\
\hline & & Significance (2-tailed) & . & .000 \\
\hline & & $\mathrm{N}$ & 132 & 132 \\
\hline & maturity_level & Correlation Coefficient & $.873^{* *}$ & 1.000 \\
\hline & & Significance (2-tailed) & .000 & . \\
\hline & & $\mathrm{N}$ & 132 & 132 \\
\hline
\end{tabular}

**. Correlation is significant at the 0.01 level (2-tailed).

Table 2. Spearmen correlation between age of BI initiative and BI maturity level

\begin{tabular}{|rrr|r|r|}
\hline & & company_size_n \\
& & 0 & maturity_level \\
\hline Spearman's rho company_size_no & Correlation Coefficient & 1.000 & $.608^{\prime \prime}$ \\
& Sig. (2-tailed) & .000 \\
& $\mathrm{~N}$ & 132 & 132 \\
\cline { 2 - 5 } & Correlation Coefficient & .608 & 1.000 \\
& Sig. (2-tailed) & .000 & 132 \\
& $\mathrm{~N}$ & 132 \\
\hline
\end{tabular}

**. Correlation is significant at the 0.01 level (2-tailed).

Table 3. Spearmen correlation between company size and BI maturity level

From the table 3, it is found that Spearman Correlation, rho $=0.608$, indicates that there is moderate relationship between the company's size and the BI maturity.

Conclusion: There is moderate relationship between the company's size and BI maturity

\section{RQ1.3: What is the relationship between the types of industry and BI maturity?}

Type of industry can be categoried as service and non service. Service industries focus on improving products and services for their customers (example : financial, healthcare, education, telecommunication) whille non service focus on improving processes for the production and distrbution of the products and services (retail, logistic, manufacturing and construction). From the table 4 , it is found that Spearman Correlation, rho $=0.087$,, indicates that there is no relationship between the type of service and the BI maturity.

Conclusion: There is no relationship between the type of service and BI maturity 


\begin{tabular}{|lll|r|r|}
\hline & & type_no & maturity_level \\
\hline Spearman's rho & type_no & Correlation Coefficient & 1.000 & .087 \\
& & & \\
& Sig. (2-tailed) & .319 \\
& $\mathrm{~N}$ & 132 & 132 \\
\cline { 2 - 5 } & maturity_level & Correlation Coefficient & .087 & 1.000 \\
& Sig. (2-tailed) & .319 & 132 \\
& $\mathrm{~N}$ & & 132 \\
& & & \\
& & &
\end{tabular}

Table 4. Spearmen correlation between type of service and BI maturity level

RQ1.4: What is the relationship between the numbers of IT/BI employees and BI maturity?

Number of IT/BI employees can be categorized as low (1-5 persons) and medium (6-10 persons).

\begin{tabular}{llll}
\hline no_of_employee & Mean & N & Std. Deviation \\
\hline Low & 3.0000 & 112 & 0.65760 \\
Medium & 3.8000 & 20 & 0.41039 \\
Total & 3.1212 & 132 & 0.68829 \\
\hline
\end{tabular}

Table 5. Description statistic for number of IT/BI employees maturity level

\begin{tabular}{|c|c|c|c|c|}
\hline & & & no_of_staff & maturity_level \\
\hline \multirow[t]{2}{*}{ Spearman's rho } & no_of_staff & $\begin{array}{l}\text { Correlation Coefficient } \\
\text { Sig. (2-tailed) } \\
\text { N }\end{array}$ & $\begin{array}{r}1.000 \\
132 \\
\end{array}$ & $\begin{array}{r}.429 * \\
.000 \\
132 \\
\end{array}$ \\
\hline & maturity_level & $\begin{array}{l}\text { Correlation Coefficient } \\
\text { Sig. (2-tailed) } \\
\text { N }\end{array}$ & $\begin{array}{r}.429^{-1} \\
.000 \\
132\end{array}$ & $\begin{array}{r}1.000 \\
. \\
132\end{array}$ \\
\hline
\end{tabular}

**. Correlation is significant at the 0.01 level (2-tailed)

Table 6. Spearmen correlation between number of IT/BI employees and BI maturity level 
From the table 6, it is found that Spearman Correlation, rho $=0.429$,, indicates that there is weak relationship between the number of staffs and the BI maturity.

Conclusion: There is weak relationship between the number of staffs and BI maturity

RQ1.5: What is the relationship between the revenue of the organization and BI maturity?

With respect to the revenue of an organization, it was classified into small (Less than RM 20 million), medium (RM 20 million to RM200 million), and large (more than RM200 million) enterprises.

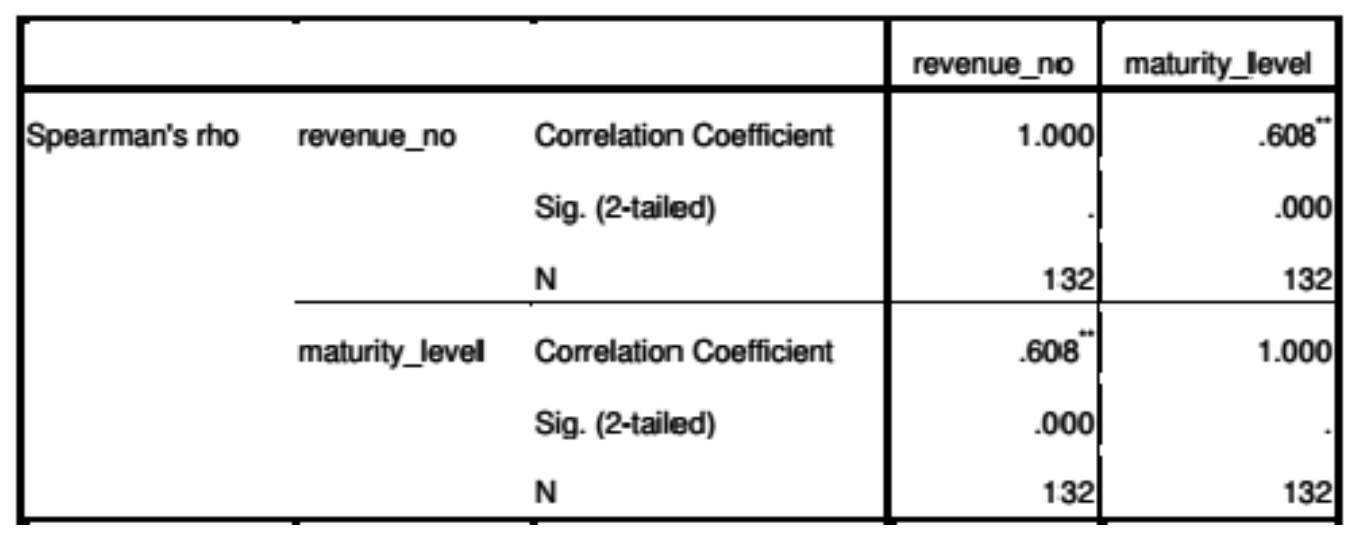

**. Correlation is significant at the 0.01 level (2-tailed)

Table 7. Spearmen correlation between the revenue of the organization and BI maturity level

From the table 7 , it is found that Spearman Correlation, rho $=0.608$, indicates that there is moderate relationship between the revenue of an organization and the BI maturity.

Conclusion: There is moderate relationship between the revenue of an organization and BI maturity

\section{Conclusion}

This chapter has condensed the findings of the analysis based on survey data collected from 132 participating companies in Malaysia. Results shows that age of BI initiatives, organizational size, number of IT/BI employees and the revenue of an organization have relationship on BI maturity level. Results above also show that the type of industry has no relationship on the BI maturity level. The result above also tally with Eckerson's study [20], which stated that in the phenomenon of increasing the age of BI initiatives, the mean of BI maturity will increase. The recent survey conducted by Rabel et.al [16] also indicated that BI maturity and the number of year conducting are related to each other. Han et.al [10] pointed out that BI maturity rating 
undertaken in different organization and BI maturity is increase with the longer the company implement BI. Elbashir et.al [17] proved that there is a positive relationship between the organization size and the BI maturity mean while Sen et.al [18] argued that for organization size is one of the success factors in order for data warehouse or BI technology.

This research project may be used as a framework to lead any future research towards advancing the theory of Enterprise Business Intelligence Maturity. In the future, large samples size could be used to strengthen the generalizability of the proposed framework. Moreover, this research could intend to explore more maturity indicators that contribute to the EBI maturity model. This is because technology and business environment is always keeping changing and there are more maturity indicators that could emerge in the future.

\section{Author details}

Min-Hooi Chuah ${ }^{1^{*}}$ and Kee-Luen Wong ${ }^{2}$

*Address all correspondence to: chuahmh@utar.edu.my

1 Faculty of Information and Communication Technology, Universiti Tunku Abdul Rahman, Perak, Malaysia

2 Faculty of Business and Finance, Universiti Tunku Abdul Rahman, Perak, Malaysia

\section{References}

[1] Turban, E., Sharda, R., Aronson, J. E., and King, D. 2011. Business Intelligence: A Managerial Approach. Prentice Hall.

[2] Fisher, D., Drucker, S., and Czerwinski, M. 2014. Business Intelligence Analytics. Microsoft Research, pp. 22-24.

[3] Knabke, T., and Olbrich, S. 2013. Understanding information system agility - the example of business intelligence. Proceedings of the 2013 46th Hawaii International Conference on System Sciences (HICSS), pp. 3817-3826.

[4] Wixom, B.H., and Watson, H.J. 2010. The BI based organization. International Journal of Business Intelligence Research 1, 13-28.

[5] Eckerson, W.W., and Howson, C. 2009. Enterprise Business Intelligence: Strategies and Technologies for Deploying BI on an Enterprise Scale. Available from http://download 101com com/tdwi/research_report/TDWI_EBI_web pdf (accessed June 10, 2009).

[6] Fernandes, A.A., Amaro, L.C., and Serrano, A.M.R. 2012. Construction of ontologies by using concept maps: a study case of business intelligence for the federal property 
department. Proceedings of the 2012 Fifth International Conference on Business Intelligence and Financial Engineering (BIFE), pp. 84-88.

[7] Damjanovic, V., and Behrendt, W. 2014. UNDERSTANDER: Business intelligence seeker-user agent. Proceedings of the 37th Information and Communication Technology, Electronics and Microelectronics (MIPRO), pp. 1491-1496.

[8] Yoon, T.S., Ghosh, B., and Jeong, B.K. 2014. User acceptance of business intelligence (BI) application: technology, individual difference, social influence, and situational constraints. Proceedings of the 47th Hawaii International Conference on System Science, pp. 3758-3766.

[9] Mathrani, S., and Mathrani, A. 2013. Leveraging business intelligence to build metaknowledge. Proceedings of the 2013 46th Hawaii International Conference on System Sciences (HICSS), pp. 3787-3796.

[10] Han, Y.M., and Farn, C.K. 2013. A study on the effects of empowerment and habit on continuance usage of pervasive business intelligence systems. Proceedings of the 2013 46th Hawaii International Conference on System Sciences (HICSS), pp.37683777.

[11] Hwang, M.I. 2009. Success factors for business intelligence: perceptions of business professionals. Proceedings of the 19th Annual Conference of the Association of Chinese Management Educators, pp. 484-490.

[12] Pauli, D. 2009. BI Project Fail Due to a Lack of Training and Business Support. Computer World, Australia.

[13] Williams, S., and William, N. 2007. The Profit Impact of Business Intelligence. Morgan Kaufmann Publishers, San Francisco.

[14] Gartner Research. 2009. Gartner EXP Worldwide Survey of More than 1, 500 CIOs Shows IT Spending to Be Flat in 2009. Retrieved from http://www gartner com/it/page jsp? $\mathrm{id}=855612$ (accessed 01/04/2009).

[15] Eckerson, W. 2004. 'Gauge Your Data Warehouse Maturity', Information management. Retrieved from : <http://www information-management com/issues/ 20041101/1012391-1 html> (accessed April 29, 2009).

[16] Raber, D., Wortmann, F., and Winter, R. 2013. Situational business intelligence maturity models: an exploratory analysis. Proceedings of the 46th Hawaii International Conference on System Science, pp. 3797-3806.

[17] Elbashir, M.Z., Collier, P.A., and Davern, M.J. 2008. Measuring the effects of business intelligence systems: the relationship between business process and organization performance. International Journal of Accounting Information Systems, 9(3), 135-153.

[18] Sen, A., Ramamurthy, K., and Sinha, A.P. 2008. An empirical investigation of the key determinants of data warehouse adoption. Decision Support Systems, 4, 817-841. 
[19] Williams, S., and William, N. 2007. The Profit Impact of Business Intelligence. Morgan Kaufmann Publishers, San Francisco.

[20] Hewlett-Packard. 2007. The HP Business Intelligence Maturity Model. Retrieved from http://h71028 www7 hp com/ERC/downloads/4AA1-5467ENWpdf (accessed April 21, 2009).

[21] Hagerty, J. 2006. AMR Research's Business Intelligencel Performance Management Maturity Model, Version 2, Retrieved from http://www cognos com/pdfs/analystreports/ ar_amr_researchs_bi_perf pdf (accessed 21 April 2009).

[22] Sacu, C., and Spruit, M. 2010. BIDM: The business intelligence development model. Proceedings of the 12th International Conference on Enterprise Information Systems, Funchal, Madeira-Portugal.

[23] Gartner Research, 2010. IT score overview for business intelligence and performance management. Retrieved from http://www gartner com/resources/205000/205072/ itscore_overview_for_busines_205072 pdf (accessed November 11, 2010).

[24] Rajterič, I.H. 2010. Overview of business intelligence maturity models. International Journal of Human Science, 15(1), 47-67.

[25] Baskarada,. 2009. IQM-CMM: Information Quality Management Capability Maturity Model. Vieweg Teubner Research. 
Section 3

Management of Cities 



\title{
Chapter 4
}

\section{A Development Vision and Strategy Model as a Response of Cities to the Challenges of Globalization}

\author{
Anita Maček and Vito Bobek \\ Additional information is available at the end of the chapter \\ http://dx.doi.org/10.5772/60979
}

\begin{abstract}
Exposure to new sources of competition across the world encourages cities to become more competitive and to allocate their resources more effectively and efficiently. Responding to the demands of many different groups and managing the allocation of resources between different claims is nowadays one of the most important challenging tasks for city governments.

To reach their desired destination, cities must be aware of where they are starting out. First, they should identify their strengths and weaknesses and after that define the position they want to strive for in the future. By defining the position of the future, they need to be aware of the significant trends and other factors that will influence the direction in which the future unfolds.

To overcome the challenges mentioned, many successful European cities designed a model that simplifies the monitoring of long-term goals. The important thing is that these goals are consistent with the city's development vision and strategy, and both must be based on values, wishes, and priorities of the local residents.

In the proposed chapter, the authors present the vision and strategy model that was developed for Slovenian cities.
\end{abstract}

Keywords: Vision and strategy model, cities, globalization challenges

\section{Introduction}

Cities have an important political, social, economic, and cultural role in their regions. They are the foundation of economic development and the core of exchange and trade; they help 
promote personal freedom and are the centers of creativity, development, and innovation. Globalization has caused many societal changes and influenced the role of cities, which in turn must face the challenges globalization brings about.

There are numerous studies available on the consequences of globalization in various countries, but many fewer focus solely on cities, although the volume of research has been growing in recent years. Analysis of globalization effects on cities in South Africa showed that the economic, social, and cultural consequences are especially noticeable (see [1]). Globalization has caused an increase of foreign direct investment in Indian cities (in [2]) while study (see [3]) shows that direct investments were the main consequences of globalization in Cairo. Study on how globalization affects developing cities highlighted the need for a model which would help those cities overcome the obstacles of globalization (in [4]). Looking into different globalization effects, some studies analyse the connection between cities, trade, and economic growth (see [5]).

The challenges cities face because of globalization are strengthening the need to manage cities more effectively, and they demand the implementation of new decision-making models on all levels. In this chapter, we present the vision and strategy model which could serve as a tool by overcoming globalization challenges.

\section{Factors of cities' development}

In the past, various factors influenced the development of cities. With the emergence of globalization, however, this worldwide movement has become the main factor, putting the interplay between the globalization process and the local potential to the forefront and thus creating new opportunities for cities. People's individualism has created a so called I-generation (individualistic, informal, informed, interactive, and international), and it affects the dialog between the city managements and the ever more demanding city residents. The third factor of development can be seen in the integration of all fields, which encourages new potential synergies. The development of information and communication technology is enabling an ever faster rate of progress. Through an increasing proportion of elderly populations and lower fertility rates, the changing demographic environment in developed countries creates financial pressures on public health and retirement systems, and a smaller base of economically active people is creating new conditions on job markets.

A growing share of urban populations increases the impact cities have on the prosperity and welfare of regions and even entire countries. An important factor of urban development is also the migration of populations, which presents an especially big challenge in the areas of cohesion, integration, and employment, and at the same time generates new opportunities and threats for the creation of social capital, identity, and knowledge potential in cities, regions, and countries. What kind of effects the factors mentioned above have on cities depends on many circumstances; however, some of the effects can be negative and cities can only avoid them with a suitable strategy. 
The negative effects of city development primarily apply to the consumption of natural resources, reflected by severe environmental problems, such as polluted air, polluted soil, polluted groundwater and surface water, etc. In some cities, where the population density grew faster than the capacities and plans of local authorities, this has caused social problems. In business, deindustrialization and the implementation of new technologies limited local income and drove some residential quarters to the brink of financial ruin, which also hurt the developmental efforts of entire cities. Various authors have thus developed several kinds of tools for the revival and further development of cities.

The efficiency factors relevant for city development can be grouped into three key groups (in [6-13]:

- Economic

- Technological

- Social factors

In [6] economic diversity (industrial/service sectors, international/domestic, and large/small companies, old/new economy), educated workforce (availability, demand and supply ratios at universities, research institutes, in governments and in the private sector), connectedness (internal/external, physical/electronic/cultural), ability to lead strategically (vision, leadership, partnerships, politics), knowledge and innovation in companies and other organizations (investment in modern, knowledge-based equipment, investment in research and education, investment in innovation, work productivity), and quality of life (social, cultural, and environmental) are among the most important factors of cities' competitiveness.

The Huggins Index of Urban Competitiveness ([in 14]) emphasizes the importance of the local economy's ability to attract and maintain companies with stable or growing market shares, while simultaneously sustaining or improving the standard of living in the city. The index is divided into several subcategories, including knowledge-based companies, economic activity, company density, GDP per capita, productivity, wages, and unemployment. The urban resources base consists of location, age, favorable economic structure, company characteristics, ability to learn and innovate, communication, high-quality environment and services, and local leadership (see [15]).

"Cities of the future" will need to be able to provide and manage six interrelated forms of capital (strategic assets and resources of the city) (see [9]):

- Intellectual and social capital

- Democratic capital

- Culture and leisure activities capital

- Environmental capital

- Technical capital

- Financial capital 


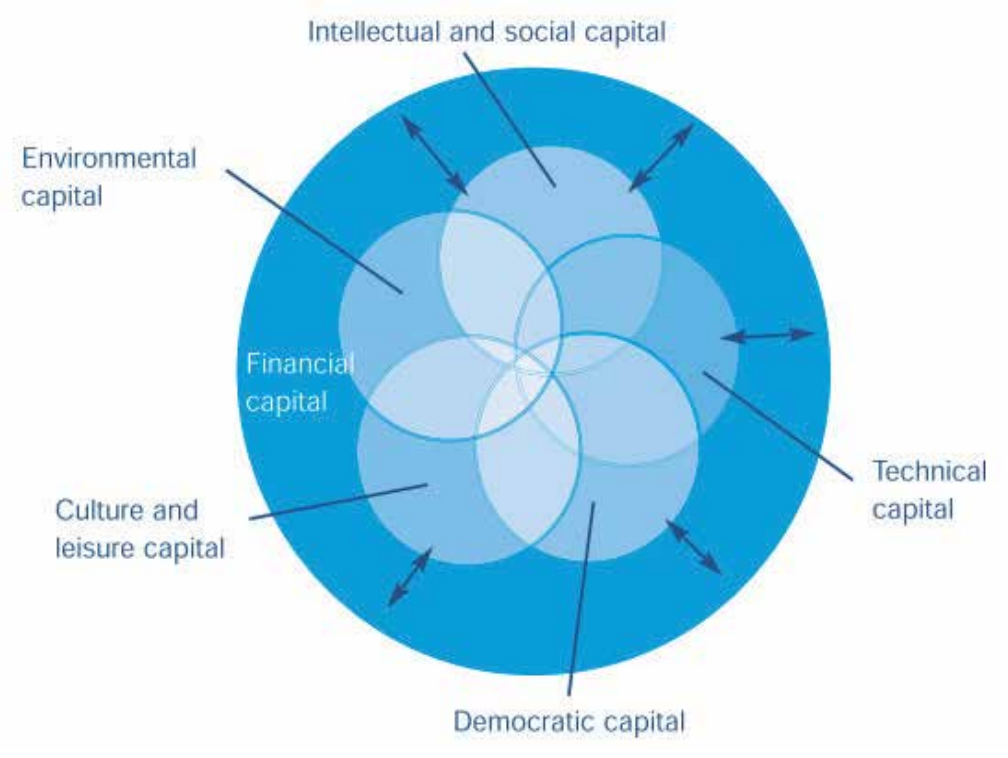

Source: ([9]).

Figure 1. Integrating capitals

Intellectual and social capital consists of people and knowledge resources, including urban residents' skills, competencies, and know-how. This form of capital is the main success factor for attracting investments. The level of social capital is reflected through the quality of formal and informal relationships in a city and is linked with a low crime rate, a low education level, and a lower level of segmentation and segregation.

Democratic capital (transparency, cooperation, and partnerships) stresses the need to include city residents in policy making and decision making. The awareness that city residents are no longer only voters and consumers but also cocreators of policies that shape the future of cities is coming to the forefront (ibid, 2005, p. 4). The information technology boom has made it possible to use democratic capital more extensively, and a number of cities are thus taking advantage of the internet, using it as a new channel for interaction between city leaderships and residents.

Culture capital and leisure activity capital encompasses values, behaviors, and public expressions and manifests itself through numerous attributes, which provide the city with a unique identity. Many cities build their unique identities by creating their own trademarks. In addition to a range of high-quality cultural services and lifestyles on offer, those trademarks also draw attention to other city attributes, which help attract and retain people's attention.

Environmental capital means natural resources, including clean, green, safe, and attractive environment. Balancing environmental impact with economic development is a big challenge. Pollution is a major problem for many cities, and their policies should therefore incorporate economic and environmental considerations. 
Technical capital is the city's infrastructure and consists of both the basic infrastructure (housing, transport, water, and energy under strain) and the infrastructure needed for efficient communication within the city administration.

Financial capital (money and assets) is important because cities nowadays are facing a number of financial challenges. In order to respond to them, cities have to establish accounting policies and analyses that allow them to understand their financial position. Often cities adopt an entrepreneurial approach to financing and providing services.

Although every city has its own unique identity, they face numerous common opportunities and challenges. The diversity and abundance of factors affecting city development require a unified strategy or model for long-term urban development that will effectively include all kinds of capital. Numerous successful European cities have already created their strategies, outlining their transformation into so-called knowledge or creative cities. These strategies are based on encouraging city residents' knowledge, creativity, and innovation, as well as the use of their varied experiences. Most urban city strategies favor a traditional, economic growthoriented development policy, with an emphasis on attracting investors. Cities provide them with the best opportunities, modern infrastructures, highly trained workforce, low taxes, highquality public services, and selective industrial policies that favor investments in modern strategic fields. This kind of policy requires strong support from all public authorities in their respective strategic fields, and also includes the establishment of research institutes and modern education programs.

Regardless of which type of strategy is employed, it is important to have one in place in order to define a city's direction of development. If a development strategy is not defined, projects often remain unrealized, not taken advantage of to their full potential, or simply unsuitable for a certain area. In the following subchapter, we are presenting a vision and strategy model that cities can use by planning their development. The authors of this chapter participated by developing a model created based on the needs of the Slovenian market and which has been tested in various Slovene cities with success.

\section{The vision and strategy model for strategic management of a city}

The vision and strategy model for Slovenian cities has been developing for years. The research on existing strategies in foreign cities, an analysis of strategic documents at the European and national level, and an analysis of the needs and capabilities of cities in Slovenia served as the basis for the model.

We had several goals in designing the model. First, we wanted to create a model that would facilitate the equal inclusion of opinions and priorities of city residents and other stakeholders of the cities. Within the principles of model transformation, we were mindful of the stability and the efficiency principle. We created a model that makes it possible to define development objectives and measures needed for their realization for a period of up to 20 years. 
At its core, the model focuses on five main pillars, which have been identified as those vital for a city's development. They are as follows:

- Economy

- Transport and communication

- Environment

- Quality of life

- Education

The framework of VIS model is shown in Figure 2 below.

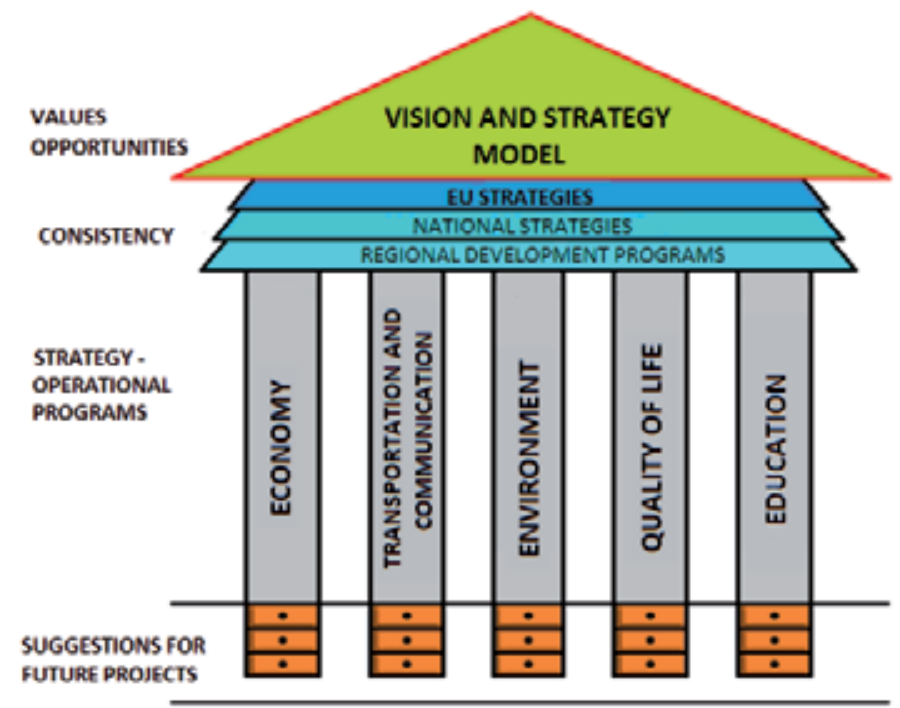

Figure 2. The vision and strategy model

All pillars are interconnected and mutually complementary. The main objective of each city is a strong economic position, and this has been primarily taken into account in the model's creation. By "strong economic position," we mean not only economic growth but also economic development, which is a reflection of progressive change in the socioeconomic social structure. The transport and communication pillar has been incorporated into the model because transport is part of the environment, and as a tertiary industry, it contributes greatly to economic development and the interconnection of different places. Transport and communication infrastructure has to meet the needs of economic development. In addition to adequate construction and the technical state of the transport network, there is a need for good-quality and high-capacity roads, which have a positive impact on economic activities and traffic accessibility. An important role must also be given to environmental protection in the creation 
of the long-term development vision and strategy. The environment pillar thus includes the prevention of biodiversity loss as well as the implementation of efficient and smart electric power grids and the development of a more competitive low-carbon economy, which efficiently and sustainably uses resources and other forms of environmental protection. The fourth important pillar of the vision and strategy model is education. It is a fact that we live in a knowledge-based society and that the skills of residents influence their lives in the greatest possible way. We are all aware that knowledge is the best investment; therefore, personal development and growth have also been included in the vision and strategy model. The last pillar of the model is the quality of life, including cultural events, accessible sports and recreational facilities, social activities, residence safety, neighborly relations, and spiritual care. In all phases of the model, attention is directed toward the above-mentioned pillars, and each step of the model is structured around those pillars.

The model methodology demands the completion of a structured questionnaire among various interest groups, a field survey on residents' life satisfaction, a survey for the definition of the selected city's identity (recognizability), and an analysis of existing statistical indicators for the city. Below, we present an example step-by-step representation of the vision and strategy model.
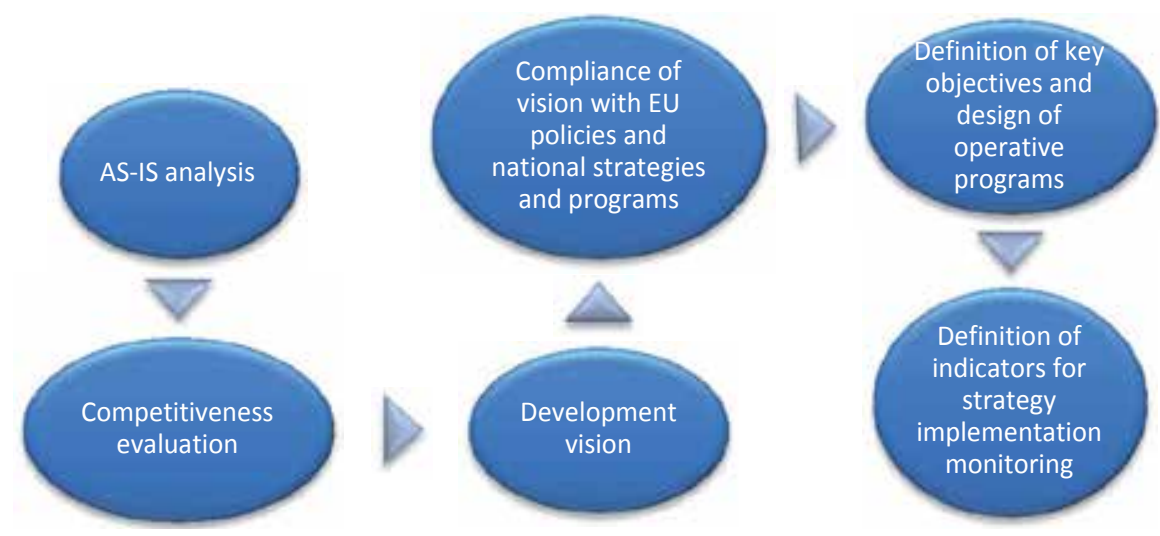

Sheme 1 . The process for the creation of city vision and strategy model

The above picture shows the process, which consists of six steps. The first step of the process is an analysis of the city's current situation.

\subsection{The AS-IS analysis}

The AS-IS analysis is an evaluation of the current situation in a city. The first step encompasses a precise definition of demographic and social indicators, economic indicators, and environmental and natural resource-related indicators. In general, a study of available capital is conducted; strengths, weaknesses, opportunities, and threats are explored, and at the same time, the location's attractiveness and the importance of economic and sociopolitical environment for the selected city are defined. 
Besides a statistical analysis of publicly accessible statistical data, the AS-IS analysis also includes the following:

- A public opinion analysis based on a life satisfaction survey among city residents

- A public opinion analysis among residents of other cities in the country with the goal of defining the selected city's recognizability in the region

- An analysis of individual responses from a sample of focus groups, which serve to gather information on the status quo of various aspects of city life. The individual focus group participants are carefully selected, and some of them are visible members of the city in one of the fields that could turn out to represent the city's development potential. In-depth interviews are carried out with those individuals.

Based on the data gathered with the help of the above-mentioned statistical methods, development potential and possible obstacles to development are defined. Within the AS-IS analysis, particular attention is paid to the city's budget, which is an important basis for later steps and for the definition of an individual city's competitiveness. The next step in the process is the evaluation of the selected city's competitiveness.

\subsection{Competitiveness evaluation}

Competitiveness is defined with the help of two methods - the benchmarking method and the SWOT analysis. Publicly accessible data from the Statistical Office and data gathered with the help of questionnaires, filled out by residents and various interest groups already in the first phase (AS-IS analysis), comprise the main statistical base for the competitiveness evaluation.

With the competitiveness evaluation, we also define general strategic questions that a city is faced with on a daily basis. We use the following matrix to define strategic issues for the city (Table 1).

\begin{tabular}{|c|c|c|}
\hline $\begin{array}{c}\text { Broad strategic } \\
\text { context }\end{array}$ & Symptoms & Strategic orientation/questions \\
\hline Declining city & $\begin{array}{l}\text { - High level of inactive population } \\
\text { - The city is not within commuter distance to a } \\
\text { stable or growing economic center } \\
\text { - Very few income generating activities } \\
\text { - A constant outward migration from the city for } \\
\text { various years }\end{array}$ & $\begin{array}{l}\text { The city needs } \\
\text { - a good connection to other urban centers } \\
\text { - the adaption of services to ensure provision of } \\
\text { essential city services at lower cost } \\
\text { - to reverse trends in a city }\end{array}$ \\
\hline $\begin{array}{l}\text { The city is in } \\
\text { transition }\end{array}$ & $\begin{array}{l}\text { - Unemployment is high } \\
\text { - Some "key" old industries closed down } \\
\text { - The labor market is focused too much on } \\
\text { outdate industries } \\
\text { - Favorable chances for new ideas }\end{array}$ & $\begin{array}{l}\text { The city needs the appropriate } \\
\text { - assistance of a transformation of city } \\
\text { - way of transforming old industrial locations into } \\
\text { new spaces for modern living, working, art, and } \\
\text { culture } \\
\text { - adaption of local skills }\end{array}$ \\
\hline
\end{tabular}




\begin{tabular}{lll}
\hline $\begin{array}{l}\text { Broad strategic } \\
\text { context }\end{array}$ & \multicolumn{1}{c}{ Symptoms } & \multicolumn{1}{c}{ Strategic orientation/questions } \\
\hline & & - encouragement of new ideas and new business \\
& & - positioning \\
\hline The city is & - The city is successful & The city needs provision of adequate infrastructure \\
growing & - There is inward migration & and services \\
& - Existing infrastructure is becoming inadequate & - to increase the population \\
& because it was not designed for a larger & - to ensure adequate environmental standards for a \\
& population & growing population and quality of life \\
City resources are- The city does not have the ways and means to & - to ensure social integration and cohesion \\
tight & generate sufficient income & - generate more income \\
& - The city is not using its resources efficiently & - make tax collection more effective \\
& enough & - make safe investments for the future \\
& - This situation can take place in any of the above & \\
three mentioned situations & \\
\hline
\end{tabular}

Source: (see [16]).

Table 1. Strategic issues relevant for the city

With the help of the matrix above, we can analyze in which stage the city is and define the most important strategic questions and orientation our model of vision and strategy should answer.

\subsection{Creating the vision}

Some cities and people see the vision and strategy as a piece of paper or as a tool for political promotion. In forming the model, we avoided this risk by including stakeholders and their ideas in the process of forming the vision of the city.

When creating the vision, we took into consideration the fact that every city needs a strong and interesting vision, which then serves as the basis of its long-term development strategy. It is important that the vision include stakeholders and their ideas from various fields, but simultaneously the general public must be made familiar with the vision in order to build their enthusiasm around it and enable them to identify with it. The creation of the development vision is based on the AS-IS analysis and the competitiveness evaluation.

Residents' values, including traditional and postmodern values, also play an important role in defining the vision. At the same time, indicators measuring the performance and potential of a city are also taken into consideration when creating the vision.

In this stage, we use the prioritization matrix, for which we formed an automated template in an Excel spreadsheet. This spreadsheet includes criteria for judging priorities. 
In the next step, the development vision's compliance with existing strategic development documents on the EU and national levels are checked.

\subsection{Compliance of vision with EU and national policies}

In this step, the residents' knowledge of EU policies and national strategies is examined, and at the same time, the new city's vision is checked against those documents. First, compliance is checked against development documents at the EU level, then the state, then at the regional level, and finally at the city level. Simultaneously, a list of existing projects is made and their alignment with the new vision is reviewed as well. The next step is the definition of key objectives and operative programs.

\subsection{The definition of key objectives and the design of operative programs}

Key objectives and operative programs are prepared for each of the above-mentioned five pillars (economy, transport and communication, environment, education, and quality of life).

Each of the five development pillars is divided into three parts. Part one shows elements from the residents' point of view and it reflects their perception of the current situation and certain expectations. In the second part, clear, quantified, realistic, and challenging objectives are set, which form the basis of a transparent system for monitoring the execution of the development strategy. Quantified objectives are also complemented by values or satisfaction of residents. This ensures a permanent participation of the residents. The third part of each development pillar is a pool of potential concrete measures for the attainment of objectives set. The pool of measures stems from existing documents, the city's legal obligations, and best practice case studies, and it serves as a reminder for the actions taken by the city council and the city administration. Based on the measures pool, the city prepares project ideas in advance so that they are ready to be undertaken.

\subsection{The definition of indicator values for the monitoring of strategy implementation}

Using the statistical tool "expert choice," the last step consists of setting the indicator target values, applicable for the same period of time as the vision. Based on our experiences, 20 years is the most relevant period. After the calculated final values, which are influenced by weights assigned to individual indicators, cities have an efficient tool to monitor strategy implementation progress.

When the process of creating a vision and strategy model is completed, the strategic development document must then be presented to city residents. Awareness of the direction of future development gives residents additional motivation and desire to be involved in the realization of measures that will contribute to the city's development.

\section{Introduction of the model in practice}

The model is designed in such a way that it can be used for any city. A committed city leadership, which motivates residents and creates an atmosphere where everyone wants to 
contribute to development, greatly contributes to the model's more efficient realization. Residents' values, which form the foundation of the vision, make it possible for individual cities to differ from their competitors, and they make it possible for the city to stand out and get noticed to the fullest possible extent. The model's introduction requires the prudent application of strategic thinking at all levels and in all dimensions. The special added value of the model, however, lies in residents' participation in all phases of the creation of the city's vision and strategy. The development vision and strategy created by using the model presented above will give the city answers to the following questions:

1. Who are the relevant subjects for the development of the city?

2. What is the current state of affairs in various fields (economic activity, social activity, environment, and spatial planning)?

3. What kinds of developmental opportunities are available and what are the developmental shortcomings?

4. What are the objectives and priorities of the city's development?

5. Which measures need to be undertaken to achieve the objectives set?

6. Which projects lead toward the objectives set?

Of course, the newly created development vision and strategy only represent the first step, which must be followed up by building trust in the city, establishing partnerships in various directions and on various levels, and attracting key factors necessary for the development and realization of projects that support the city's developmental objectives. This is a long-term process, which due to residents' participation from the early start, their inclusion in the projects, and their influence on the indicators facilitate a broad consensus that minimizes the possibilities of everyday political meddling in the city's development.

The model gives cities the ability to compete and position themselves in order to provide quality of life, jobs, and services that attract business and people. Cities with vision and strategy have better conditions for funding city projects via banks, national funding, or EU funding.

To this day, the vision and strategy model has been carried out in more than 20 Slovenian cities. For all these cities, the model has helped us define specific strategic goals and the way to achieve them. The model pays special attention to practical aspects of strategy delivery. Moreover, the model also emphasizes the significance of an integrated approach and the importance of building partnerships.

\section{Conclusion}

Many challenges brought about by globalization have encouraged cities to orient themselves toward the future. Some have done that successfully and some are taking small steps with the help of individual projects and are therefore less successful. One of the reasons for a lower success rate is the absence of a development vision and strategy. 
The above-presented process for developing the vision and strategy model of a city enabled its users to understand and analyze what will be at the center of attention for their city in the future. The process consists of six steps, and its successful implementation in practice depends on several different factors. One such important factor is the courage of the city's leadership to test new ideas and to encourage a robust dialogue between politicians, the administration, companies, associations, and individuals. The fact that the model foresees the inclusion of residents, various interest groups, experts from various fields, and the city's leadership in equal measure shows that the creators of the model are well aware that a strategy can only be successful if people recognize the fulfillment of their wishes and expectations in it. Practice shows that objectives, plans, and strategies in themselves do not lead to success; only people and the values that guide their realization can achieve this.

\section{Author details}

Anita Maček ${ }^{1^{*}}$ and Vito Bobek ${ }^{2}$

*Address all correspondence to: anita.macek@net.doba.si

1 DOBA Faculty of Applied Business and Social Studies Maribor, Slovenia

2 FH Joanneum Graz, Austria

\section{References}

[1] McLachlan, G. 2001. The impact of globalization on the cities of southern Africa: a case study of the Port Elizabeth Metropolitan Area [Internet]. Available from: http:// www.isocarp.net/Data/case_studies/cases/cs01_4568/gmpaper.htm [Accessed: 10.03.2015].

[2] Mathur, P. Impact of globalization on cities and city-related policies in India. Globalization and Urban Development, pp. 43-58 [Internet]. 2005. Available from: http://link.springer.com/chapter/10.1007\%2F3-540-28351-X_4?LI=true [Accessed: 20.12.2014].

[3] Ahmed, S. N. 2010. Impact of Globalization On A Southern Cosmopolitan City (Cairo): A Human Rights Perspective [Internet]. Available from: http://www.countercurrents.org/ ahmed031210.htm [Accessed: 10.03.2015].

[4] Oduwaye, L. 2006. Effects of globalization on cities in developing countires. Journal of Social Science; 12:199-205.

[5] McCann, P., and Acs, Z. J. 2007. Globalisation: Countries, Cities and Multinationals [Internet]. Available from: http://www2.econ.uu.nl/users/marrewijk/pdf/ihs\%20workshop/ mccann\%20paper.pdf. [Accessed: 3.6.2013]. 
[6] European Institute for Urban Affairs (EIUA). 2004. Competitive European Cities: Where Do the Core Cities Stand? [Internet]. Available from: http:// www.communities.gov.uk/pub/441/CompetitiveEuropeanCitiesWheredotheCoreCitiesStandFullReportPDF444Kb_id1127441.pdf [Accessed: 09.12.2014]

[7] Turok, I. 2004. Cities, regions and competitiveness. Regional Studies, 38:1069-1083.

[8] Cushman and Wakefield. 2005. European Cities Monitor 2005 [Internet]. Available from: http://www.cushmanwakefield.com/cwglobal/docviewer/European\%20Cities \%20Monitor.pdf [Accessed: 10.12.2014]

[9] PricewaterhouseCoopers (PcW). 2005. Cities of the Future. Global Competition, Local Leadership [Internet]. Available from: http://www.pwcglobal.com/extweb/pwcpublications.nsf/docid/940ABE55AB5865A6852570F400722582/\$FILE/cities-final.pdf [Accessed: 10.03.2015].

[10] Polèse, M. Cities and national economic growth: a reappraisal. Urban Studies. 2005; 42:1429-1451.

[11] Markusen, A., and G. Schrock. The distinctive city: divergent patterns in growth, hierarchy and specialisation. Urban Studies. 2006; 43:1301-1323.

[12] Keil, R. The Global Cities Reader. 2006. 1st ed. London: Routledge. Organisation for Economic Cooperation and Development (OECD). City Competitiveness in the Global Economy. 2006. Paris: OECD. 445 p.

[13] Sassen, S. Cities today: a new frontier for major developments. ANNALS of the American Academy of Political and Social Science. 2009; 626.

[14] Huggins, R. The State of Urban Britain: The Competitiveness of the UK's Cities. Robert Huggins Associates. 2002.

[15] Robson, B., Parkinson, M., Boddy, M., and Maclennan, D. The State of England's Cities. London. 2000.

[16] Hauser, F., and Marjanovič, M. City Development Strategy Process. Netherlands: VNG. 2010. 54 p. 

Chapter 5

\title{
Measuring Urban Development and City Performance
}

\author{
Jasmina Mavrič and Vito Bobek \\ Additional information is available at the end of the chapter \\ http://dx.doi.org/10.5772/61063
}

\begin{abstract}
Cities represent the driving force of development in economic, social, and cultural life, reflecting also the spatial organization of human society. Taking into account the fact that cities are becoming generators of economic development and a source of growth for the national economy, there is an increasing urge to identify the stages of development and to establish a system for the ranking and positioning of cities and regions in this process (the level of categorization). This will allow the preparation of appropriate strategic and development guidelines for cities and urban regions to take place. In order to be able to compare the level of their efficiency in fostering development, there is an intensifying need to develop indicators that measure the performance of cities, are representative and comparable between countries, and allow verification to others. At present, there are many different urban indicators and institutions that compile and analyze them. Performance measurement systems, developed for internal use in some cities, already show a degree of measurement feasibility. The fundamental problem is that this variety of indicators lacks consistency and comparability (over time and between compared cities). Therefore, their use cannot be approved in a wider context (benchmark) of comparative situations. Upon the case of medium-sized cities, we consequently have to question the applicability of the methodology and indicators, used mostly in cases of large, global cities by internationally recognized institutions. With the established set of indicators and assistance of computer programs for multiparameter decision-making processes (analytic hierarchical process [AHP]), this paper also seeks to investigate comparisons between performance of selected European cities (on a qualitative basis).
\end{abstract}

Keywords: city, region, urban development, globalization, urbanization, measurement systems, development of urban indicators, indicators, city ranking, quality of life, competitiveness 


\section{Introduction}

Existing methodologies in comparison to performance and quality of urban city structure affect more or less a wider field of urban and regional disparities, while specific approaches cover only limited areas. [34] focuses exclusively on infrastructure impacts, Callois and Aubert (2007) empirically analyze the impact of social capital on regional development. The advantage of quoted approaches represents limited number of variables involved in analysis. In the area of measuring the quality of life, [53] provide an overview of indicators of sustainable development, as well as [54] and [55], but the interpretation of the indicators of quality of life is missing. In the field of competitiveness, [62] presents the synopsis of indicators measuring urban competitiveness on a European scale, while [39] indicate the multicast nature of sustainable development that consequently leads to the unclear definition of the measuring indicator. Missing thematic indicators can also be found in the context of measuring regional disparities, both at the level of the broader European countries [58] and in the narrow sense of the regions [36]. Comparing cities by the use of indicators that represent diverse aspects of urban life is only possible with the meaningful structured set system; easily adding a large number of indicators to achieve a single index may result in criticism of uncertainty and noticeable limitation of its interpretation. Similar effects can also be achieved by using a larger set of nonaggregated indicators; therefore, identification of appropriate, small number of relevant indicators is crucial. In the process of establishing the set of indicators, the inclusion of indicators with higher impact on the general differences between selected cities in different countries is necessary; an additional assumption incorporates the integration of indicators from the field of environmental, human, and social capital as well as the demographic point of view.

\section{Theoretical background and applied practices}

When searching for the most relevant performance indicators of city development, we proceed from the fact that more than two-thirds of the population live in urban areas. The urban environment provides a fertile ground for the development of science and technology, culture, and innovation. On the other hand, in cities, there is also more emphasis on the problems such as unemployment, discrimination, segregation of society, and poverty. The cities are also faced by challenges, associated with mitigating the effects of climate change, job creation, prosperity, and quality of life. Therefore, the development of cities has a decisive impact on the future of the economic, social, and territorial development. As highlighted by the recent European Commission survey entitled "Cities of the Future-Challenges, Ideas and Expectations" (EC, 2011), a phase of urban sprawl in recent decades has shown serious problems associated with the deterioration of urban areas due to lack of infrastructure construction and basic services. Promoting urban renewal as the driving force of prosperity and creating opportunities together with strengthening the link between cities and development, and between urban centers and surrounding areas, are the main challenges to provide stable economic growth. 
Establishing a system of indicators for measuring performance development of selected cities included the consideration of contemporary city's complex aspects with reference to (a) the 72 attributes of a smart city, ${ }^{1}$ (b) the performance of the city, and (c) urban status or urban sustainability.

The case study example of Glasgow classifies city performance indicators as follows: (1) population (mortality, fertility, population projections), (2) economic participation (employment, unemployment, vacancies), (3) poverty (access to bank accounts, children poverty, financial hardship, low-income households), (4) health (life expectancy, inability to work), (5) social capital (social inclusion, social networks, trust and reciprocity, civic participation), (6), environment (green environment, open space, air quality, recycling), (7) transport (transport volume, journeys to work and school, traffic accidents, cycling), (8) education (children education, the highest qualification obtained, the qualification of the working population, training of young people), (9) safety of local communities (overall level of crime, antisocial behavior, violence, unintentional injuries), (10) lifestyle, (11) cultural vitality (involvement in sport and cultural events), and (12) mind-set (religion, politics, involvement in the community, trust, national identity).

Indicators of sustainable development reflect the complex and dynamic structure of the urban environment. With the adoption of Agenda 21 (1992), this type of indicator was developed by a number of institutions, including the World Bank (UN-Urban Indicators Programme), followed by indicators of the World Health Organization (WHO), as the analytical tools for studying population health and quality of life in urban environment. A wider set of indicators also includes project SUD-LAB EC (European Commission) with an expanded database of European cities, where indicators are divided into the following categories: (a) air quality, (b) composed environment, (c) cultural endowments, (d) social disparities, (e) quality of transport, (f) urban management, and (g) waste management. For each of listed categories, a set of indicators is reflecting the level of urban functionality. Indicators of the EU-TISSUE Programme, in use in 15 European countries, relate to the areas of sustainable urban management (descriptive indicators), sustainable urban transport, sustainable urban construction, and sustainable urban design [2].

In accordance with the Charter on European Sustainable Cities and Towns, [60] lists six key areas of sustainable development and urban transformation: (1) active city/town, (2) beautiful town, (3) green city/town, (4) town with a better environment, (5) cooperation for a better city, and (6) town catalogue. The strategy of urban sustainability consequently includes urban sustainability performance indicators such as (1) local involvement (citizen's participation); (2) employment; (3) city deficit; (4) economic growth; (5) urban mobility; (6) urban metabolism, resources, and consumption; (7) environment and social expenditure; (8) urban safety; (9) public health; (10) social justice; and (11) global change.

Among indicators of central city area development, Niţulescu (2000) includes the following: (1) types of land using (constructions, green areas), (2) green areas surface from the total town center's surface, (3) percent of residential buildings from the total number of buildings from

1http://www.smart-cities.eu. 
the center of the town, (4) percent of trade buildings from the total number of buildings from the town center, (5) percent of central functions buildings (administrative, international, unique endowment) from the total number of buildings from the center of the town, (6) built areas of public utility related to then inhabited areas, (7) employment density (number of working places related to the town center surface), (8) rate of employed population for each sector (industry, trade, services), (9) number of crossroads for the surface of the town center, (10) surface of pedestrian circulation for the surface of the town, and (11) surface of pedestrian circulation for the surface of roadway [2].

Among indicators of urban status ranks, Şuler's (2005) category of population and labor force indicators are as follows: (1) number of inhabitants, (2) population density (per hectare), (3) working places/1000 inhabitants, and (4) proportion of the population employed in the service sector. The category of living and quality of life indicators include the following: (5) number of residential buildings per 1000 inhabitants, (6) houses equipped with plumbing (\% of buildings), (7) number of personal cars per 1000 inhabitants, (8) number of houses with bathrooms inside the building, (9) number of hospital beds per 1000 inhabitants, (10) number of doctors per 1000 persons, (11) financial/banking institutions (headquarters, working points), and (12) accessibility to lines of communication (railway station, bus station). The indicators of category society, culture, and leisure include the following: (13) education units (high school, secondary, postsecondary school), (14) secondary school in primary and secondary educational units (\%), (15) cultural and sports endowments (theaters, public libraries, gyms, auditorium, stadium), and (16) accommodation places/1000 inhabitants. Indicators of the urban network are specified as follows: (17) modernized streets (\%), (18) streets with water pipes (\%), (19) waste water treatment, (20) household gas distribution pipes (\%), (21) sanitation motor vehicles for $100 \mathrm{~km}$ of street, (22) scavengers for 1000 inhabitants, and (23) green area surface $\mathrm{m}^{2} /$ inhabitant.

[2] defines an index of local development as an integrated indicator, including the importance (weights) of individual elements as category of infrastructure (4), followed by the economy (3), community (2), and the public administration (1):

$$
I_{d l}=\left[\left(I_{i} \times 4\right)+\left(I_{e} \times 3\right)+\left(I_{m c} \times 2\right)+\left(I_{a p} \times 1\right)\right] / 10,
$$

where $I_{\mathrm{dl}}$ is the local development index, $I_{\mathrm{i}}$ is the infrastructure index, $I_{\mathrm{e}}$ is the local economy index, $I_{\mathrm{mc}}$ is the local community index, and $I_{\mathrm{ap}}$ is the public administration index.

Category infrastructure includes utilities, transport infrastructure, health infrastructure, natural resources, and natural environment. Economy includes financial services and insurance, labor, and public budget. Public administration includes public administration, services and support to small and medium-sized enterprises, urban planning, communication, and information dissemination. Among the indicators of development, Bănică (2010) introduces the community spirit, safety of citizens, tourist attractions, cultural/sports facilities, and cultural/historical heritage. 
[63] formed an indicator of the public urban transport quality using available Eurostat database indicators, including the following subindicators: (1) the proportion of journeys to work by public transport, (2) the length of the public transport network, (3) the number of stops of public transport per $\mathrm{km}^{2}$, (4) the price of a monthly public transport ticket, (5) the number of stops per 1000 population, (6) the number of stops per $1 \mathrm{~km}$ of public transport network, (7) the ratio between the public transport network on fixed infrastructure and flexible connections, and (9) the proportion of land for transport use.

World Bank Urban Development Indicators include the following: (1) proportion of urban population with access to improved health services, (2) proportion of urban population with access to water resources, (3) number of motor vehicles per 1000 population, (4) number of passenger cars per 1000 inhabitants, (5) emissions of PM10 (micrograms per $\mathrm{m}^{3}$ ), (6) proportion of poverty, (7) fuel prices, (8) fuel consumption per capita, and (9) the percentage of the urban population.

Significant importance among urban sustainability indicators belongs to European Common Indicators (ECI), first established in 1999-2003, by the research institute Ambiente Italia. Within a base with more than 1000 indicators, 10 key indicators, reflecting the development trends of European cities in accordance with the principles of social inclusion, local governance and democracy, local/global integration of the city, local economy, environment, cultural heritage, and quality of the institutional environment was selected: (1) citizens' satisfaction with the local community, (2) local contribution to global climate change $\left(\mathrm{CO}_{2}\right.$ emissions per capita), (3) local mobility and passenger transportation, (4) availability of local public open areas and services, (5) quality of the air (emissions of $\mathrm{PM}_{10}$ ), (6) children's journeys to and from school, (7) sustainable management of the local authority and local enterprises, (8) noise pollution, (9) sustainable land use, and (10) products promoting sustainability.

With reference to the cited attributes of a smart city, ${ }^{2}$ city performance, and urban sustainability, a system of indicators, whose structure is presented in the following text, for measuring performance development of the city was developed. Areas of measurement, enabling the international comparison of cities, covered six areas: (1) demography, labor market, and economy; (2) quality of life; (3) society, culture, and leisure activities; (4) research and development; (5) accessibility of urban networks and international connectivity; and (6) management of sustainable resources. Within listed areas of measurement system, categories enabling grouping of individual indicators and appropriate weighting of the their relative importance were set. Relevant indicators resulted from knowledge of current topics and problems of urban development as well as the renewal priorities of local development model. The indicator system, based on current challenges of a multicultural society, was reaching the areas within the sphere of local communities, trust in institutions, prosperity, quality of life, environmental change, social exclusion, unemployment, poverty, polarization, and demographic changes. From this perspective, it can be regarded as a dynamic system, where 53 selected indicators serve as a basis, always possible to upgrade and adapt to the situation and degree of urban development.

2 Specifically explained in Section 6 . 


\section{Selection of indicators}

The selection of appropriate indicators included research and exploration, evaluation, and selection of relevant databases, through which adequate indicators of measurement as a basis for determining the level of the city performance development and consequently a useful tool for ranking of comparable medium-sized European cities was obtained. Indicators in the study were selected on the basis of following assumptions: (1) objectivity (clear, easy to understand, precise, and unambiguous); (2) relevance, measurability, and reproducibility (quantitative, systematic observable); (3) validity (with the possibility of verification and data quality control); (4) statistical representativeness (at the city level); (5) comparability/standardization-longitudinal (over time) and transverse (between cities); (6) flexibility (with the possibility of continuous improvement); (7) efficiency/performance (as decision making and local management planning tool); (8) accessibility (available databases, use of existing data); (9) interaction (social, environmental, economic); and (10) consistency and temporal stability. Last but not least, the selection of appropriate indicators was also related to the concept of data homogeneity. In searching for the relevant data, many of the existing semantic information about the state of the city and urban region were expected to be available; therefore, the data credibility was highlighted.

\section{Selection of cities}

In Europe, more than 600 cities and urban regions are classified as medium-sized with a population between 100,000 and 500,000 inhabitants (selection criteria). In the case of a single manual data collection, the data processing for such number of cities are practically impossible. Therefore, the reselection of urban sample in terms of a data source (all selected cities should be covered by a specific source, e.g., Urban Audit) was necessary to eliminate the risk of the diverse resources' use, related to the area and the region of the city, induced by the dimension of the selected city sample. In case of insufficient data, the use of different spatial levels (Eurostat database is corresponding to NUTS2, representing regions and provinces, while the Eurobarometer data correspond to NUTS0/national level) was imminent. Quoted databases focus on the European cities' profiles, which further narrowed the selection frame. The final selection of cities was defined (Table 2) on the basis of the following: location (criterion 1: all selected cities are located in Europe), database (criterion 2: inclusion in the database Urban Audit), definition in terms of a smart city (criterion 3: placed in the "Smart Cities" base), comparability in terms of urban size (criterion 4: comparable population size: medium-sized cities with the range of 100,000 to 200,000 inhabitants), and regional significance (criterion 5: capital region or important regional center). With reference to fulfilled criteria, research cities represented Maribor (Slovenia), Pleven (Bulgaria), Linz (Austria), Erfurt (Germany), Trieste (Italy), and Brugge (Belgium). 


\begin{tabular}{|c|c|c|c|c|c|c|c|c|c|c|c|c|}
\hline Arna & Cotegory & & & tedixangy & Withlint & Mtariber & Fren & Ins & Erfun & Int & Brugse & $\begin{array}{l}\text { Dun } \\
\text { souree }\end{array}$ \\
\hline Dewagrapty. & population & lasicater & $t$ & Poplasist : reitients & 0,05 & 111392 & 112972 & Istsa & zouess & $20532 ?$ & 117013 & titusa \\
\hline \multirow{13}{*}{$\begin{array}{l}\text { labour marke } \\
\text { tstaswy }\end{array}$} & popelation & labicator & 2 & Popdasos destey sed retidest pop yer squart & 0,05 & 7679 & 2.2 & $=2.2$ & 755,5 & 2402 & 9232 & Colan \\
\hline & populubes & Sabator & 3 & Tobd populutes at workat ats & 0,05 & 77825 & 83920 & 12753 & 13794 & 125172 & 76120 & the \\
\hline & pepulaten & Saficator & 4 & 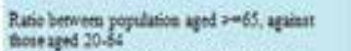 & 0,05 & 28.3 & 18.8 & 303 & 32.6 & 49,8 & 344 & $\begin{array}{l}\text { thena } \\
\text { Aust }\end{array}$ \\
\hline & popelation & abicator & 5 & Nasicasit at a propertisa of wel populatise & 0,05 & 95 & 996,4 & 36,4 & क, 7 & 93,3 & 97 & Colen \\
\hline & Lakeu maktet & Sabcator & 6 & 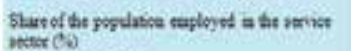 & 0,25 & 44 & 35 & 2005 & 49 & 90 & 39. & Uweat \\
\hline & lateur akebet & Saficsior & 7 & 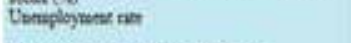 & 0,15 & 9,6 & 19 & 33 & 12.8 & $43^{*}$ & $2 *$ & Eareste: \\
\hline & linbour arelket & tabessor & 8 & Propersed a put - teet exploypeet & 0,15 & 8,3 & 21. & 21. & 25,1 & a. & 11 & $\begin{array}{l}\text { Uibas } \\
\text { Apdit }\end{array}$ \\
\hline & lateur aaket & Satcalor & 9 & 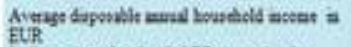 & 0,15 & sest & 329 & $\begin{array}{l}20500 \\
20105\end{array}$ & 21360 & 23917 & 28300 & tems \\
\hline & peductinfy & Sackevor & 10 & 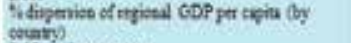 & 0.15 & $=p$ & 99.6 & 191 & 16,4 & 22,3 & 262 & Eareste \\
\hline & extepreanhip & Iabesor & 11 & Seld-enpley=ment tast & 0,15 & 9. & 21 & 1 & $n$ & a. & Is & $\begin{array}{l}\text { Uhes } \\
\text { Antit }\end{array}$ \\
\hline & expquarabis & satextor & 12 & New buabas rotgated a agropsthce & 0,25 & 159 & 18.8 & 2.2 & $\$ .1$ & $\$ 4$ & 6,3 & Wean \\
\hline & exreprsaesubip & ladcron & 12 & $\begin{array}{l}\text { Coapai its goot bmaluopt is reiteresse year } \\
\text { (Ihare) }\end{array}$ & 0,19 & 0,916 & 0,458 & $\begin{array}{l}1,452 \\
(1959 . \\
2002)\end{array}$ & 0,258 & 29 & $0,92 \pi$ & $\begin{array}{l}\text { Witan } \\
\text { Audt }\end{array}$ \\
\hline & exteraeanhip & tabensor & 14 & 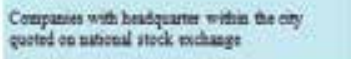 & 0,15 & 9 & isis & 2 & 3 & 90 & ax & $\begin{array}{l}\text { Uetas } \\
\text { Audst }\end{array}$ \\
\hline \multirow{4}{*}{$\begin{array}{l}\text { Qaality of } \\
\text { Ling } \\
\text { (QOL) }\end{array}$} & \multirow{4}{*}{ 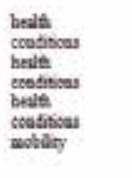 } & Sadcropr & 15 & 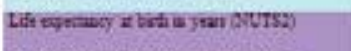 & 0,20 & Tos & 78 & 11,4 & 998 & 82,4 & $\mathbf{n}, 1$ & \multirow{4}{*}{ 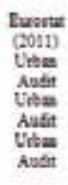 } \\
\hline & & babessor & 16 & Nimbere of herpinl bedr per 1000 seriders & 0,20 & $\mathrm{n}, \mathrm{st}$ & $\$, 97$ & 1999 & 968 & $9, \pi$ & 19,4, & \\
\hline & & ladicas & 17 & 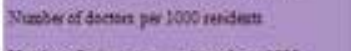 & 0.20 & $5:$ & Q & 10 & 2 & 12 & 3 & \\
\hline & & Sadcroor & 18 & 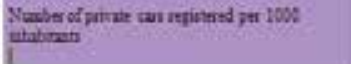 & 0,20 & $472, ?$ & 46,9 & an & 37,6 & $225, ?$ & 492 & \\
\hline
\end{tabular}

\begin{tabular}{|c|c|c|c|c|c|c|c|c|c|c|c|c|}
\hline \multirow{6}{*}{ I } & sulity of tiving & Iaficust & 19 & Nuetet of bretizat) & 0,20 & $\$ 213 \%$ & 52199 & 110004 & mod & II1230 & $\begin{array}{l}45373 \\
1972 \\
1900 \%\end{array}$ & $\begin{array}{l}\text { Withas } \\
\text { Andut }\end{array}$ \\
\hline & puality of' Iriag & Faticatser & 20 & Qot ader:oti aUtrot & 0,20 & 72 & 69 & 9 & 7 & 7 & 78 & Shersented \\
\hline & fality of iniat & Intictese & u & 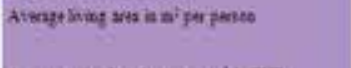 & $a, 20$ & $\begin{array}{c}361 \\
6999 . \\
20021\end{array}$ & 199 & $\begin{array}{c}31 \\
\text { (1960. } \\
199 \%)\end{array}$ & 1465 : & $\begin{array}{l}39,16 \\
9999 \\
20029\end{array}$ & $\begin{array}{l}14,65 \\
1996 \\
2002\end{array}$ & Wudta \\
\hline & guality oftiniag & loticaser & 22 & Avaragt prist for a bous per at' is ER & 0,20 & 1693 & 400 & 2016,32 & 1260 & 2100 & 317 & $\begin{array}{l}\text { Whaw } \\
\text { Andit }\end{array}$ \\
\hline & pulify ef livias & taticuser & 23 & 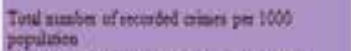 & 0.10 & 65,6 & HE, & 100.8 & 1045 & 448 & 116,4 & $\begin{array}{l}\text { Thas } \\
\text { Aust }\end{array}$ \\
\hline & $\begin{array}{l}\text { netid } \\
\text { cebertice }\end{array}$ & Tafiester & 24 & 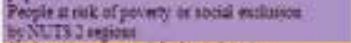 & Q.10 & $(20.2)$ & क्यin & (29) & 17,5 & 9013 & (20) & Fuater. \\
\hline \multirow{13}{*}{ 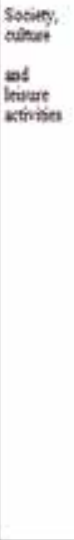 } & $\begin{array}{l}\text { ģutatensen } \\
\text { lend }\end{array}$ & tobieuser & 25 & 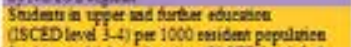 & 0,20 & $3 t$ & 71, & $\sin$ & is & 10,9 & 1139 & $\begin{array}{l}\text { tyone } \\
\text { Ander }\end{array}$ \\
\hline & $\begin{array}{l}\text { Fubfensea } \\
\text { Ind }\end{array}$ & Dabievist & 26 & 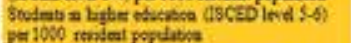 & 0.20 & $\operatorname{sos} 3$ & 14,2 & 1035 & 439 & 83.2 & 299 & Withe \\
\hline & utem direstiny & toficater & 27 & 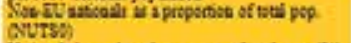 & 0,10 & 4 & 12 & 10,5 & 8,7 & 7 & 9,7 & $\begin{array}{c}\text { Darsotat } \\
2010\end{array}$ \\
\hline & uatum dinestiky & lodicatur & $x$ & 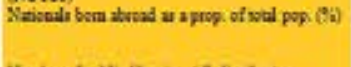 & 0,10 & 112 & $\begin{array}{c}0.1 \\
(1999 . \\
2000)\end{array}$ & $\mathrm{AP}$ & 22 & ax & $\begin{array}{c}21 \\
(1999 . \\
2002)\end{array}$ & $\begin{array}{l}\text { Uithan } \\
\text { Ancde }\end{array}$ \\
\hline & Lifkosg leanitg & faficuest & 29 & 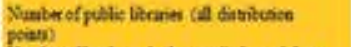 & 0.20 & 10 & 3 & 2 & 9 & EL & 13 & $\begin{array}{l}\text { Uithan } \\
\text { Andit }\end{array}$ \\
\hline & Lifkong leanite & Taficuast & 30 & 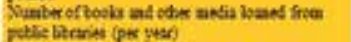 & 0,20 & 13,1 & 0.5 & 48 & 48 & s. & 12 & $\begin{array}{l}\text { Uithan } \\
\text { Alesit }\end{array}$ \\
\hline & LifNoeg lestids & Doticuter & $n$ & 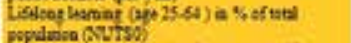 & 0,30 & 15,9 & 1,2 & 13,4 & 7,3 & 5,7 & $7, t$ & $\begin{array}{l}\text { Dorsent } \\
\text { 20it }\end{array}$ \\
\hline & Lufleres levang & fofiester & 32 & 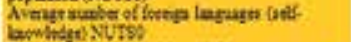 & 0,20 & 2,4 & 09 & 1,2 & L.1 & 2 & 09 & Exiset \\
\hline & Avelubiling of & tobicust & 33 & 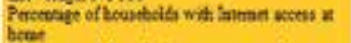 & 0.20 & 51: & 359 & 20009 & 6: & 2004 & 2800 & titum \\
\hline & 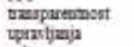 & lodicator & 34 & 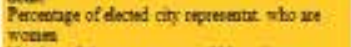 & Q,10 & 35,6 & 25.5 & 34,4 & 90 & 17.1 & 45,1 & Uibain \\
\hline & culture & fodicator & 35 & Sulmer of cinema seas per 1600 serident & 0,20 & 15,5 & 22 & 16,8 & n & D. & 26,5. & $\begin{array}{l}\text { Uaban } \\
\text { Ande }\end{array}$ \\
\hline & edtare brast & fotienese & 36 & Neskes at araena & 0,20 & 3 & 6 & 1 & 14 & 31 & 12 & Ustan \\
\hline & caltart brast & Toficters & $n$ & Nenter oftenasts & 0,20 & 2 & 1 & 4 & 2 & $\mathrm{Bz}$ & 7 & $\begin{array}{l}\text { Trtat } \\
\text { Alst }\end{array}$ \\
\hline
\end{tabular}




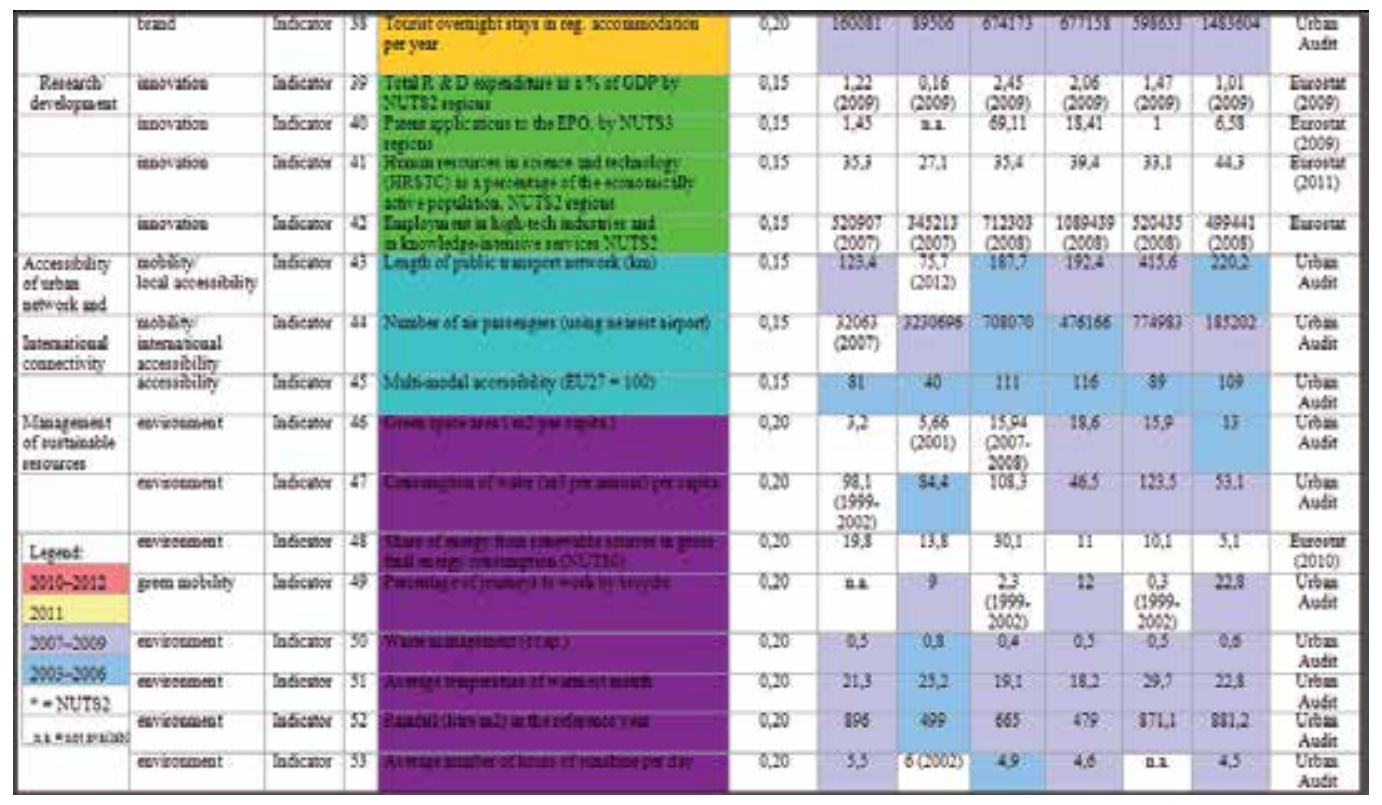

Table 1. City performance measurement indicators

\begin{tabular}{lllll}
\hline City & NUTS0 & NUTS1 & NUTS2 & NUTS3 \\
\hline Maribor & Slovenia & SI0: Slovenia & SI02: West Slovene region & SI012 Podravje region \\
\hline Pleven & Bulgaria & BG3: North I SE Bulgaria & BG31: Northwest & BG314 Pleven \\
\hline Linz & Austria & AT3: Westösterreich & AT31: Oberösterreich & AT312 Linz-Wels \\
\hline Erfurt & Germany & DEG: Thüringen & DEG0: Thüringen & DEG01 Erfurt \\
\hline Trieste & Italy & ITH: North-East & ITH4: Friuli-Venezia Giulia & ITH44 Trieste \\
\hline Brugge & Belgium & BE2: Vlaams Gewest & BE25: Prov. West-Vlaandeeren & BE251 Arr.Brugge \\
\hline
\end{tabular}

Source: http://ec.europa.eu/eurostat/ramon/nomenclatures

Table 2. Selected cities and the corresponding regions (NUTS classification)

\section{Data structure and categorization}

\subsection{Database}

The database of the research was largely represented by an Urban Audit indicator set for core cities, available as a part of a broader Eurostat collection. The base of data analysis (accessed February 2012) covered 30 countries: the EU-27, along with Turkey, Switzerland, Norway, and 372 urban units (city and the wider urban area) and specific metropolitan areas. The temporal 
span, used in the research, included periods 2010-2012, 2007-2009, and 2003-2006, exceptionally 1999-2002, but only to illustrate the missing measurement in the time series. In addition to Urban Audit, research also implied regional databases of EUROSTAT (appsso.eurostat.ec.europa.eu), and the index of quality of life in each country was defined by using ranking of International Living survey. Taking into account the selection of cities from different countries in terms of validity and international comparability, and to avoid inaccuracies due to diverse methodological approaches, the research additionally incorporated data from the Statistical Office of the Republic of Slovenia (www.stat.si), Austria (Statistik Austria; www.statistik.at), Italy (SISTAN Sistema statistico nazionale; www.sistan.it and www.istat.it), Germany (www.destatis.de), Belgium (statbel.fgov.be), and Bulgaria (www.nsi.bg). Urban Audit database, used in $75.47 \%$ of cases, was followed by Eurostat database with $22.64 \%$ and other data sources $(1.89 \%)$; overall data coverage rate reached $87 \%$. Limitations of the research referred to the missing data; the inclusion of the secondary databases that would otherwise fill out the data gap could be due to the chosen methodology of data collection and evaluation, which will result in the reduced data comparability of data and furthermore between cities within individual indicators. Dropping variables was potentially admissible in cases of minor influence on the dependent variable $(y)$, which, in most cases, proved to be the best choice since it pointed out the problems associated with data collection (listwise/casewise deletion of missing data of the valuation criterion). Options of replacing missing data represented single imputation as the arithmetic mean (overall mean) or multiple imputation methods (e.g., program Amelia II). When using programs of multicriteria decision making (Expert Choice) in research, only indicators without data gaps were evaluated.

\section{Criteria weighting}

\subsection{Determining the weights of indicators: different approaches}

Weighting of indicators emphasized the suitability requirements, with the value of the weight indicating the impact of each criterion on the final goal (objective). Weighting methods are different, are very widely used, and are scalable in many cases applied, where 0 equals the insignificant impact of the indicator, range 1-3 represents a significantly less important indicator, range 4-7 represents a little less important indicator, and range 8-10 represents an equally important indicator in terms of the relative importance with the most important criteria $[1,30]$. In the case of a clearly defined target group, the determination of relevant weightings is also possible by using the questionnaire survey. Stepwise methods label 5-6 as low importance indicators (complementary, supplementary, secondary, incidental, indirect, and no impact), 7-8 as average significant indicators (imperative, mandatory, or required indicator), and $9-10$ as high importance indicator (fundamental, essential, decisive, definitive, and guidelines).

The weighting is also possible with the prioritization of functional variables in the form of a matrix (CICAPSO, 2012), consisting of the power zone with a low dependence of variable $x$ (abscissa axis) and a high impact $y$ (ordinate axis); connection zone, linked with a high depend- 
ence of $x$ and a high influence of $y$; isolated zone, with a low dependence of $x$ and a low impact of $y$; and exit zone, with the high dependence of $x$ and low impact of $y$. The weightings in the power zone are the most important, influential, and less dependent; those identified in the connection zone are often associated with conflicts, relevant by influence, but at the same time very dependent. In the isolated zone, the weights with low or no dependence and influence on other, mostly useful at the end of the evaluation, can be found. As last in the exit zone, weights of minor importance and high dependence, with the purpose for understanding the power and connection zone, are located.

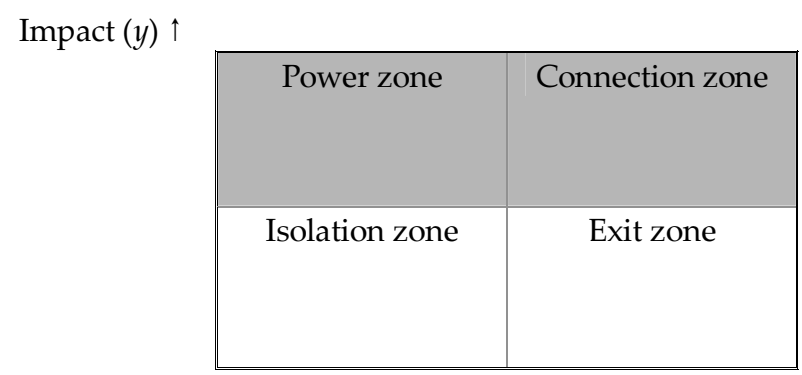

Source: [9].

Dependence $(x) \rightarrow$

Table 3. Matrix of weights.

Conceptualization of the system of indicators in research was based on the relevance of the individual categories, taking into account the relative importance of weights on the objective measurement: performance development of selected cities. Considering that the system of indicators represents a baseline tool, the weighting depends on the purpose of the decision maker in terms of defining the specific goal of measuring and monitoring. Comparability of the indicators was previously reached by using available, credible databases (Section 5.1).

In the case of the desk research data collection, the $z$-transformation method, which provides standardization and data aggregation, is suggested. In the concept of the "smart city," establishing a standardized indicator value of each city was followed by determining the weightings in accordance with the coverage degree of indicators (lower weightings indicated that values of indicators were not covering all cities). Indicators were assumed to have equal influence on a particular category (currently 70 cities with 74 indicators represent $87 \%$ level of coverage). Indicators of "smart economy" include innovative spirit (3 indicators with a weight of 0.17), entrepreneurship ( 2 indicators with a weight of 0.17 ), economic image/trademark (1 indicator with a weight of 0.17$)$, productivity ( 1 indicator with a weight of 0.17$)$, and flexibility of labor market ( 2 indicators with a weight of 0.17 ). "Smart mobility" indicators represent the following: local accessibility (3 indicators with a weight of 0.25$)$, (inter-)national accessibility ( 1 indicator with a weight of 0.25 ), availability of ICT infrastructure ( 2 indicators with a weight of 0.25 ), and sustainable, innovative, and safe transport systems ( 3 indicators with a weight of 0.25). Among indicators of "smart environment," the attractiveness of natural conditions (2 
indicators with a weight of 0.25 ), pollution ( 3 indicators with a weight of 0.25 ), environmental protection ( 2 indicators with a weight of 0.25$)$, and sustainable resource management (3 indicators with weighting of 0.25 ) are considered. Indicators of the category "smart people" include the following: level of qualification (4 indicators with a weight of 0.14 ), affinity to lifelong learning ( 3 indicators with a weight of 0.14 ), social and ethnic plurality ( 2 indicators with a weight of 0.14 ), flexibility ( 1 indicator with a weight of 0.14 ), creativity (1 indicator with a weight of 0.14), cosmopolitanism/open-mindedness (3 indicators with a weight of 0.14), and participation in public life ( 2 indicators with a weight of 0.14 ). Indicators of the category "smart life" represent the following: cultural facilities ( 3 indicators with a weight of 0.14 ), health conditions ( 4 indicators with a weight of 0.14 ), individual safety ( 3 indicators with a weight of 0.14 ), housing quality ( 3 indicators with a weight of 0.14 ), education facilities ( 3 indicators with a weight of 0.14 ), touristic attractiveness ( 2 indicators with a weight of 0.14 ), and social cohesion ( 2 indicators with a weight of 0.14 ). Participation in decision-making processes (4 indicators with a weight of 0.33 ), public and social services ( 3 indicators with a weight of 0.33 ), and transparent governance ( 2 indicators with a weight of 0.33 ) form the category of "smart regulation" indicators.

By determining the adequate weighting, the research in this section also considered weighting of indicators, measuring the competitiveness of cities in the context of the knowledge economy, where the greatest importance was given to categories of quality of life (weighting 0.20 ) and knowledge base (weighting 0.20), followed by the categories of innovation (weighting 0.10 ) accessibility (weighting 0.10), urban diversity (weighting 0.10), productivity (weighting 0.10), and social connectivity (weighting 0.10 ). Areas of agglomeration and economic heritage were defined with a weight of 0.05 [62].

With reference to quoted concepts, the largest weighting importance in research was assigned to the categories of quality of life, environment, lifelong learning, development of information, and communication technology and city brand (weighting 0.20 ), followed by labor market, productivity, entrepreneurship, innovation, and mobility (weighting 0.15). The importance of social cohesion, governance, and urban diversity was defined with a weight of 0.10 ; a minimum effect on the performance development measurement was attributed to demographic categories (weighting 0.05). Weightings for individual categories of indicators $1-53$ are presented in Table 1.

In terms of weighting credibility, the study also considered Mercer's classification and evaluation indicators (weights) of quality of life (Quality of Living Report) in European cities (Urban Audit database, benchmarking analysis of 246 European cities). The study of 10 dimensions, namely, (1) quality of life, economic environment, (2) political and social environment, (3) sociocultural environment, (4) health and medicine, (5) schools and education, (6) public services and transport, (7) recreation, (8) consumer goods, (9) housing possibilities, (10) natural environment, and 39 quality of life indicators showed a certain degree of area similarity to the selected indicators' system in the research (demography, labor market, economy, quality of life, society, culture and leisure activities, and R \& D). Mercer's weights in specific areas are defined as follows: political and social environment (weighting 0.283); economic environment (0.048), which includes employment in the services sector (NACE 
classification J-K); area of health and medicine (0.229), which also includes life expectancy in years; schools and education (ISCED with weight of 0.041); public services and transportation (0.157), including air passengers using nearest airport; recreation (0.109); housing possibilities (0.062); and the natural environment (0.071), including rainfall [33].

\section{Multiattribute decision models and system of indicators' simulation with computer-based programs}

\subsection{Methods for decision support}

After the system of indicators for monitoring performance development of the city had been set, the purpose of the study was to enable quality decision making in a systematic, organized manner. The preparation of scenario and the selection of the chosen strategy involved either verbal or numerical representation of inputs in principle, which required the inclusion of artificial intelligence. Multicriteria models represent a useful tool to support decision making in complex decision situations, where a large number of factors and variants affect the final decision. Supporting software tools in designing a decision model evaluate variants and offer a range of different analyses for detailed decision's verification and justification [6, 7].

Systematic decision-making processes for supporting smart decisions should be based on combining normative theories and cognitive aspects, forming an integral part of decision making in practice. According to [23], problem solving can be done in several ways: intuitively, routinely - by adopting the past used procedures, or random selection - by systematic rational thinking using relevant information. In the latter, the decision maker measures the values of alternatives by each individual criterion or by multiple criteria simultaneously [11].

The general approach of decision analysis originates from axioms of the game theory, by John von Neumann and Oskar Morgenstern. The main steps represent problem structuring, estimating the likelihood of possible outcomes, determining their utility, evaluating alternatives and selecting strategies. Briefly, the process of multiattribute decision making involves problem identification and its structuring, the model building, and activities of problem solving planning, wherein[5] have foreseen also returning from each following to the previous phase [11].

The major role in decision making according to multiple criteria goes to classification or ranking. Identifying the decision maker's relative importance of each criterion can be expressed as a priority (the criterion is more important than the other) or weighting, which declares the relative importance of the various criteria [10].

In the research, comparison of the cities' development performance was carried out using the analytic hierarchical process (AHP) method, developed by Thomas L. Saaty. In accordance with the theory of AHP, multicriteria problems are initially presented in the form of a hierarchical model. Several papers demonstrated the AHP efficiency in different areas [19, 21, 26, 31, 32, 37, 51, 52, 59, 64]. The oldest reference we have found dates from 1972 [41]. After this, a paper in the Journal of Mathematical Psychology [42] precisely described the method [26]. 
The method's basis represent pairwise comparisons of the two criteria at the same level in relation to the element on the next (higher) level. In order to help the decision maker to provide the pairwise comparisons, Saaty created a 9-point intensity scale of importance between pair of elements (Table 4). If the estimation a.., is assigned to criterion $i$ in comparison with $j$, then to criterion $j$ when compared with $i$, the reciprocal value is assigned $[44,48,50]$.

Weighting criteria and priorities to alternatives are not assigned directly by decision makers; they are calculated from the judgments, entered by comparing the importance of criteria and preferences of alternatives in pairs in verbal, graphic, or numerical manner [10].

A top-down approach of AHP method leads from the goal to the alternatives, while the bottomup approach represents expression of judgments about alternatives before expressing judgments on the criteria [16, 38].

\begin{tabular}{cl}
$\begin{array}{l}\text { Intensity of } \\
\text { importance }\end{array}$ & Definition/explanation \\
\hline 1 & $\begin{array}{l}\text { The criteria are equally important; alternatives are equally preferred/equally } \\
\text { contribute to the objective. }\end{array}$ \\
\hline 3 & $\begin{array}{l}\text { Experience and judgment slightly favor one activity over another. The criterion is moderately/ } \\
\text { slightly more important than the comparable criterion. }\end{array}$ \\
\hline 5 & $\begin{array}{l}\text { Experience and judgment strongly favor one activity over another. The criterion is strongly more } \\
\text { important than the comparable criterion; alternative is strongly more preferred. }\end{array}$ \\
\hline 9 & $\begin{array}{l}\text { Very strong or demonstrated importance. Criterion is powerfully more important than the } \\
\text { more preferred, highest possible favoring of one criterion over another. }\end{array}$ \\
\hline
\end{tabular}

Source: [10].

Table 4. The fundamental scale for pairwise comparisons.

Evaluating the importance of criteria and preference of alternatives, according to individual criteria, includes a criteria importance estimation by setting the appropriate weights; for AHP, the sum of the weights for each group of criteria is considered equal to 1 (hierarchical manner of determining the weights).

Attributes (criteria at the lowest hierarchical level) are represented as follows [10]:

$z_{1}, z_{2}, \ldots, z_{k}$, while

$w_{1}, w_{2}, \ldots, w_{k} w_{k}$ represent the weights.

It is assumed that:

$$
w_{1}+w_{2}+\ldots w_{k}=1 ; w_{m} \geq 0 ; m=1,2, \ldots, k,
$$


$w=\left[w_{1} w_{2} \ldots w_{k}\right]^{T}$ and

$$
a_{i j}=\frac{w_{i}}{w_{j}} ; i=1,2, \ldots, k ; j=1,2, \ldots, k, \text { meaning: }
$$

attribute $z_{i}$ is $a_{i j}$ - times as important as the attribute $z_{j}$.

By calculating the values of alternatives with respect to each attribute is:

$v_{m}\left(A_{i}\right)$ value of alternative $A_{i}$ with respect to the attribute $z_{m}$ and

$v_{m}\left(A_{j}\right)$ value of alternative $A_{j}$ with respect to the attribute $z_{m}$.

Given n objects, e.g., attributes or alternatives, we suppose that the decision maker is able to compare any two of them. In preference modelling, this assumption is called comparability. For any pairs $(i, j) ; i, j=1,2, \ldots, n$, the decision maker is requested to tell how many times the $i$-th object is preferred (or more important) than the $j$-th one, which result is denoted by $a_{i j}$ :

$$
a_{i j}=\frac{v_{m}\left(A_{i}\right)}{v_{m}\left(A_{j}\right)} ; i=1,2, \ldots, n ; j=1,2, \ldots, n,
$$

ratios of values of alternatives, indicating that alternative $A_{i}$ is with respect to attribute $z_{m} \mathrm{a}_{i j}$ times as good as alternative $\mathrm{A}_{j}[10]$.

By pairwise comparison, regarding the importance of the criteria, a square matrix $A$ whose elements are the ratios of $a_{i j}$ criteria weights $[10,15,22]$ can be composed as follows:

$$
A=\left[a_{i j}\right]
$$

The characteristics of the matrix are as follows [10]:

$$
\begin{gathered}
a_{i j}>0, a_{i j}=\frac{1}{a_{j i}}, a_{i i}=1 \text { and } \\
a_{i m} a_{m j}=a_{i j}, i, m, j=1,2, \ldots, k .
\end{gathered}
$$

The consistency of matrix is confirmed in the case of:

$$
A w=k w
$$


In practice, the consistency is usually incomplete; therefore,

$$
A w=\lambda w,
$$

where $\lambda$ represents the eigenvalue and $w$ the eigenvector of the matrix $A$, which belongs to the eigenvalue $\lambda$. Only if $k=\lambda$, the consistency of the decision maker is complete. $[5,10]$ defined a measure of consistency or consistency index (CI) as follows:

$$
\mathrm{CI}=\frac{\lambda \max -k}{k-1}
$$

where $\lambda_{\max }$ represents the principal eigenvalue and $k$ the size of matrix.

The calculation of the consistency of the decision maker is defined as follows [10, 50]:

$$
C R=\frac{C I}{R}
$$

where $C R$ is the consistency ratio, and $R$ represents the random consistency index.

The consistency index is compared to a value, derived by generating random reciprocal matrices of the same size, to give a consistency ratio (CR), which is meant to have the same interpretation, regardless the size of the matrix. The comparative values from random matrices are as follows for $3 \leq k \leq 10$ [5].

\begin{tabular}{ccccccccc}
\hline Size of matrix $k$ & 3 & 4 & 5 & 6 & 7 & 8 & 9 & 10 \\
\hline $\begin{array}{c}\text { Comparative value } \\
R\end{array}$ & 0.58 & 0.90 & 1.12 & 1.24 & 1.32 & 1.41 & 1.45 & 1.49 \\
\hline
\end{tabular}

Source: [42, 5 and [10].

Table 5. Comparative values.

A consistency ratio of 0.1 or less is generally considered to be acceptable. Evaluating the importance of the criteria results $[15,22]$ in:

$$
\left[\begin{array}{ccc}
a_{12} & a_{13} & a_{1 k} \\
& a_{23} & a_{2 k} \\
& & a_{k-1, k}
\end{array}\right]
$$


Advantages of the method include (1) unity (a single, comprehensive, and flexible model for unstructured problems), (2) interdependence (of the system elements), (3) complexity (combining deductive and systemic approaches to problem solving), (4) hierarchical structure, (5) measurement (descriptive expressed properties by corresponding scale), (6) consistency (foresees the consistency of judgments for determining priorities), (7) synthesis, (8) exchange (considers relative priorities and enables selection of the best alternative), (9) judgment and consensus (combining various judgments in the result), and (10) reiteration (allows reconsideration of the problem definition, correction of judgments, and improved understanding of the problem) [48].

[10] classifies activities of solving the multicriteria decision-making problem as (a) structuring the problem (criteria tree), (b) determining weights of the criteria, (c) calculating aggregated values of alternatives, (d) alternatives ranking, and (e) sensitivity analyses.

In accordance with the method of AHP, by using leading supporting software Expert Choice, research compared previously selected cities (Table 1), with the aim to identify the performance of urban development, using the criteria (indicators) and alternatives (variants), arranged in a hierarchical model. Synthesis results replied to the question of the performance development effectiveness of selected national city compared to chosen European cities.

\section{Problem modeling}

The structuring of a decision making process started by defining the global objective (goal setting) - selecting the most development successful among six preferential cities, followed by entry of criteria, which represent six areas: (1) demography, labor market, and economy; (2) quality of life; (3) society, culture, and leisure activities; (4) research and development; (5) accessibility, urban networks, and international connectivity; and (6) management of sustainable resources. The process continued with defining alternatives (cities: Maribor, Pleven, Linz, Erfurt, Trieste, and Brugge) and structuring the problem-specific criteria and subcriteria entry.

The chosen indicators were derived from the set of 53 indicators (Table 1 ), where selection was narrowed to 24 indicators $(3,6,7,9,13,15,20,22,23,25,26,31,33,38,39,42,43,44,45,46,47$, 48,50 and 52) due to the availability and completeness of data (no data gaps) for all criteria and all alternatives, thus providing credible values regarding to the attribute and the global objective. In addition to the presented weighting approaches (Chapter 6), the importance of each criterion in comparison with the importance of other criteria of an area (1 to 6, a total of 24 indicators $=$ criteria) following the concept of classifying indicators (Table 3 ) was introduced. Weights in the power zone are the most important and influential (indicators: 3, 7, 15, 22, 25, $26,42,43,45,46)$, those identified in the connection zone are important regarding the influence, but at the same time significantly dependent from others (indicators: 9, 20, 31, 39, 44, 47, 48), while weights located in the isolated zone, with small influence above others, are the most useful at the end of the estimation (indicators: 6, 13, 23, 33, 38, 50, 52).

Figure 1 demonstrates the process of problem structuring using criteria tree. Weights are based on available data and methods for calculating the factor weights (Saaty). At each node of the 


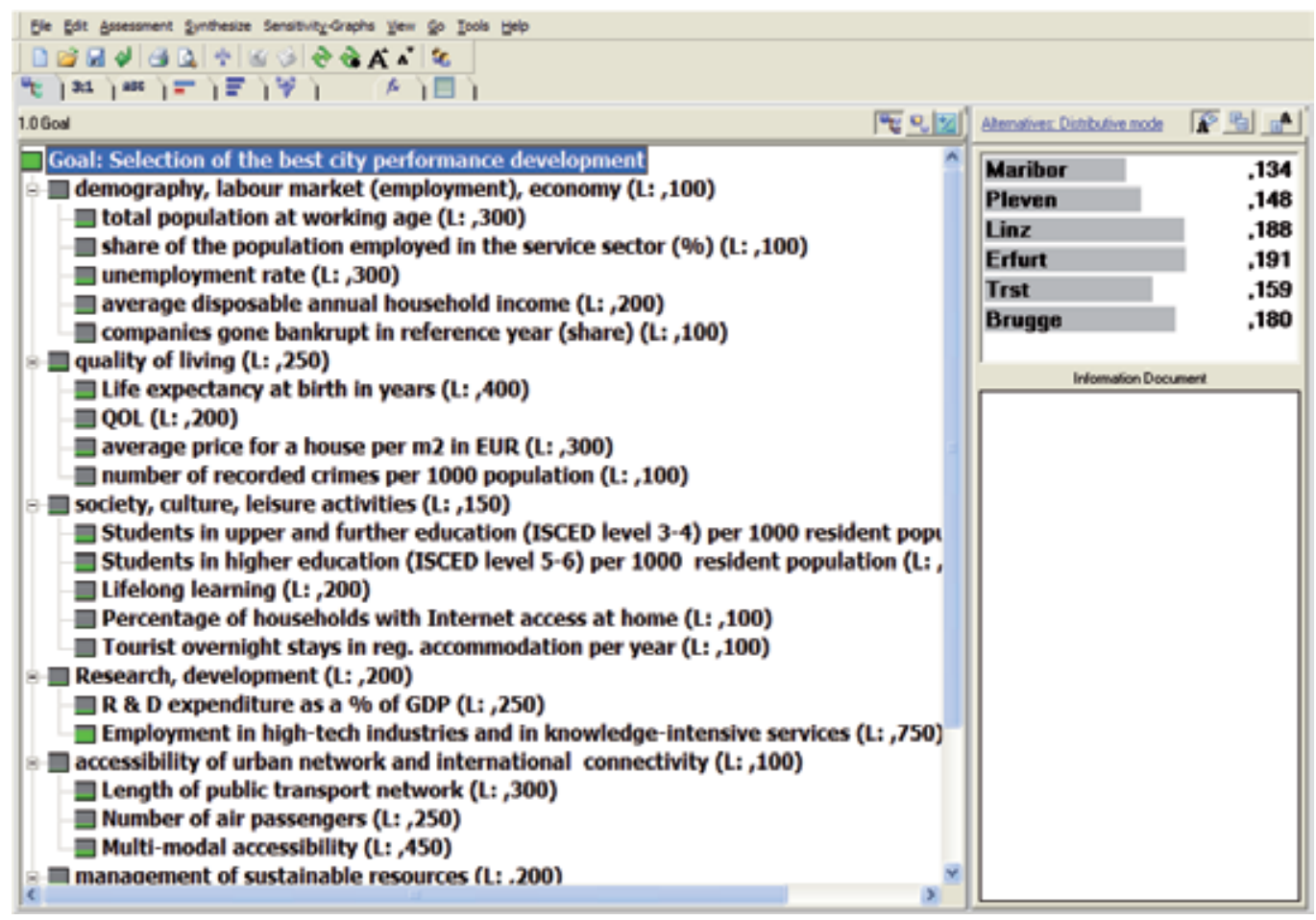

Source: Expert Choice processing of collected data.

Figure 1. Structuring the problem (criteria tree).

hierarchy, a matrix will collect the pairwise comparisons of the decision maker for the criteria and subcriteria, e.g., subcriterion of the total working population is three times more important than the proportion of the population employed in the service sector, equally important as the unemployment rate, and 1.5-times more important than average disposable income (Figure 2).

The total working population includes employment not only in the services but also in other sectors (agriculture, hunting, forestry, fishing, mining, manufacturing, construction, etc.); consequently, the importance assigned is greater. Compared with the rate of unemployment, its importance is equal, owing to the fact that the entire working population and unemployment rate represent an important factor of social inclusion. Confirming the strength of the importance judgment, theoretical principles define "labour force participation rate," expressed as [3]:

Pop = total population LF = labor ("labour force") $=\mathrm{U}+\mathrm{E}$

$\mathrm{LF}_{\text {pop }}=$ total working population $\mathrm{p}=$ participation rate $=\mathrm{LF} / \mathrm{LF}_{\text {pop }}$

(males and females 15-64)

$\mathrm{E}=$ number of employees ("employed") $\mathrm{e}=$ rate of employment $=\mathrm{E} / \mathrm{LF}$

$\mathrm{U}=$ number of unemployed persons $\mathrm{u}=$ unemployment rate $=\mathrm{U} / \mathrm{LF}$. 


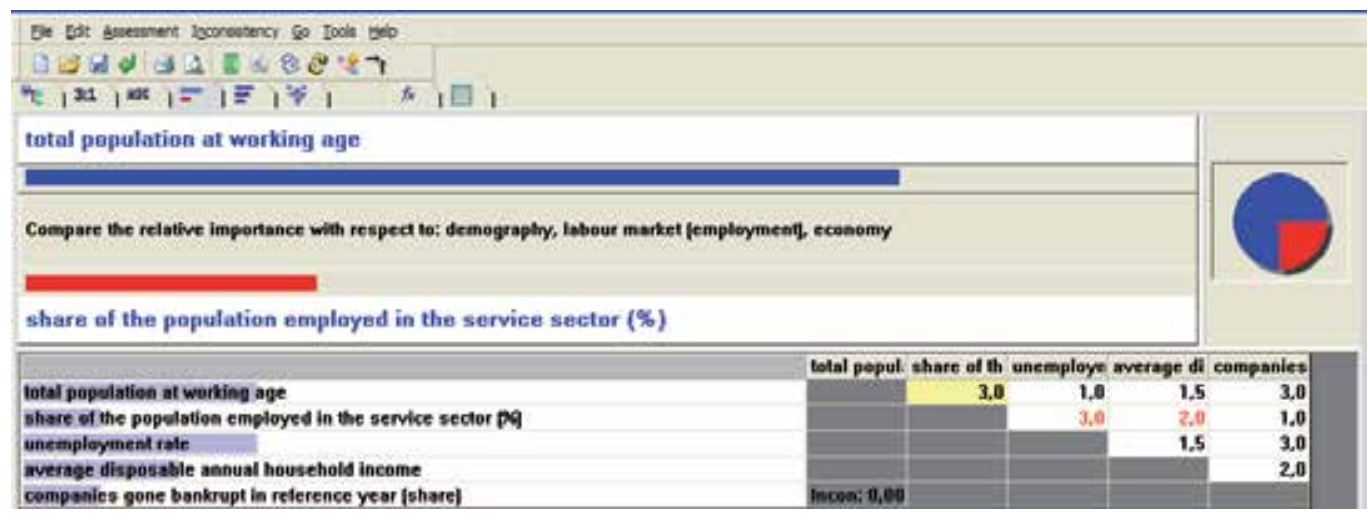

Source: Expert Choice processing of collected data.

Figure 2. Comparison matrix of the first node (graphical scale).

The increase of the unemployment rate can be simultaneously reflected by the increase of employment, e.g., if a larger number of new workers are entering the workforce segment, but only a small fraction actually becomes employed, an increase in the number of unemployed exceeds the growth in employment. The rate of presence in the labor market is therefore a key component of long-term economic growth, almost as important as productivity [3].

One of the AHP's strengths is the possibility to evaluate quantitative as well as qualitative criteria and alternatives on the same preference scale of nine levels, also verbal (Figure 3). The subcriterion - number of students in upper and further education ISCED 3-4 per 1000 resident population, is according to the criterion of society, culture, leisure activities, equally important as subcriterion - number of students in higher education ISCED 5-6 per 1000 resident population. The strength of the given importance judgment is based on the results of the research about skills, needed in Europe by focusing on the 2020 objectives, carried out by European Centre for the Development of Vocational Training in 2008.

Defining future employment opportunities, the research highlighted the importance of qualifications ISCED 3-4 and 5-6 against the others (trend of "replacement demand"). Forecasts include 105 million new jobs by 2020 (2006-2020); among them, 41 million require a high level of qualification (ISCED 5-6). The existing qualification structure must be, in accordance with quoted, necessarily transformed as the foreseen remaining 55 million new jobs expectedly require medium-level education (ISCED 3-4), which traditionally include vocational qualifications, while less than 10 million new jobs include lower qualification levels (CEDEFOP, 2008, p. 13).

Pairwise numerical criteria comparisons (Figure 4) showed that criterion employment in hightech industries and knowledge-intensive sectors (NUTS 2) is three times more important than the R \& D expenditure in \% of GDP (NUTS 2). The strength of the criterion importance judgment was expressed on the basis of the United Nations Educational, Scientific, and Cultural Organization (UNESCO) survey measuring R \& D personnel, carried out by Institute for Statistics in 2009. Salaries of researchers in high-tech and knowledge-intensive sectors 


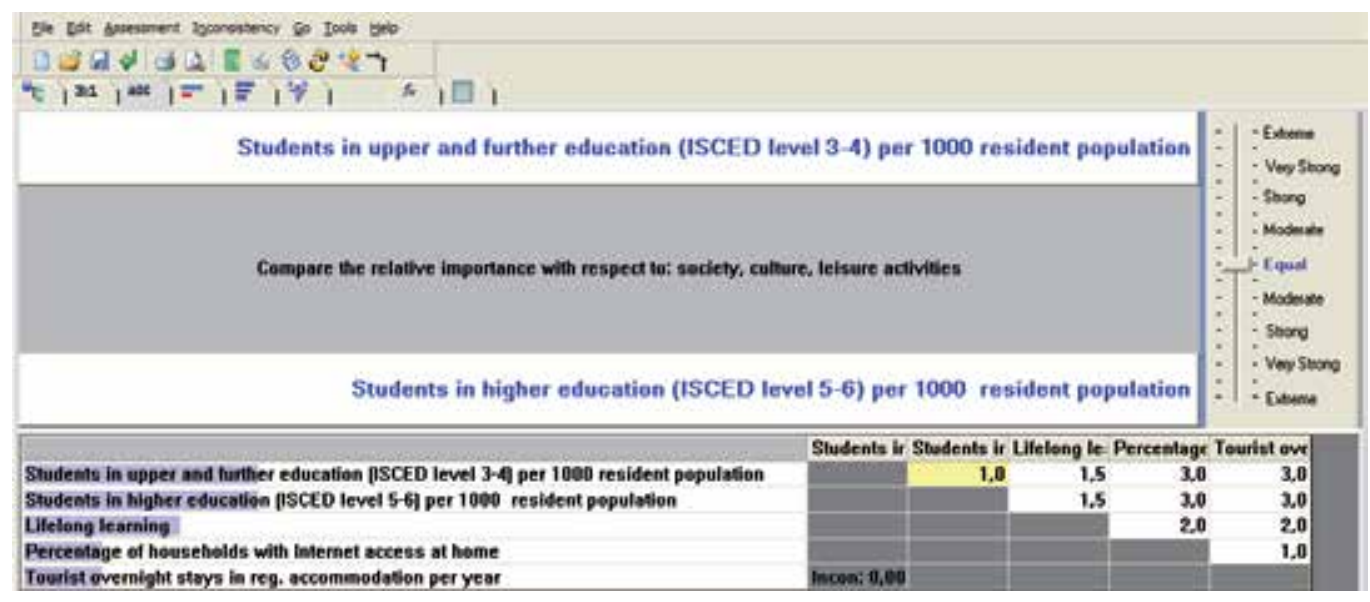

Source: Expert Choice processing of collected data.

Figure 3. Judgment scale (verbal).

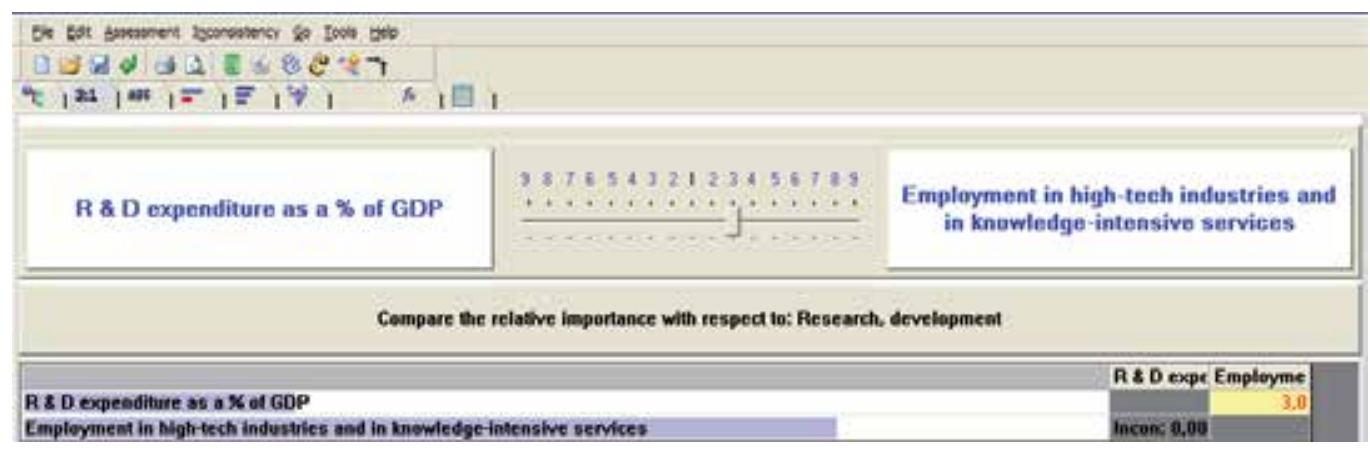

Source: Expert Choice processing of collected data.

Figure 4. Judgment scale (numerical).

represent a significant part of expenditures for research and experimental development, taking into account the total $\mathrm{R} \& \mathrm{D}$ personnel by sector and occupation as well as the level of qualification and full-time employment ("FTE method"). The consideration of the head count (HC) methodology, half-, part-, and full-time FTE, consequently led to overestimated expenditure (research and experimental development) in \% of GDP, which again reinforced the validity of the criterion importance judgment (UNESCO, 2009). The matrix was shown as perfectly consistent (inconsistency ratio $=0.00$ ).

When calculating the final value of alternatives, in the synthesis, where local priorities change to global, the additive model is used in a research. Expert Choice allows two modes of synthesis: (a) the distributive (the sum of the priorities on each level equals 1), used in the case of the desired alternative selection, better in relation to the other, and (b) an ideal mode, used in the case of obtaining only the best variant, regardless to any other [10]. If the priorities are 
already known, the distributed mode is the only approach, which retrieves these priorities. Introducing or removing (Troutt, 1988) a copy [4] or a near copy [17] of an alternative results in a rank reversal of the appeared alternatives. The latest was subject to criticism [17, 27, 28, 56] but also legitimization [24, 40, 43, 46, 47, 49, 59]. In accordance to Wang and Luo (2009), the rank reversal is not unique to AHP but to all additive models [29]. In this study, the distributive mode was selected; adding or removing alternatives was reflected in the adjustment of ratios and rankings.

The final values of alternatives to the objective (main goal) of "the best city performance development" (Figure 5) were as follows: Erfurt (0.191), Linz (0.188), Brugge (0.180), Trieste (0.159), Pleven (0.142), and Maribor (0.134).

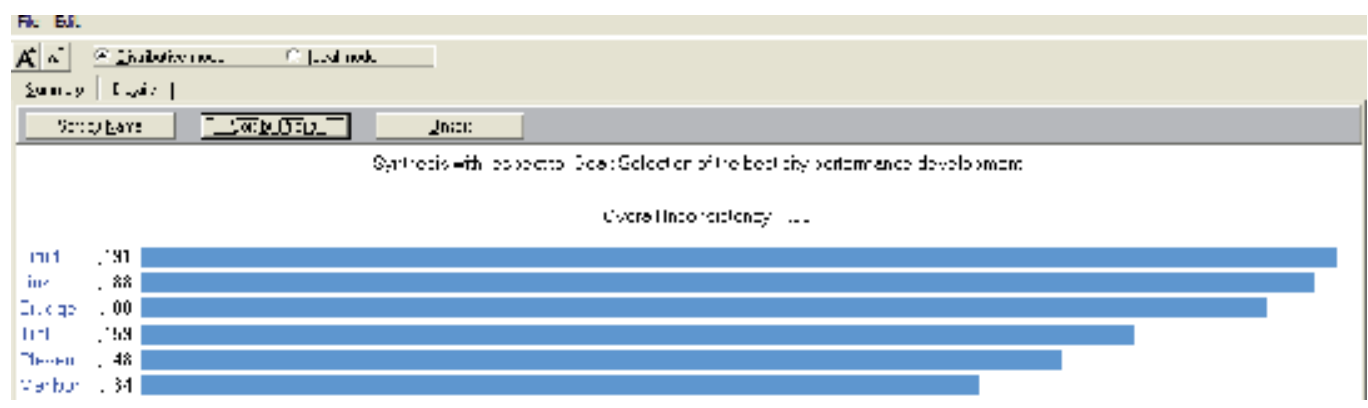

Source: Expert Choice processing of collected data.

Figure 5. Selection of the best city performance development: the final values of alternatives.

\subsection{Interpretation of results}

By analyzing the evaluation results (Table 6) using the criterion of demography, labour market - employment, economy (and its subcriteria), the city of Maribor reached a value of 0.120 , reflecting the weakest result in comparison with other cities, with $57.97 \%$ realization of "the best city performance development" main goal, as compared to Linz. Trieste reached this objective by 95.17 , Brugge by 89.37 , and Erfurt by $67.63 \%$. According to the criterion quality of life, Maribor reached a rating of 3 by $59.84 \%$ realization of the main objective; its position worsened with a rating of 5 according to the criterion society, culture, and leisure activities (56.83\% of main goal accomplishment). Improved classification (rating 4 ) was achieved in the field of research and development. However, by the criteria of accessibility of urban networks and international connectivity $(46.70 \%$ as compared with the leading Trieste and the value of 0.212 ) and management of sustainable resources $(51.11 \%)$, the weakest goal realization was recorded. Considering all quoted (sub)criteria of areas 1-6, the latter was most successfully reached by the city of Erfurt, followed by Linz, Brugge, Trieste, and Pleven, with last rating belonged again to Maribor (realization of $70.16 \%$ ).

With the purpose of determining the stability of the resulting solutions [12], respectively, the sensitivity of the result by varying criteria weights (the latter identifies in changing values and the order of the alternatives), the sensitivity analysis in forms of "performance," "dynamic" 


\begin{tabular}{|c|c|c|c|c|c|c|}
\hline Scope/rating (ratings) & 1 & 2 & 3 & 4 & 5 & 6 \\
\hline $\begin{array}{c}\text { Demography, labor market- } \\
\text { employment economy }\end{array}$ & $\begin{array}{l}\text { Linz } \\
(0.207)\end{array}$ & $\begin{array}{c}\text { Trst } \\
(0.197)\end{array}$ & $\begin{array}{l}\text { Brugge } \\
(0.185)\end{array}$ & $\begin{array}{l}\text { Pleven } \\
(0.151)\end{array}$ & $\begin{array}{l}\text { Erfurt } \\
(0.140)\end{array}$ & $\begin{array}{c}\text { Maribor } \\
(0.120)\end{array}$ \\
\hline Quality of life & $\begin{array}{l}\text { Pleven } \\
(0.249)\end{array}$ & $\begin{array}{l}\text { Brugge } \\
(0.220)\end{array}$ & $\begin{array}{l}\text { Maribor } \\
(0.149)\end{array}$ & Erfurt (0.142) & Trst (0.133) & $\operatorname{Linz}(0.106)$ \\
\hline $\begin{array}{c}\text { Society, culture, leisure } \\
\text { activities }\end{array}$ & Linz $(0.271)$ & $\begin{array}{l}\text { Brugge } \\
(0.184)\end{array}$ & $\begin{array}{l}\text { Erfurt* } \\
(0.155)\end{array}$ & $\operatorname{Trst}^{*}(0.155)$ & $\begin{array}{l}\text { Maribor } \\
(0.154)\end{array}$ & Pleven (0.081) \\
\hline Research and development & $\begin{array}{l}\text { Erfurt } \\
(0.283)\end{array}$ & $\operatorname{Linz}(0.218)$ & Trst (0.150) & $\begin{array}{c}\text { Maribor } \\
(0.142)\end{array}$ & Brugge (0.132) & Pleven (0.075) \\
\hline $\begin{array}{l}\text { Accessibility of urban networks } \\
\text { and international connectivity }\end{array}$ & Trst (0.212) & $\begin{array}{l}\text { Pleven } \\
(0.201)\end{array}$ & $\operatorname{Linz}(0.171)$ & Erfurt (0.165) & Brugge (0.153) & $\begin{array}{l}\text { Maribor } \\
(0.099)\end{array}$ \\
\hline $\begin{array}{l}\text { Management of sustainable } \\
\text { resources }\end{array}$ & $\begin{array}{l}\text { Erfurt } \\
(0.225)\end{array}$ & $\operatorname{Linz}(0.200)$ & Brugge (0.184) & Trst (0.158) & Pleven (0.118) & $\begin{array}{c}\text { Maribor } \\
(0.115)\end{array}$ \\
\hline $\begin{array}{l}\text { Total } 1-6 \text { to the objective of "the } \\
\text { best city performance } \\
\text { development" }\end{array}$ & $\begin{array}{l}\text { Erfurt } \\
(0.191)\end{array}$ & $\operatorname{Linz}(0.188)$ & Brugge (0.180) & Trst (0.159) & Pleven (0.148) & $\begin{array}{l}\text { Maribor } \\
(0.134)\end{array}$ \\
\hline
\end{tabular}

*Rating 3 is shared by Erfurt and Trieste (equal values).

Table 6. Comparison of the evaluation results.

"gradient," "two-dimensional (2D) plot," and "head to head" (between two alternatives) was performed.

Performance sensitivity graph in the Figure 6 indicates which alternatives are better or weaker at a particular criterion (Čančer, 2009), e.g., Erfurt is the best according to the criteria of research and development and sustainable resource management. Pleven is the best according to the criterion quality of life and weakest regarding society, culture, leisure activities, and research and development. Maribor is the weakest in terms of the criteria demography, labour market - employment, and economy; the accessibility of urban networks; and the sustainable resource management. Trieste is the best regarding the accessibility of the urban network.

The gradient analysis enabled to identify influence on the final value of alternatives due to individual criteria weightings alterations [12]. Dynamic sensitivity analysis (Figure 7) indicates the weight increase of the criterion of society, culture, and leisure activities from 0.150 to 0.164 or more for the second-ranked alternative to become the best one.

Head-to-head analysis, by comparing two alternatives, clearly demonstrated the superior one by accomplishing individual criterion and global goal (Čančer, 2009). As apparent from the Figure 6, the city of Pleven was more successful according to the criterion of demography, labor market-employment, economy, quality of life criterion and the criterion of accessibility of urban network, while the city of Maribor indicated better performance according to the criteria society, culture, and leisure activities, as well as research and development. Pleven gathered higher final value, namely, for 0.0144 . 
Analysis of the 2D plot led to identifying the dominated and nondominated alternatives regarding the pair of selected criteria [12]. As shown in Figure 6, according to the criteria of demography, labor market-employment, economy, and quality of life, Linz, Trieste, Brugge, and Pleven represent the nondominated alternatives, while Erfurt and Maribor belong to dominated alternatives.

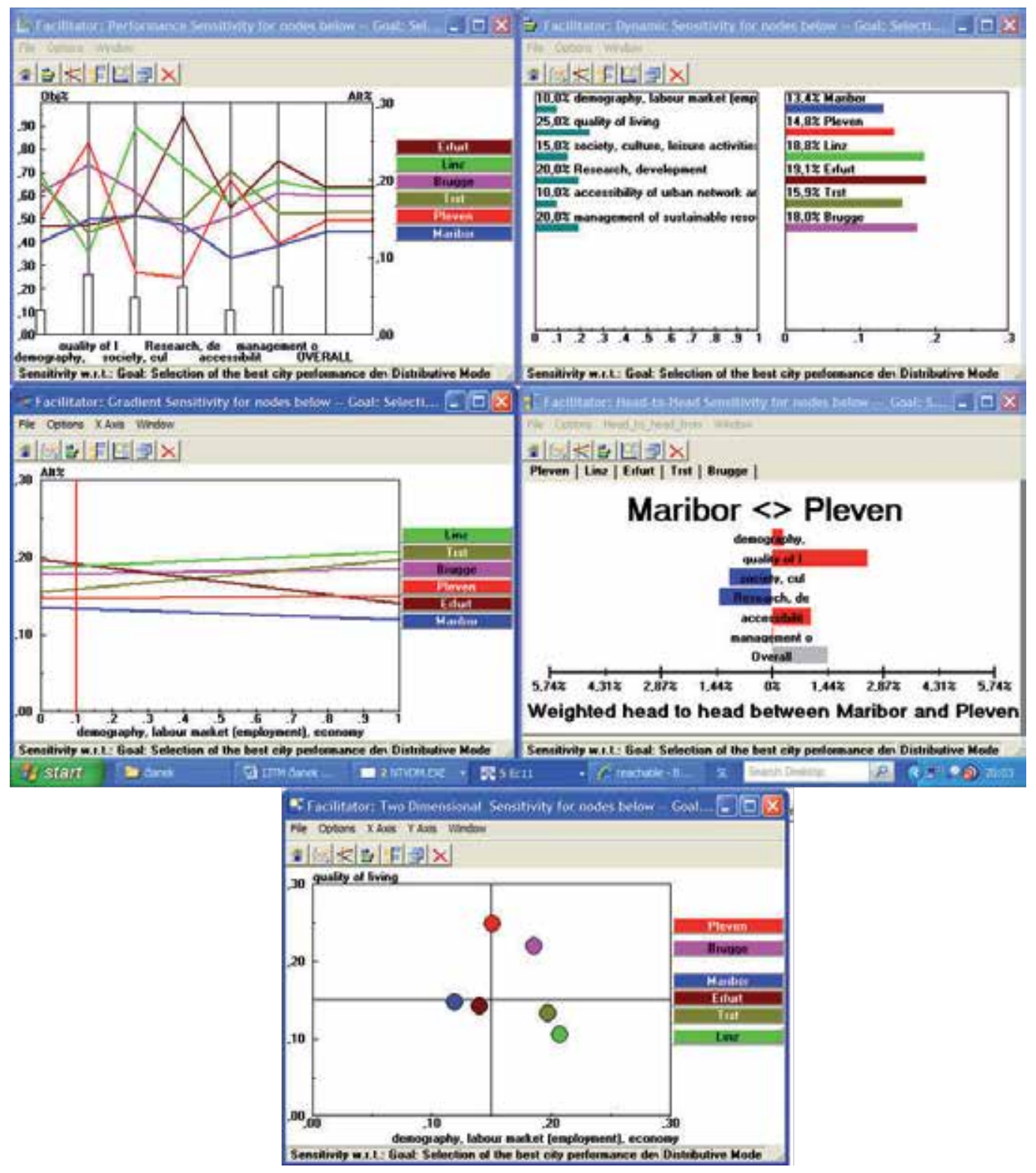

Source: Expert Choice processing of collected data.

Figure 6. Sensitivity analysis. 


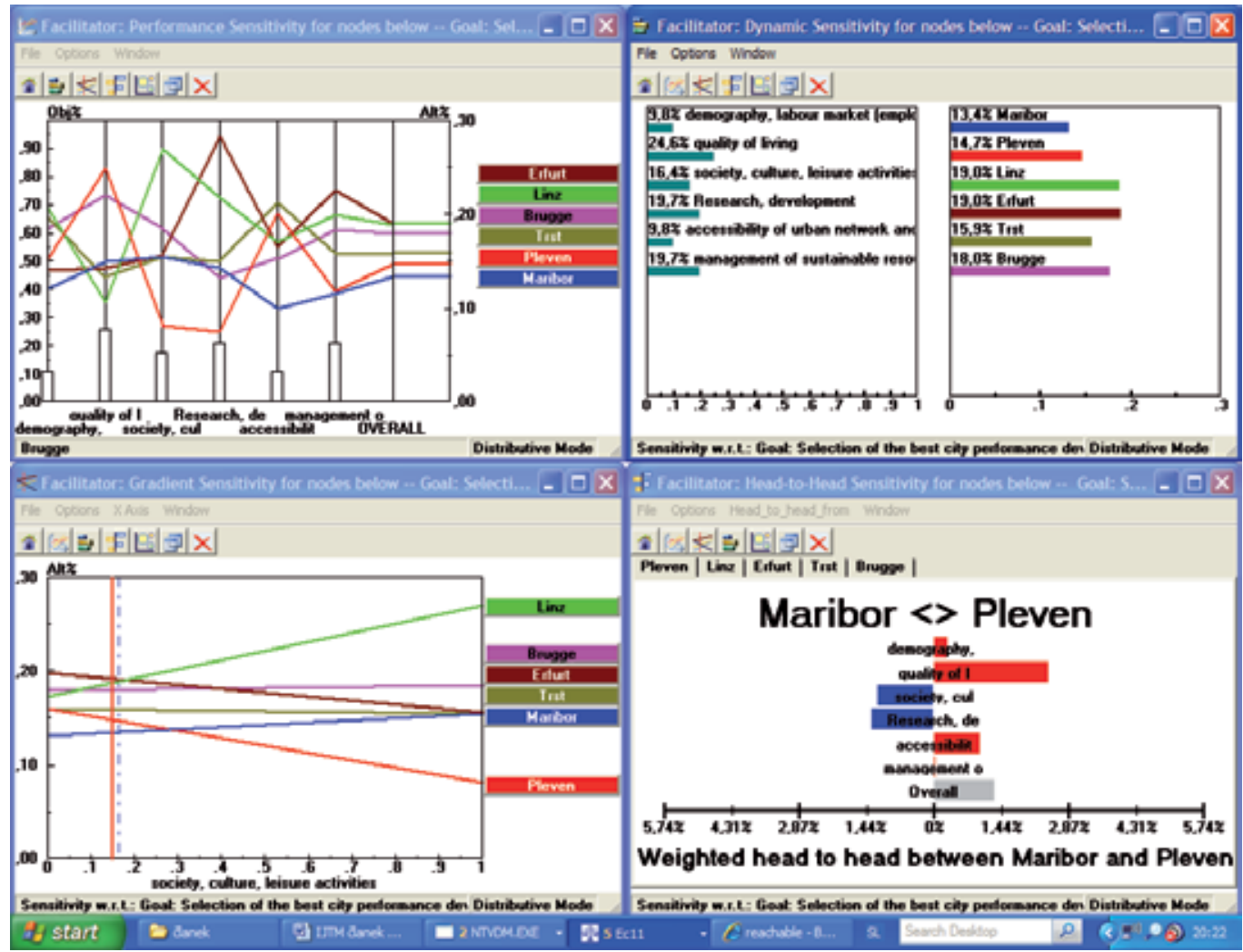

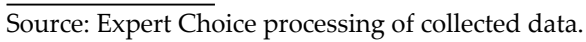

Figure 7. Change in weightings.

\section{Conclusion and future development}

The research aimed at testing the development efficiency of such a methodology for measuring performance success of urban development, which would be useful within the national as well as international (European) comparable city sample. For the testing purposes, the selection of cities followed certain criteria. The determination of adequate measurement indicators, closely associated with evaluation of known methodological concepts (Smart City, city performance, and urban status and sustainability) and relevant databases, resulted in obtained useful tool: a system of 53 selected indicators by field measurement, meaningfully divided into six areas and added categories to enable ranking of comparable medium-sized European cities.

Using AHP and its supporting Expert Choice program tool for quantitative data analysis, which included narrowed set of 24 indicators (no data gaps), the research sought out for the confirmation of selection decision possibility in quoted city sample. AHP evaluation of alternatives provided clarity in multiattribute decision-making process, resulting in ranking 
in accordance with a defined hierarchy and relative importance of decision criteria (criteria tree and weightings). Achieving the best possible decision due to complex problem structure therefore demands a trade-off between prefect modeling and usability of the model.

Meanwhile, advantages of the hierarchical problem modeling included the possibility to adopt verbal judgments and the verification of the consistency, Expert Choice incorporated intuitive graphical user interfaces, automatic calculation of priorities and inconsistencies, as well as several ways to process a sensitivity analysis. It has to be pointed out that, beside the traditional application of AHP and supporting software, a new trend in use, namely combining others methods, e.g., neural networks, SWOT analysis, and others, is emerging, as AHP is still part of certain theoretical discussions, resulting from the limitation due to assumed criteria independence and hierarchy problems due to appropriate judgment scale.

\section{Author details}

Jasmina Mavrič ${ }^{*}$ and Vito Bobek ${ }^{2}$

*Address all correspondence to: jasmina.mavric@krs.net

1 Economic institute Maribor, Maribor, Slovenia

2 University of Applied Sciences, FH Joanneum, Graz, Austria

\section{References}

[1] Alanne, K. (2004). Selection of renovation actions using multi-criteria "knapsack" model. Automation in Construction, Vol. 13, No. 3, pp. 377-391.

[2] Bănică, A. (2010). Sustainable urban development indicators case study: Tørgu Ocna Town, Present Environment and Sustainable Development, No. 4, pp. 346-347.

[3] Barth, P. and Heffley, D. (2004). Taking Apart Taking Part: Local Labor Force Participation Rates, University of Connecticut.

[4] Belton, V. and Gear A. (1983). On a Shortcoming of Saaty's method of analytical hierarchies, OMEGA, Vol. 11, No. 3, pp. 228-230.

[5] Belton, V. and Stewart, T.J. (2002). Multiple Criteria Decision Analysis: An Integrated Approach, Kluwer Academic Publishers, Boston.

[6] Bohanec, M. and Rajkovič, V. (1990). DEX: An expert system shell for decision support, Sistemica, Vol. 1, No. 1, pp. 145-157. 
[7] Bohanec, M. and Rajkovič, V. (1995). Večparametrski odločitveni modeli, Organizacija, Vol. 28, No. 7, pp. 427-438.

[8] Callois, J. M. and Aubert, F. (2007). Towards indicators of social capital for regional development issues: the case of French rural areas, Regional Studies, Vol. 41, No. 6, pp. 809-821.

[9] CICAPSO SAC-Centro Internacional de Capacitacion y Soporte. (2012). Metodo de priorizacion de variables basado en matrices [online], www.planificacion.upla.edu.pe/portal/images/REFLEXIONES/METODOPARAPONDERGECYT(conf).pdf (accessed April 3, 2012).

[10] Čančer, V. (2003) Analiza odločanja, Ekonomsko-poslovna fakulteta Maribor, Maribor.

[11] Čančer, V. (2007). Okvirni postopek za večkriterijsko odločanje, Organizacija, Vol. 40, No. 5, pp. A160-A167.

[12] Čančer, V. (2009) Kvantitativne in računalniško podprte metode ustvarjalnega razmišljanja in odločanja, Ekonomsko-poslovna fakulteta, Maribor.

[13] Čančer, V. (2010). Considering interactions among multiple criteria for the server selection, Journal of Information and Organizational Science, Vol. 34, No. 1, pp. 55-65.

[14] Čančer, V. and Mulej, M. (2005). The roles of creative thinking and decision making tools for building knowledge societies [online], https://dspace.jaist.ac.jp/dspace/ bitstream/10119/3962/1/20005.pdf (accessed July 10, 2013).

[15] Čančer, V., Bobek, V. and Korez-Vide, R. (2006). A contribution to the measurement and analysis of the globalization of national economies, Društvena istraživanja, Vol. 15, No. 3, pp. 531-555.

[16] Čančer, V., Knez-Riedl, J. and Podgornik, R. (2003). Presojanje bonitete poslovnih partnerjev z metodologijo AHP, Naše gospodarstvo, Vol. 49, No. 3-4, pp. 286-301.

[17] Dyer, J. (1990). A clarification of "Remarks on the Analytic Hierarchy Process," Management Science, Vol. 36, No. 3, pp. 274-275.

[18] EC. (2011). Cities of tomorrow-challenges, visions, ways forward [online], http:// ec.europa.eu/regional_policy/conferences/citiesoftomorrow/index_en.cfm (accessed April 20, 2013).

[19] Forman, E. and Gass, S. (2001). The analytic hierarchy process - an exposition, Operations Research, Vol. 49, No. 4, pp. 469-486.

[20] Golden, B. et al. (1989). The Analytic Hierarchy Process: Applications and Studies, Springer-Verlag, Heidelberg.

[21] Golden, B. et al. (1989). The Analytic Hierarchy Process: Applications and Studies, Springer-Verlag, Heidelberg. 
[22] Grah, P. (2009). Oblikovanje strateških razvojnih vidikov mest, Ekonomsko-poslovna fakulteta Maribor, Maribor.

[23] Grüning, R. and Kühn, R. (2005). Successful Decision-Making: A Systematic Approach to Complex Problems, Springer, Berlin.

[24] Harker, P. and Vargas, L. (1987). The Theory of Ratio Scale Estimation: Saaty's Analytic Hierarchy Process, Management Science, Vol. 33, No. 11, pp. 1383-1403.

[25] Harker, P. and Vargas, L. (1990). Reply to "Remarks on the analytic hierarchy process," Management Science, Vol. 36, No. 3, pp. 269-273.

[26] Ho, W. (2008). Integrated analytic hierarchy process and its applications-a literature review, European Journal of Operational Research, Vol. 186, No. 1, pp. 211-228.

[27] Holder, R. (1990). Some comment on the analytic hierarchy process, Journal of the Operational Research Society, Vol. 41, No. 11, pp. 1073-1076.

[28] Holder, R. (1991). Response to Holder's comments on the analytic hierarchy process: response to the response, Journal of the Operational Research Society, Vol. 42, No. 10, pp. 914-918.

[29] Ishizaka A. and Labib A. (2009). Analytic hierarchy process and expert choice: benefits and limitations, ORInsight, Vol. 22, No. 4, pp. 201-220.

[30] Kocjančič, B. (2006). Izbira ukrepov obnove stanovanjske zgradbe s pomočjo večkriterijske metode odločanja, Fakulteta za gradbeništvo in geodezijo, Ljubljana.

[31] Kumar, S. and Vaidya, O. (2006). Analytic hierarchy process: an overview of applications, European Journal of Operational Research, Vol. 169, No.1, pp. 1-29.

[32] Liberatore, M. and Nydick, R. (2008). The analytic hierarchy process in medical and health care decision making: a literature review, European Journal of Operational Research, Vol. 189, No. 1, pp. 194-207.

[33] Morais, P., Migueis, V. L. and Camanho, A. S. (2011). Quality of life experienced by human capital: an assessment of European cities, Social Indicators Research. DOI 10.1007/s11205-011-9923-5, Springer Science+Business Media.

[34] Nijkamp, P. (1986). Infrastructure and regional development: a multidimensional policy analysis, Empirical Economics, Vol. 11, No. 1, pp. 1-21.

[35] Niţulescu, D. C. (2000). Indicatori comunitari ai dezvoltørii urbane, Calitatea vieții, Vol. 7, No. 1-4, pp. 71-77.

[36] Oliveira Soares, J., Lourenço Marquês, M. M. and Ferreira Monteiro, C. M. (2003). A multivariate methodology to uncover regional disparities: a contribution to improve European Union and governmental decisions, European Journal of Operational Research, Vol. 145, No.1, pp. 121-135. 
[37] Omkarprasad, V. and Sushil, K. (2006). Analytic hierarchy process: an overview of applications, European Journal of Operational Research, Vol. 169, No. 1, pp. 1-29.

[38] Ornik, J. (2008). Uporaba metod za presojanje bonitete podjetij v banki po več kriterijih hkrati, EPF, Maribor.

[39] Parris, T. M. and Kates, R. W. (2003). Characterizing and measuring sustainable development, Annual Review of Environment and Resources, Vol. 28, No.1, pp. 559-586.

[40] Pérez, J. (1995). Some comments on Saaty's AHP, Management Science, Vol. 41, No. 6, pp. 1091-1095.

[41] Saaty, T. (1972). An eigenvalue allocation model for prioritization and planning. Working paper, Energy Management and Policy Center, University of Pennsylvania.

[42] Saaty, T. (1977). A scaling method for priorities in hierarchical structures, Journal of Mathematical Psychology, Vol 15, No 3, pp. 234-281.

[43] Saaty, T. (1986). Axiomatic foundation of the analytic hierarchy process, Management Science, Vol. 32, No.7, pp. 841-855.

[44] Saaty, T. (1988). The Analytic Hierarchy Process, RWS Publications, Pittsburgh.

[45] Saaty, T. (1990). An exposition of the AHP in reply to the paper "Remarks on the analytic hierarchy process," Management Science, Vol. 36, No.3, pp. 259-268.

[46] Saaty, T. (1991). Response to Holder's comments on the analytic hierarchy process, Journal of the Operational Research Society, Vol. 42, No.10, pp. 909-929.

[47] Saaty, T. (1994). Highlights and critical points in the theory and application of the Analytic Hierarchy Process, European Journal of Operational Research, Vol. 74, No. 3, pp. 426-447.

[48] Saaty, T. (1999). Decision Making for Leaders, RWS Publications, Pittsburgh.

[49] Saaty, T. (2006). Rank from comparisons and from ratings in the analytic hierarchy/ network processes, European Journal of Operational Research, Vol. 168, No. 2, pp. 557570.

[50] Saaty, T. (2008). Fundamentals of Decision Making and Priority Theory with the Analytic Hierarchy Process, Pittsburgh, RWS Publications.

[51] Saaty, T. and Forman, E. (1992). The Hierarchon: A Dictionary of Hierarchies, RWS Publications, Pittsburgh.

[52] Shim, J. (1989). Bibliography research on the analytic hierarchy process (AHP), SocioEconomic Planning Sciences, Vol. 23, No.3, pp. 161-167.

[53] Singh, R. K., Murty, H. R., Gupta, S. K. and Dikshit, A. K. (2009). An overview of sustainability assessment methodologies, Ecological Indicators, Vol. 9, No. 2, pp. 189-212. 
[54] Slottje, D. J. (1991). Measuring the quality of life across countries, Review of Economics and Statistics, Vol. 73, No. 4, pp. 684-693.

[55] Somarriba, N. and Pena, B. (2009). Synthetic indicators of quality of life in Europe, Social Indicators Research, Vol. 94, No. 1, pp. 115-133.

[56] Stam, A. and Duarte Silva, P. (2003). On multiplicative priority rating methods for AHP, European Journal of Operational Research, Vol. 145, No. 1, pp. 92-108.

[57] Şuler, J. (2005). Metode de fundamentare pentru elaborarea şi implementarea strategiilor de urbanizare, Editura Tehnic®, Bucureşti.

[58] Tausch A., Heshmati, A. and Bajalan, C.S.J. (2007). On the Multivariate Analysis of the Lisbon.

[59] Vargas, L. (1990). An overview of the analytic hierarchy process and its applications, European Journal of Operational Research, Vol. 48, No. 1, pp. 2-8.

[60] Voula, M. (1996). Our city, our future: towards sustainable development in European cities, Environment and Urbanization, Vol. 8, No. 1, pp. 133-154.

[61] Wang, Y. and Luo, Y. (2009). On rank reversal in decision analysis, Mathematical and Computer Modelling, Vol. 49, No. 5-6, pp. 1221-1229.

[62] Winter, A. (2010). Competitiveness of the City of Graz in the Knowledge-Based Economy, FHJ, Graz.

[63] Yatskiv, I. and Pticina, I. (2010). The urban public transport system quality indicator for European cities [online], http://www.tsi.lv/Research/Conference/RelStat10/ Proceedings/Procceding/Sess_1_Pticina_Yatskiv.pdf (accessed March 10, 2012).

[64] Zahedi, F. (1986). The analytic hierarchy process: a survey of the method and its applications, Interface, Vol. 16, No. 4, pp. 96-108.

[65] Eurostat's Metadata Server [online], http://ec.europa.eu/eurostat/ramon/nomenclatures (accessed December 20, 2012).

[66] European Centre for the Development of Vocational Training [online], http://www.cedefop.europa.eu/EN/Files/5191_en.pdf (accessed November 7, 2012).

[67] Mercer [online], http://www.mercer.com/press-release/quality-of-living-report (accessed October 16, 2012).

[68] European smart Cities [online], http://www.smart-cities.eu/model.html (accessed October 10, 2012).

[69] The Glasgow indicators project [online], http://www.understandingglasgow.com/indicators (accessed January 12, 2013). 
[70] Measuring $R \quad \mathcal{E} \quad D$-UNESCO [online], http://www.unesco.org/new/fileadmin/ MULTIMEDIA/HQ/SC/pdf/sc_workshop_botswana_measuring2_en.pdf (accessed January 16, 2013).

[71] UIS activities in the collection and analysis of RED indicators [online], http:// www.who.int/phi/4-UNESCO_UIS_international_RandD_data.pdf (accessed January $16,2013)$.

[72] Urban Audit Database [online], http://appsso.eurostat.ec.europa.eu/nui/show.do? query=BOOKMARK_DS-055270_QID_63858921_UID_-3F171EB0\&layout=CITIES,B,X,0;TIME,C,Y,0;INDIC_UR,L,Z,0;INFO,L,Z,1;INDICATORS,C,Z,2;\&zSelection=DS-055270INDICATORS,OBS_FLAG;DS-055270INDIC_UR,EN5024I;DS-055270I NFO,VALUE;\&rankName1=INFO_1_2_-1_2\&rankName2=INDIC-UR_1_2_-1_2\&rankName3=INDICATORS_1_2_-1_2\&rankName4=CITIES_1_2_0_0\&ran-

kName5=TIME_1_1_0_1\&sortR=DESC_-1_FIRST\&pprRK=FIRST\&pprSO=DESC\&ppc RK=FIRST\&ppcSO=PROTO-

COL\&rStp $=\& c S t p=\& r D C h=\& c D C h=\& r D M=$ true $\& \mathrm{cDM}=$ true $\&$ footnes=false\&emp ty $=$ false\&wai=false\&time_mode=ROLLING\&lang=EN\&cfo= $\% 23 \% 23 \% 23, \% 23 \% 23 \% 23 . \% 23 \% 23 \% 23$ (accessed February 2, 2013). 

Chapter 6

\title{
FDI Blessing - How Is It Recognized by Local \\ Communities? - A Comparative Study of Slovenia and Serbia
}

\author{
Anita Maček, Rasto Ovin and Jelena Zvezdanović Lobanova \\ Additional information is available at the end of the chapter
}

http://dx.doi.org/10.5772/60978

\begin{abstract}
Foreign direct investments play a vital role in generating economic growth. National governments as well as local communities therefore need an appropriate strategy for attracting foreign direct investments on the one hand and maximizing their benefits on the other.

In the proposed chapter, authors discuss the development and effects of foreign direct investments on local communities of Slovenia and Serbia. Based on data gathered through a questionnaire, a comparative statistical analysis was used to find stylized facts, which could be a sign of a different stage of transition in both countries. The study was conducted at the end of 2014, and the sample consists of 66 communities from Slovenia and 61 communities from Serbia. The study proves that the more progressive path of transition in Slovenia was not offset by a significantly higher level of foreign direct investment activities. In both countries, however, foreign direct investments proved to have mostly positive effects on the economic development of the local communities concerned.
\end{abstract}

Keywords: FDI, local communities, transition

\section{Introduction}

Despite several issues and European governments' reluctance to follow it, the EU Directive on takeovers (see [1]) by now has been somehow embedded into real policy. It has become clear 
that industry consolidation encompasses technical development requires capital liberalization. In this respect, it is no wonder that the literature dealing with pros and cons of the FDI and especially C-B M\&A has become less frequent.

When local communities are concerned, the FDI economic effect in principle should not differ from the national economy. Despite the threats, they should mostly represent the chance for the economy's competitiveness and technological development in the sectors concerned (see [2-6]). Due to the fact that local communities usually possess only few instruments to steer the FDI and control its effects, the outcomes of foreign investment can very much differ between the regions. It is the fact that here regions orientated toward basic industries (raw materials, energy) can be subject to excessive degradation of the environment and social structure. On the other hand, the regions with sectors that are subject to industry consolidation can mostly expect positive effects similar to those valid for national economy. Evaluated for the USA, the effects of FDI at the local level proved quite differentiated (in [7]). While country wages have grown essentially, the effects on spending were not one-sided: foreign employment led to declines in per capita revenues and expenditures at the country level. At the same time, there was a considerable redistribution of the country's expenditures away from public school funding and toward transportation and public safety.

The following chapter first presents main transition features that are connected to FDI and FDI environment in both countries serving as an example (Slovenia and Serbia). The third part brings methodology and data used for analysis also presenting the sample as well as the poll conducted by the authors in responding local municipalities in Slovenia and Serbia. The conclusions offer a summary of results and concluding remarks.

\section{Main transitional features of Slovenia and Serbia}

Reaching $82 \%$ of the EU GDP per capita level according to PPS in 2002, Slovenia was by far the most developed former communist country in Europe, as well as in the world. This was firstly a consequence of relatively favorable economic history that this country had experienced. Here we first mean the fact that until the outbreak of World War I, Slovenia shared the central European model as a part of Austria. This economic tradition has remained an advantage in ante- and postbellum Yugoslavia, where Slovenia maintained its leading position having a rather large internal market offering stable demand and at the same time offering weak competition. Namely, through the centuries, the other former republics of former Yugoslavia shared less efficient models of economic development such as Hungarian model (Croatia) or the Ottoman model (other parts of former Yugoslavia).

Slovenia succeeded in avoiding the Balkan conflict in the 1990s, and since the decay of Yugoslavia, it has exercised a gradualist approach to transition. A lack of political will for change and half-hearted reforms, however, together with the financial and economic crisis, which actually lasted from 2009 to 2013, has gradually dethroned Slovenia as the leader of the pack of transition countries. In 2013, it was eventually caught by Czech Republic, with Slovakia and the Baltic countries clearly converging. 


\begin{tabular}{llllll}
\hline & $\mathbf{2 0 0 2}$ & $\mathbf{2 0 0 7}$ & $\mathbf{2 0 1 3}$ & $\mathbf{2 0 1 4}$ & \multicolumn{2}{c}{ Index 2014 2002 = } \\
\hline Czech Republic & 74 & 84 & 82 & 83 & $\mathbf{1 0 0}$ \\
\hline Estonia & 48 & 69 & 73 & 74 & 154 \\
\hline Lithuania & 43 & 61 & 73 & 75 & 174 \\
\hline Hungary & 60 & 61 & 66 & 68 & 113 \\
\hline Poland & 47 & 69 & 67 & 70 & 149 \\
\hline Slovakia & 53 & 67 & 75 & 76 & 143 \\
\hline Slovenia & 82 & 87 & 84 & 102 \\
\hline
\end{tabular}

Source: (in [8]).

Table 1. Catching up with the EU 28 (2002-2014)-indexes, average EU $=100$

Table 1 shows that in 2014, Slovenia somehow recuperated its leading position, although the developments in the past 12 years demonstrate the negative consequences of gradualism and a lack of political will for developing a full-fledged market economy. On the other side, a remarkable progress has been made by Lithuania and Estonia, followed by Poland and Slovakia. These developments in a way also demonstrate the obvious presence of a "middle income trap," especially when considering developments in Slovenia and Czech Republic. Nevertheless, as seen from the Czech example, the arrears that Slovenia has been heading to are a consequence of less appropriate transitional measures as described above.

Following the topic of this chapter, it is relevant to check the FDI inflow compared with select transition countries. As seen in Table 2, the Slovenian art of transition also consisted of a reluctant opening toward foreign capital, thus also indirectly explaining the arrears that Slovenia has demonstrated after a favorable start in the nineties.

\begin{tabular}{cccccc}
\hline Czech Republic & Croatia & Estonia & Serbia & Slovakia & Slovenia \\
\hline 32.2 & 38.9 & 79.8 & 59.9 & 31.0 & 12.4 \\
\hline
\end{tabular}

Source: (in [8]).

Table 2. FDI, net inflows (\% of GDP), average 2005-2014

Soon after the beginning of the 1990s Balkan conflict, Serbia became a constituting part of the Federal Republic of Yugoslavia (founded in 1992), consisting also of Montenegro, which, however, declared independence in 2006. For the first part of this period, Serbia was subject to political and economic sanctions (lifted in 1995 after the Dayton Accords, peace agreement, was signed). These sanctions have influenced trade flows, FDI, bank transfers, access to international financial markets, membership in international organizations, general inflow of information, and free travel abroad. A sharp decrease in economic activity was marked in 1992 
with an inflation rate expressed in trillions of index points. Numerous restrictive measures and sanctions toward the FRY are brought by the EU came in force again in 1998 following the crisis, which arose in Kosovo and Metohia, and were gradually abolished only after political changes in October 2000. In such an environment, it is not surprising that the transition in Serbia is still in its decisive phase. This can also be seen from select comparative data presented in Table 3 below.

\begin{tabular}{|c|c|c|c|c|c|c|}
\hline & Czech Repu & & Estonia & Serbia & Slovakia & Slovenia \\
\hline $\begin{array}{l}\text { GDP/capita PPS, EU = } \\
100 \text { (2013) }\end{array}$ & 82 & 61 & 73 & 37 & 75 & 82 \\
\hline Unemployment 2014 & 6.1 & 17.0 & 7.4 & $16.8^{*}$ & 13.2 & 9.8 \\
\hline $\begin{array}{l}\text { Trade balance as \% } \\
\text { GDP (2008-2013) }\end{array}$ & -0.85 & -16.9 & -5.2 & $-16.1^{* *}$ & 1.0 & -1.6 \\
\hline $\begin{array}{l}\text { Gross fixed capital } \\
\text { formation, } \% \text { GDP } \\
2008-2013\end{array}$ & 28.2 & 22.3 & 25.8 & 20.0 & 22.6 & 22.4 \\
\hline
\end{tabular}

Sources: (in [9-10]).

Table 3. Recent economic developments in chosen transition countries

The EU Agreement on Stabilization and Association with Serbia was signed in April 2008 together with the Interim Agreement on Trade and Trade Related Matters. The Serbian Government adopted the National Programme for Integration with the EU for the period 20082012, in October 2008, with the aim of coordinating its legislation with the legal attainments of the EU. Taking into consideration the significant progress toward fulfilling the Copenhagen criteria, as well as conditions from the Process of Stabilization and Association, the European Council decided in March 2012 that Serbia would be awarded candidate status for EU membership. In this way, the investment risks that are considered conflict areas by investing companies (see [11]) were substantially reduced.

\section{Method, data, and sample}

Our study analyzed the acceptance of the FDI in Slovenian and Serbian communities. In the study conducted at the end of 2014, a questionnaire was used.

The sample included 127 communities: 66 (of a total of 212) from Slovenia and 61 (of a total of 168) from Serbia. The directors of the municipalities' management formed the target audience for the study. We chose these state institutions because they should play an important role in creating an environment conducive to business, generating employment, FDI attraction, and sustainable economic development. Our aim was to find out the intensity of the efforts that 
were made by municipalities in order to attract FDI. On the other hand, we tried to research their perceptions on the most important threats and benefits that accompany this form of international capital flow.

The questionnaire for the ongoing study consists of 16 questions on inward FDI in communities. Basic differences have been spotted and analyzed in this phase of research, so this chapter presents answers to the following questions:

1. Is attracting investments within the strategic goals of your community?

2. Rank the benefits of FDI by their importance from 1 (at least benefit) to 6 (maximum benefit).

3. Rank the threats of FDI by their importance from 1 (at least threats) to 7 (maximum threat).

4. Is it useful for your community to open up to FDI?

5. In which industry your community is the most flexible toward FDI?

6. Rank the countries from where you want the most foreign investors 1 (at least welcomed) to 9 (the most welcomed).

We used descriptive statistics in analyzing all questions to show the general picture about these processes.

\section{Analysis}

Using the data gathered through the poll among local communities in both countries, make it possible to draw several conclusions and also explain some expected differences between local communities in Slovenia and in Serbia. The expectations of differences in the positive effects of FDI as well as threats obviously go back to a different level of development. On the other side, the difference in the transitional experience is felt less than someone would expect. This probably is an inheritance of the pattern of governance and development that both countries shared for more than 70 years.

As the first one, we will explain the differences that can be seen between the local communities in both countries. The question referring to FDI attraction as a local community's strategic goal actually shows the clearest discrepancy between two countries' local communities' attitude toward FDI, although in a surprising way.

Although Slovenia is clearly more integrated in the international community - at least by being a full-fledged EU member-Serbian local communities seem to have clearer picture that their growth also depends on their engagement with foreign savings. The picture could also be seen as a reason and a consequence of Slovenian closed approach when FDI is concerned and has been presented in Table 2 above. 


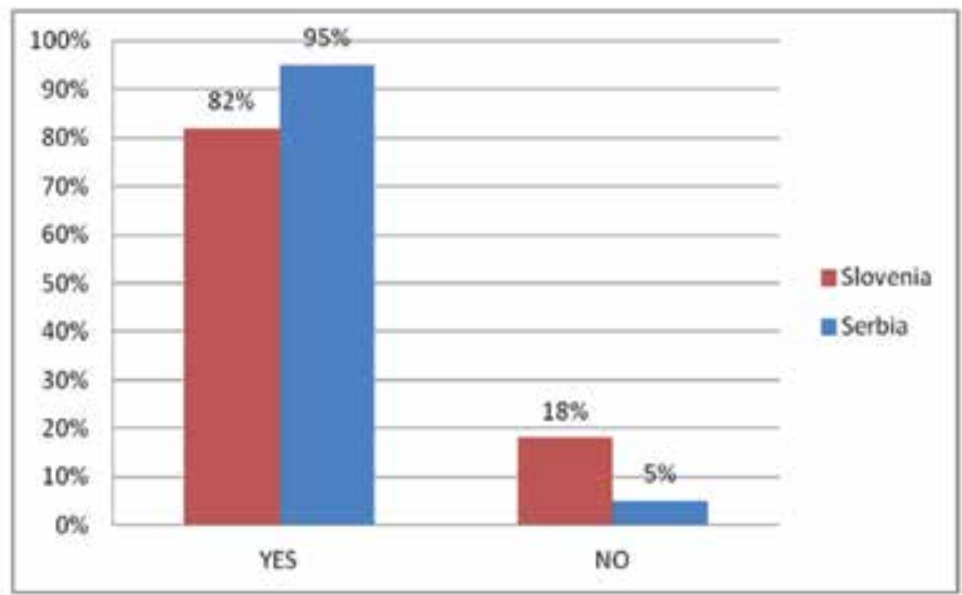

Figure 1. Attracting FDI as a local community's strategic goal

When discussing experienced and expected benefits of FDI in local communities, the poll results are closer to those that one knowing the transitional path in both countries would expect.

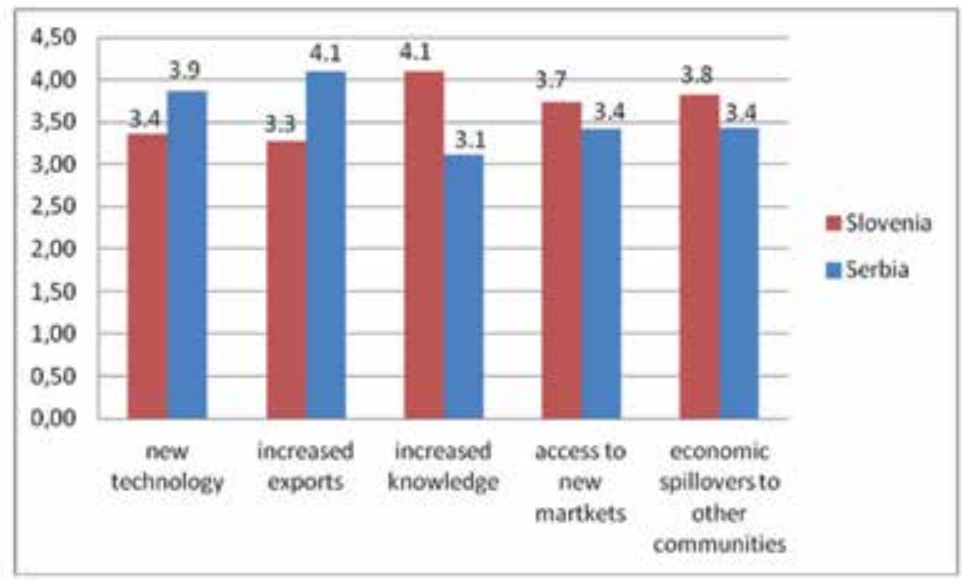

Figure 2. Benefits of FDI

Expectedly, Serbian local communities have a stronger hope for more direct benefits of FDInew technology and increased exports-although one could expect that benefits from increased knowledge should also join this group. The deviation (the biggest of them all) probably goes back to more ambitious self-estimation in the region that has physically less contact with western (business) knowledge and so up to now could not fully recognize the gap. 
Also, one would expect that indirect benefits due to its higher level in transition process would be better rated in Slovenia. Stronger positive expectations of better access to new markets as a consequence of FDI are supported by traditionally greater international trade openness of Slovenia. Also with economic spillovers into other communities, better experience with integrated markets in Slovenia (EU membership) will be recognized.

Also with the next criteria (Threats of FDI-figure 3), one could observe the differences in the transitional stage between the two countries, which are offset in the local community governments' imagination of FDI effects. Here clear difference between Slovenia and Serbia can be seen, especially with direct threats. Although there has been active debate and also opposition to privatization through FDI in Slovenia, the threat of too-low prices achieved, the growth of foreign influence, and reducing wages still are judged as less likely outcomes of FDI. Otherwise, other possible risks are seen quite as expected-demonstrating typical differences in the transition experience of both countries. When the threat that new owner would remove companies' development departments is concerned, the judgment in local communities in both countries is actually equally strong.

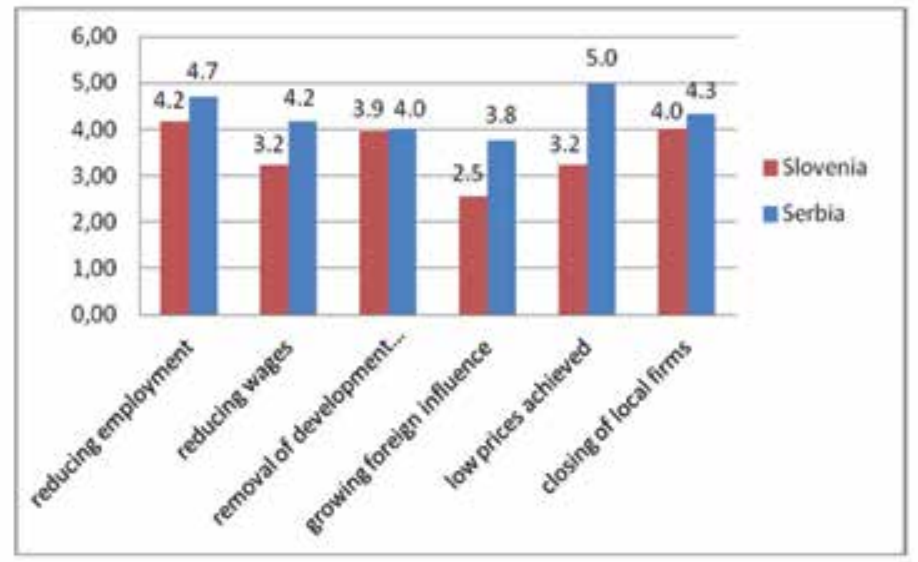

Figure 3. Threats of FDI

The difference in the transitional stages of the two countries is clearly seen also from local communities' flexibility toward FDI in different industries. A generally poor experience with banking can be spotted in both countries - the banking industry receives by far the lowest acceptance-and thus the readiness of local communities to act flexibly in the case of FDI in banking.

Relatively close is also the readiness for flexibility in the fields of green energy production and infrastructure. A bit surprising is that the need of infrastructure development is stronger in Slovenian local communities, knowing that the infrastructure there is in considerably better shape than that in Serbia. On the other hand, as expected, the willingness of Serbian local communities when agriculture and industry are concerned is higher. These two sectors 


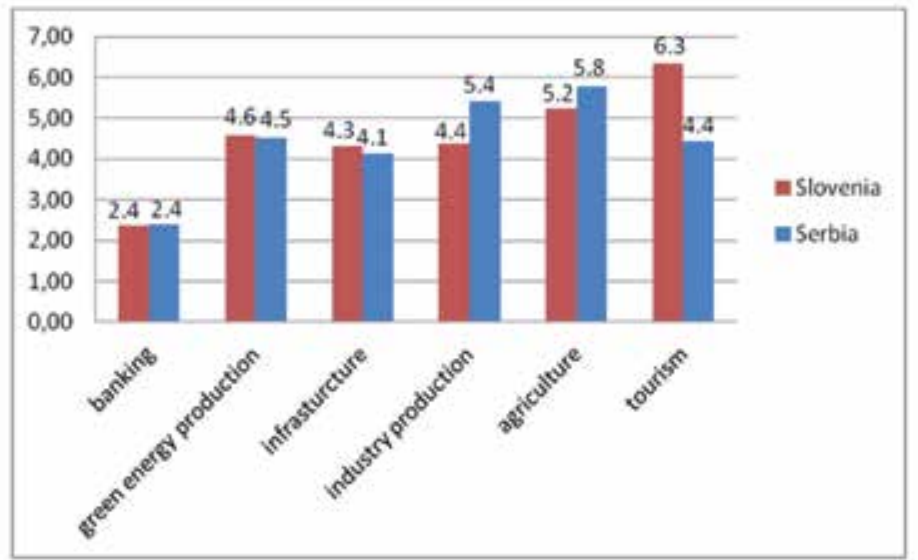

Figure 4. The flexibility of the local community toward FDI

(especially agriculture) namely contribute a considerably greater share to the nation's GDP in Serbia than in Slovenia.

\begin{tabular}{ccc}
\hline & Slovenia & Serbia \\
\hline Agriculture & 2.8 & 7.9 \\
\hline Industry & 28.9 & 31.8 \\
\hline Services & 68.3 & 60.3 \\
\hline Tourism (2012) & 2.45 & 1.13 \\
\hline
\end{tabular}

Source: (see [12-13]).

Table 4. Comparative GDP structure in Slovenia and in Serbia in 2013 (\%)

The total percentage $(100 \%)$ in the above Table 4 does not hold since tourism is a part of services. As presented in figure 4, expectedly the bigger difference in readiness for flexibility toward FDI between local communities of both countries refers to tourism. Being relatively more involved in international tourism flows, as offset in its share in national GDP, Slovenian local communities are substantially much ready to be flexible when FDI in tourism is concerned.

Next is the comparison between local communities with respect to the regions that are most popular providers of FDI. To make the results transparent, we used separate graphs for both countries, as presented in Pictures 5 and 6.

One would expect that Germany would gain the most support as the source country of the FDI entering local communities in the region. This is also proven by our results; although in Slovenia, the top country would be Austria. This refers to good experience with Austrian FDI 


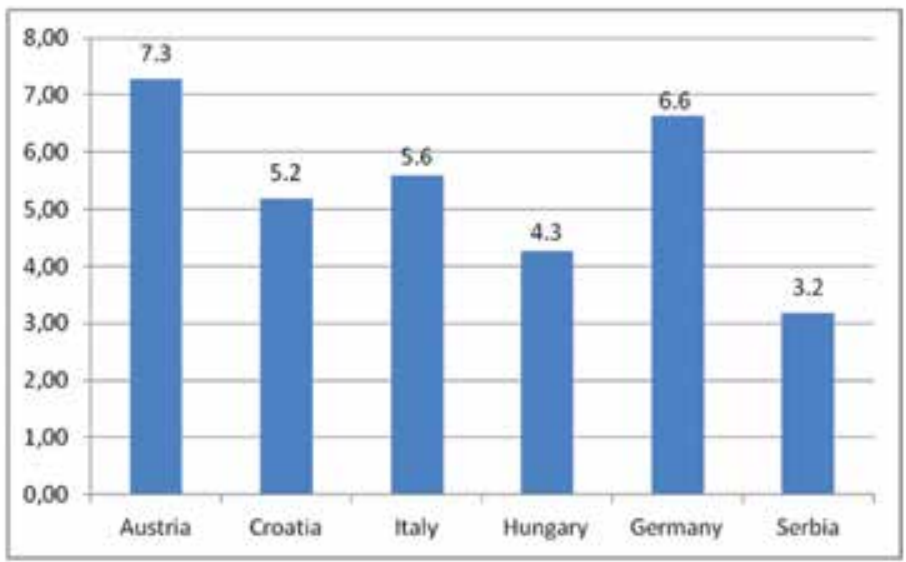

Figure 5. Regions most popular as providers of FDI-Slovenia

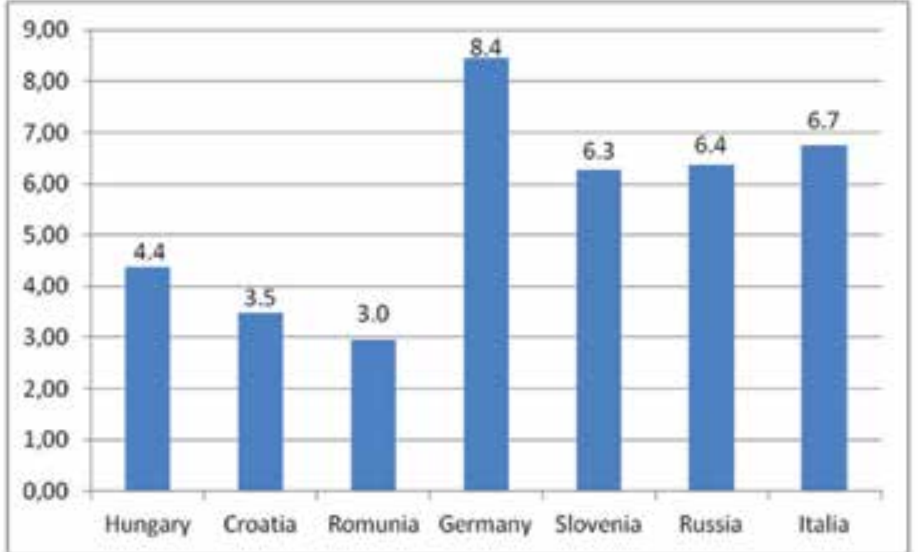

Figure 6. Regions most popular as providers of FDI-Serbia

and of course to Austria's vicinity. Also both countries were ranked in both samples, which indicate a positive common experience. There is a difference in the strength of these expectations though: logically, as an EU member and with more highly developed economic and industrial structures, Slovenia earns more attention as a possible investor than opposite. Italy is also very popular as a source country. With Slovenia, this again has to do with its vicinity, while in Serbia, a substantial FDI of FIAT in Kragujevac (2008) wakes expectations also in other local communities. It is also expectable that in Serbia, Russia has also achieved quite an important rank. 


\section{Concluding remarks}

Despite a temporary contraction during the global financial and economic crisis, international capital flows have increased dramatically over time. Gross cross-border capital flows rose from about three times faster than world trade flows from 1990 to 2013. In transition countries, Central and Eastern Europe planned and conducted foreign direct investments well, which helped not only national economies but also provided the tipping point in the development of many local communities.

Foreign direct investments are important for communities' economic development and are an effective instrument for transferring know-how, technology, and skills. International capital investments also bring other positive effects, most frequently in the form of increased employment, but because of the threats and challenges they also bring to the host countries, international investments are not always welcome.

Our study proved that FDI have been entering decision makers' perspective in local communities in Slovenia and in Serbia. Despite a reluctant opening in this field in Slovenia, local governments believe that foreign saving could substantially support their development goals. A similar perspective is also seen in local communities in Serbia, although it is expectedly partly influenced by Serbia's stance on the transition process. The differences between local communities in both countries are most striking when preferences regarding sectors of investment are concerned. The differences in transition phases between the countries are, however, most recognizable in the judgment of the benefits and threats of FDI. Here one could also clearly see the difference in openness-here probably concerned with the fact that it was only Balkan conflict resolution when Serbia's transition toward a full-fledged economy started.

\section{Author details}

Anita Maček ${ }^{1 *}$, Rasto Ovin ${ }^{1}$ and Jelena Zvezdanović Lobanova ${ }^{2}$

*Address all correspondence to: anita.macek@net.doba.si

1 DOBA Faculty of Applied Business and Social Studies Maribor, Slovenia

2 Institute of Social Sciences, Serbia

\section{References}

[1] EUR-Lex. Directive 2014/24/eu of the European Parliament and of the Council [Internet] 2014. Available from: http://eur-lex.europa.eu/legal-content/EN/TXT/?uri=celex: 32014L0024 [Accessed 30.3.2015]. 
[2] Perez, R. P. A regional approach to study technology transfer through foreign direct investment: the electronics industry in two Mexican regions. Research Policy. 2008; 37 (5): 849-860.

[3] Lin, C. H. Role of foreign direct investment in telecommunication industries: a developing countries' perspective. Contemporary Management Research. 2008; 4 (1): 29 42.

[4] Ovin, R. and A. Maček. How beneficial are inward C-B M\&A for European countries? European Journal of International Management. 2010; 4 (5): 488-505.

[5] Zvezdanović Lobanov, J., Maček, A, R. Ovin. Institutional setting as a determinant of FDI attraction-example of Serbia. 2013. In: Petrović, P. 2014. Possibilities and Perspectives for Foreign Direct Investment in the Republic of Serbia. Mala knjiga, Novi Sad.

[6] Maček, A. and R. Ovin. Does economic interventionism help strategic industries? Evidence from Europe. E+M. 2014; 17 (3): 5-14.

[7] Figlio, D. N. and B. A. Blonigen. The Effects of Direct Foreign Investment on Local Communities. NBER Working Paper No. 7274. 1999.

[8] World Bank. Indicator-GDP per capita (current US\$) [Internet]. 2015. Available from: http://data.worldbank.org/indicator/NY.GDP.PCAP.CD [Accessed 10.3.2015].

[9] Eurostat. GDP per capita in PPS [Internet]. 2015. Available from: http://ec.europa.eu/ eurostat/tgm/table.do?tab=table\&init=1\&language=en\&pcode=tec00114\&plugin=1 [Accessed 25.3.2015].

[10] Wise Broker. Serbian Macro Overview [Internet]. 2014. Available from: http:// www.britserbcham.eu/wp-content/uploads/2014/04/Serbian-Macro-Overview_March_2014.pdf [Accessed 25.3.2015].

[11] Bray, J. 2012. Foreign Direct Investment in Conflict-affected Areas. International Alert. Practice note 3.

[12] CIA. The World Factbook [Internet]. 2015. Available from: https://www.cia.gov/ library/publications/the-world-factbook/fields/2012.html [Accessed 30.3.2015].

[13] World Bank. Indicator-International tourism, receipts [Internet] 2015. Available from: http://data.worldbank.org/indicator/ST.INT.RCPT.CD [Accessed 10.3.2015]. 
